\title{
MODELOS PARA A PREVISÃO DA PRODUTIVIDADE DA CANA-DE-AÇÚCAR (Saccharum spp.) ATRAVÉS DE PARÂMETROS CLIMÁTICOS.
}

\section{MAXIMILIANO SALLES SCARPARI}

Dissertação apresentada à Escola Superior de Agricultura "Luiz de Queiroz", Universidade de São Paulo, para obtenção do título de Mestre em Agronomia, Área de Concentração: Fitotecnia.

\author{
P I R A C I C A B A \\ Estado de São Paulo - Brasil \\ Julho - 2002
}




\title{
MODELOS PARA A PREVISÃO DA PRODUTIVIDADE DA CANA-DE-AÇÚCAR (Saccharum spp.) ATRAVÉS DE PARÂMETROS CLIMÁTICOS.
}

\author{
MAXIMILIANO SALLES SCARPARI
}

Engenheiro Agrônomo

Orientador: Prof. Dr. EDGAR GOMES FERREIRA DE BEAUCLAIR

Dissertação apresentada à Escola Superior de Agricultura "Luiz de Queiroz", Universidade de São Paulo, para obtenção do título de Mestre em Agronomia, Área de Concentração: Fitotecnia.

P I R A C I C A B A

Estado de São Paulo - Brasil

Julho - 2002 


\section{Dados Internacionais de Catalogação na Publicação (CIP) DIVISÃO DE BIBLIOTECA E DOCUMENTAÇÃO - ESALQ/USP}

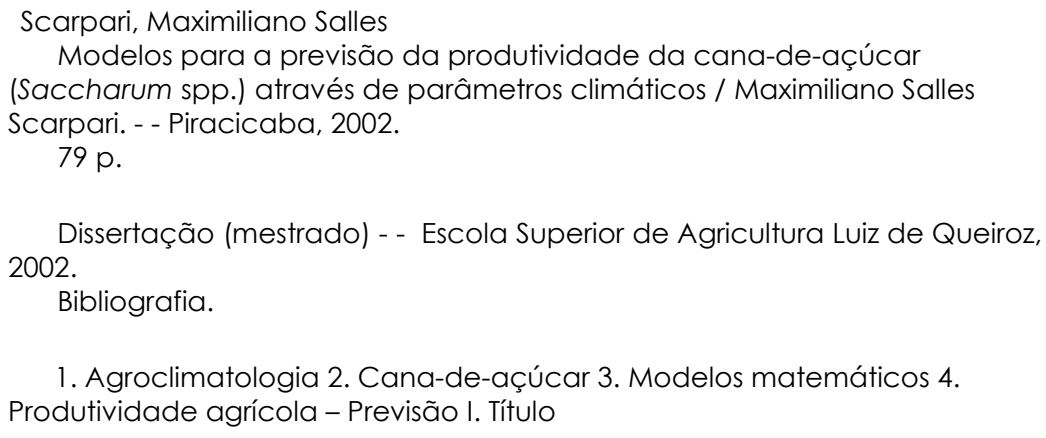

CDD 633.61

\section{"Permitida a cópia total ou parcial deste documento, desde que citada a fonte - O autor"}


Aos meus pais Antonio Carlos Scarpari e Maria Elisabete Salles Scarpari e minha irmã Ana Carolina dedico. 


\section{AGRADECIMENTOS}

Ao amigo e orientador Prof. Dr. Edgar Gomes Ferreira de Beauclair pelo incentivo e orientação ao longo desses anos.

Ao Prof. Dr. Valter Barbieri pelas sugestões.

À Usina Açucareira Bortolo Carolo na pessoa de seus diretores Marcelo Carolo e Badri Kazan, por incentivarem e fornecerem as informações fundamentais para a elaboração deste trabalho.

Ao amigo M.S. Luis Fernando Sanglade Marchiori pelo incentivo e a todos os funcionários da Fazenda Experimental Areão - ESALQ/USP.

Ao Dr. Orivaldo Brunini pesquisador do IAC, pelo fornecimento dos dados climáticos.

À CAPES pelo auxílio da bolsa de estudo.

A todos os amigos da cidade de Piracicaba onde nasci e adoro tanto e a cidade de Ubatuba onde busco inspiração para continuar caminhando. 


\section{SUMÁRIO}

Página

LISTA DE QUADROS...................................................................................... vi

LISTA DE TABELAS................................................................................ vii

LISTA DE FIGURAS.............................................................................. ix

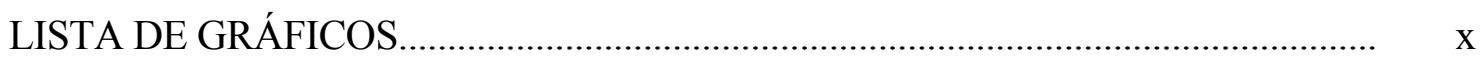

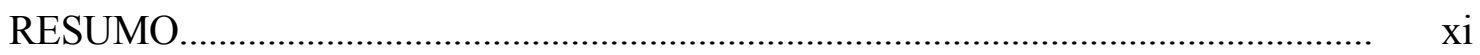

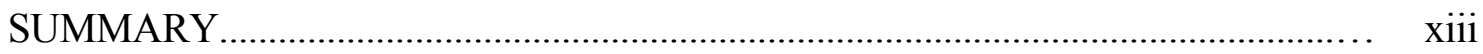

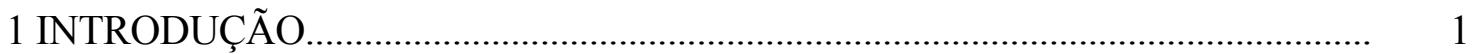

2 REVISÃO DE LITERATURA....................................................................... 5

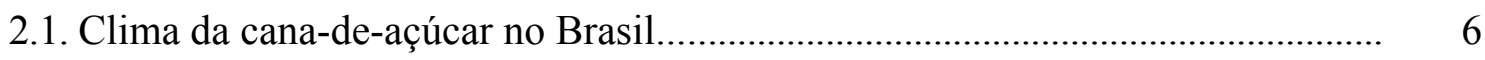

2.2. Época de plantio da cana-de-açúcar no Brasil..................................................... 8

2.3. Fatores que atuam sobre o crescimento, desenvolvimento e maturação da cana-de-

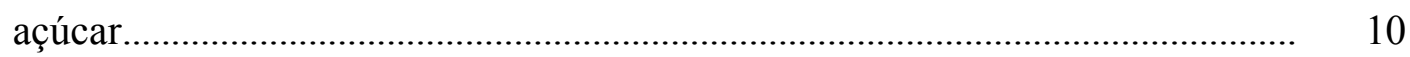

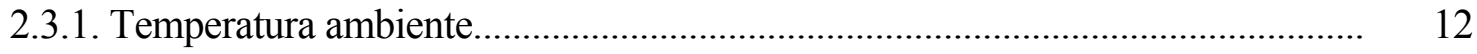

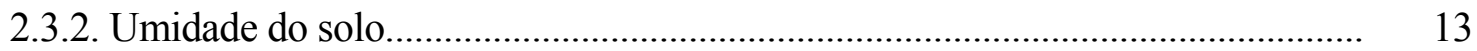

2.4. Modelos matemáticos utilizando variáveis climáticas..................................... 15

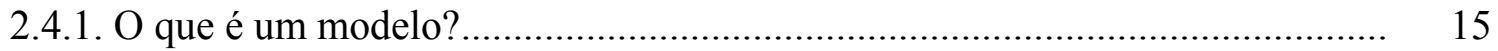

2.4.2. Exemplos de alguns modelos utilizados em cana-de-açúcar......................... 16

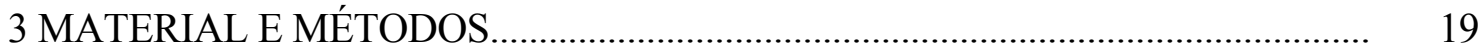

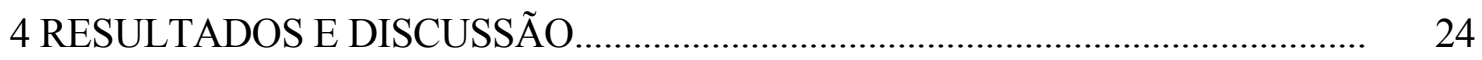

4.1. Simulações para validação dos modelos promissores........................................... 32

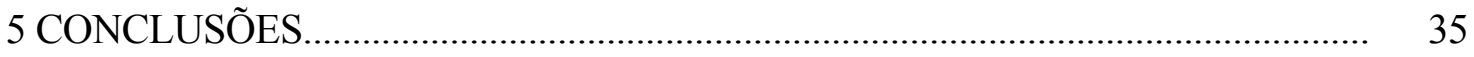

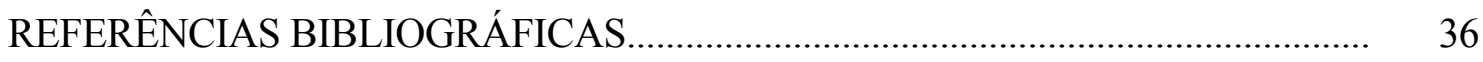

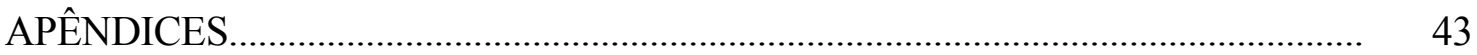




\section{LISTA DE QUADROS}

Página

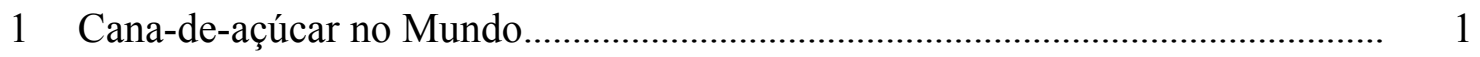

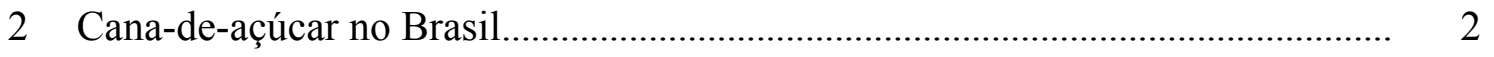

3 Demanda da força de trabalho agrícola anual no Estado de São Paulo.................. 2

4 Clima da Região Canavieira Centro-Sul do Brasil................................................ 7 


\section{LISTA DE TABELAS}

Página

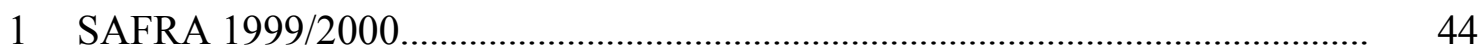

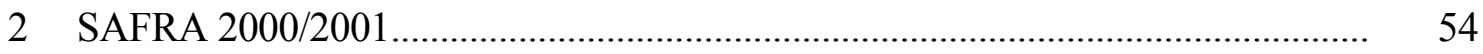

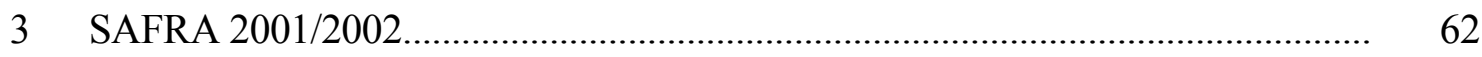

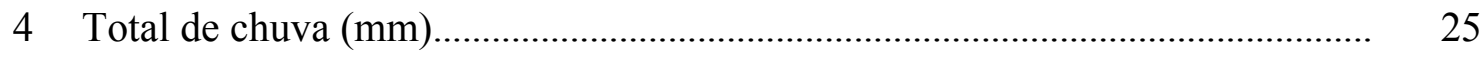

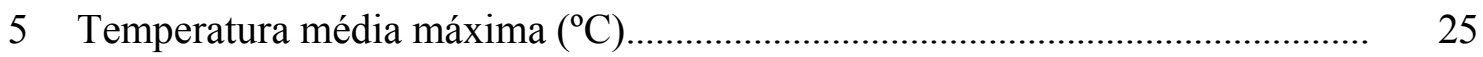

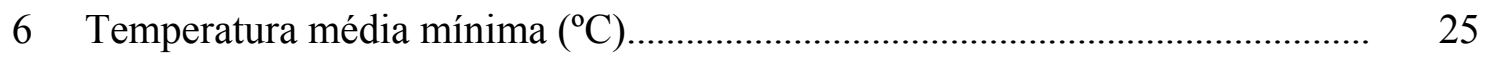

7 Duração máxima diária da insolação $(\mathrm{N})$ em horas $-15^{\circ}$ dia do mês (Barbieri \& Tuon, 1993) ........................................................................................ 25

8 Cálculo do fator f....................................................................................... 25

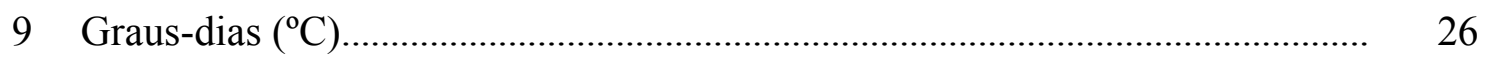

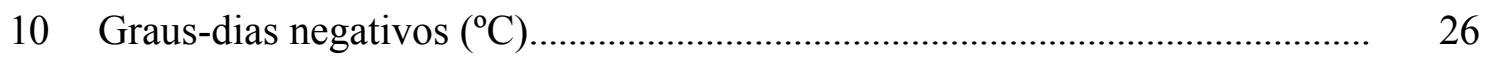


11 Série histórica da precipitação na região de Ribeirão Preto (em mm)................

12 Probabilidades iguais ou maiores que o evento ocorrido (em \%)...................... 


\section{LISTA DE FIGURAS}

Página

1 Ciclos da cana-de-açúcar e variações na temperatura e pluviosidade da região CentroSul do Brasil (Castro, 1999).................................................................................... 9

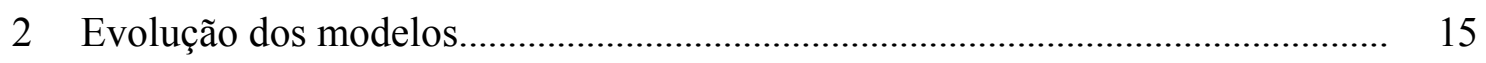

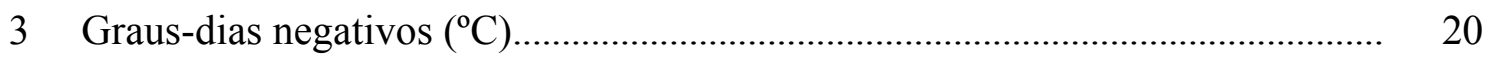




\section{LISTA DE GRÁFICOS}

Página

1 Situação teórica da evolução do ATR de duas variedades em função do mês de safra.......

17

2 Simulação entre o ATR estimado e o ATR real para cana de ano........................ 33

3 Simulação entre o ATR estimado e o ATR real para cana de ano e meio............

4 Simulação entre o TCH estimado e o TCH real para cana de ano....................... 34

5 Simulação entre o TCH estimado e o TCH real para cana de ano e meio........... 34 


\title{
MODELOS PARA A PREVISÃO DA PRODUTIVIDADE DA CANA-DE-AÇÚCAR (Saccharum spp.) ATRAVÉS DE PARÂMETROS CLIMÁTICOS.
}

\author{
Autor: Maximiliano Salles Scarpari \\ Orientador: Prof. Dr. Edgar Gomes Ferreira de Beauclair
}

\section{RESUMO}

A cultura da cana-de-açúcar é submetida durante o seu desenvolvimento a diferentes condições ambientais, sendo o rendimento agrícola afetado diretamente por estas condições. Dessa variação ao longo do ciclo, surge a necessidade de se prever as respostas da cultura aos diferentes estímulos para fins de planejamento. Modelos de previsão de produtividade e qualidade da matéria-prima tornam-se ferramentas importantes na lavoura canavieira, objetivando suprir estimativas de rendimento ao longo da safra, visando à caracterização das alternativas de manejo, aumentando a eficácia das decisões gerenciais e estratégicas. O objetivo deste trabalho foi desenvolver modelos capazes de obter previsões de ATR - Açúcar Teórico Recuperável e TCH toneladas de cana-de-açúcar por hectare, ao longo da safra, utilizando dados referentes 
aos fatores de produção como precipitação e temperatura. Os dados da Usina Açucareira Bortolo Carolo localizada no município de Pontal - SP das safras 1999/2000, 2000/2001 e 2001/2002 foram analisados em termos de produtividade (ATR e TCH), idade do canavial, solo, variedades e manejo, e com os dados testou-se modelos estatísticos de previsão de produtividade utilizando o programa computacional SAS "Statistical Analysis System". Os modelos de maturação (ATR) para cana de ano e cana de ano e meio foram os mais promissores obtendo um coeficiente de determinação $\mathrm{R}^{2}=0,6943^{*}$ e $0,7574^{*}$, respectivamente. $\mathrm{Na}$ simulação aplicou-se o teste qui-quadrado onde para cana de ano não há diferença estatística significativa entre os dados reais e calculados $(\alpha$ $<0,05)$. Para cana de ano o meio, há diferença estatística significativa ao nível de 5\%. Com isso, pode-se confirmar e quantificar a existência de influência da precipitação, graus-dias e graus-dias negativos na maturação e produtividade da cana-de-açúcar. O modelo de maturação para cana de ano mostrou-se mais confiável comparado ao modelo de maturação para cana de ano e meio, após a realização da simulação para a safra 2001/2002. A introdução do fator graus-dias negativos foi de suma importância, pois teve grande influência no modelo de maturação. Os modelos de produtividade não se mostraram confiáveis após a realização da simulação para a safra 2001/2002. 


\title{
PRODUCTIVITY PREDICTING MODELS TO SUGARCANE (Saccharum spp.) USING THROUGH WEATHER PARAMETERS.
}

\author{
Author: Maximiliano Salles Scarpari \\ Adviser: Prof. Dr. Edgar Gomes Ferreira de Beauclair
}

\section{SUMMARY}

Sugarcane crop grows under different weather condition, what affects directly the crop productivity. From this variation during its cicle, in order to plan, the prediction of the crop response to different inducements is needed. Productivity predicting models and quality of row material become important tools in sugarcane crop, the goal of these models is to supply the productivity valuation during the harvest time, aiming the characterization of the management alternatives, increasing the efficiency of strategically and administration decision. The goal of the present work was to develop models able to predict RTA - Recoverable Theory Sugar and TSH - tons of sugarcane per hectare, during the harvest time, using data refered to production factors with precipitation and temperature. The data base of Bartolo Carolo Sugar-mill localized in 
Pontal - SP of the agricultural years 1999/2000, 2000/2001 and 2001/2002 was analyzed in productivity terms (RTA and TSH), cane plantation age, soil type, variety of sugarcane used and management with these data productivity predicting statistical models were tested through the use of the software SAS "Statistical Analysis System". The maturation models (RTA) to a twelve month and a eighteen month sugarcane were the most promising, because they got a significant determination coefficient $\mathrm{R}^{2}=$ $0,6943^{*}$ e $0,7574 *$, respectively. In the simulation was applered the chi-square test, in that to twelve-month sugarcane there is no statistical significant difference between real and simulated data $(\alpha<0,05)$. To eighteen-month sugarcane there is statistical difference significant the $5 \%$ level. In conclusion, there is confirm and quantify the influence of precipitation, degrees-days and negative degrees-days in sugarcane maturation and productivity. The maturation model to twelve month sugarcane is more trustful them the eighteen month sugarcane, after the simulation with data of 2001/2002 agricultural year. The introduction of factor negative degrees-days was very important, because it had a great influence in the maturation model. The production models don't show trustful after the simulation with data of 2001/2002. 


\section{INTRODUÇÃO}

A cultura da cana-de-açúcar (Saccharum spp.) é uma das mais antigas e importantes lavouras exploradas no Brasil. No ano de 1998 foram produzidas 338.348.000 t de colmos industrializáveis, numa área de 4.944.000 ha o que conferiu ao Brasil a primeira posição mundial na produção de açúcar (Quadro 1). Nesse mesmo ano no Estado de São Paulo, a produção de colmos industrializáveis foi de 198.480 .000 toneladas, representando 58,6\% da produção nacional (Quadro 2).

\begin{tabular}{|c|c|c|c|}
\hline 1998 & $\begin{array}{c}\text { Área Colhida } \\
\text { (hectares) }\end{array}$ & $\begin{array}{c}\text { Rendimento } \\
(\mathrm{t} / \mathrm{ha})\end{array}$ & $\begin{array}{c}\text { Produção } \\
\text { (toneladas) }\end{array}$ \\
\hline Brasil & 4.944 .000 & 68,4 & 338.348 .000 \\
\hline Índia & 3.960 .000 & 66,9 & 265.000 .000 \\
\hline China & 1.201 .000 & 71,3 & 85.666 .000 \\
\hline Cuba & 1.100 .000 & 31,8 & 35.000 .000 \\
\hline Paquistão & 1.056 .000 & 50,2 & 53.106 .000 \\
\hline Mundo & 19.438 .000 & 64,4 & 1.252 .266 .000 \\
\hline
\end{tabular}

Fonte: FAO Production Yearbook, v.52 - 1998.

Quadro 1 - Cana-de-açúcar no Mundo. 


\begin{tabular}{|c|c|c|c|}
\hline 1998 & $\begin{array}{c}\text { Área Colhida } \\
\text { (hectares) }\end{array}$ & $\begin{array}{c}\text { Rendimento } \\
(\mathrm{t} / \mathrm{ha})\end{array}$ & $\begin{array}{c}\text { Produção } \\
\text { (toneladas) }\end{array}$ \\
\hline São Paulo & 2.529 .500 & 78,4 & 198.480 .000 \\
\hline Alagoas & 460.975 & 62,1 & 28.672 .266 \\
\hline Pernambuco & 355.615 & 36,8 & 13.112 .325 \\
\hline Paraná & 334.000 & 80 & 26.720 .000 \\
\hline Minas Gerais & 277.805 & 60,6 & 16.836 .716 \\
\hline Brasil & 4.944 .000 & 68,4 & 338.348 .000 \\
\hline
\end{tabular}

Fonte: Anuário Estatístico do Brasil, v.58 - 1998.

Quadro 2 - Cana-de-açúcar no Brasil.

Com esta representatividade, é a cultura de maior demanda da força de trabalho agrícola anual no Estado de São Paulo (Sensor Rural, 1998), como demonstrada no Quadro 3, assumindo grande importância sócio-econômica e por conseqüência projetos e estudos que objetivem uma redução dos custos de produção e melhor planejamento ao longo da safra tornam-se necessários.

\begin{tabular}{|c|c|c|}
\hline Cultura & EHA* (1997) $^{*}$ & EHA $^{*}(1998)$ \\
\hline Cana-de-açúcar & 236.146 & 234.007 \\
\hline Café & 109.370 & 115.402 \\
\hline Laranja & 92.212 & 94.359 \\
\hline Olerícolas & 82.007 & 88.299 \\
\hline Grãos & 77.713 & 81.795 \\
\hline
\end{tabular}

Fonte: Sensor Rural, n.6 SEADE, mai./jun., 1998.

* $\mathrm{EHA}=($ Equivalente Homem Ano $)$, índice teórico que representa "postos" de trabalho.

Quadro 3 - Demanda da força de trabalho agrícola anual no Estado de São Paulo.

De acordo com Pinazza (1985), a elevação dos índices de produtividade agrícola pode ser beneficiada ou prejudicada pela ação de quatro fatores básicos: físicos, 
estruturais, institucionais e de desenvolvimento. Os fatores físicos representam as condições edafo-climáticas de uma determinada região e a aptidão para a exploração deste ou daquele produto agrícola, enquanto os institucionais envolvem a ação governamental através das políticas agrícolas implantadas (preço, crédito, comercialização, contingenciamento, incentivos, etc.). Já o fator desenvolvimento manifesta-se através do sistema de pesquisa, e a sua capacidade em gerar conhecimentos que possibilitem incrementos na produtividade. Resta o fator estrutural, aqui focalizado como sendo o sistema gerencial adotado, que influi decisivamente no desempenho operacional e estratégico de uma empresa.

Neste trabalho, será enfocado o fator desenvolvimento acima descrito, elaborando modelos para estimar o rendimento da cultura que são necessários aos sistemas de gerenciamento e, portanto afetam o fator estrutural. É fato, que a cada ciclo, a cultura é submetida durante o seu desenvolvimento, a diferentes condições ambientais (clima, solo e manejo), sendo o rendimento agrícola afetado diretamente por estas condições. Dessa variação ao longo do ciclo, surge a necessidade de se prever as respostas da cultura aos diferentes estímulos para fins de planejamento. Com isso, modelos de previsão de produtividade e qualidade da matéria-prima tornam-se ferramentas importantes na lavoura canavieira, objetivando suprir estimativas de rendimento ao longo dos meses de safra, visando à caracterização das alternativas de manejo e aumentando a eficácia das decisões gerenciais e estratégicas.

Dentro deste contexto, o planejamento da colheita da cana-de-açúcar busca otimizar o retorno econômico da cultura baseado no conceito de que a cana tem uma época, durante a safra, conhecida como pico de maturação mais propícia para colheita, 
onde ocorre a máxima concentração de sacarose nos colmos. Inevitavelmente, o planejamento da colheita sendo otimizado ou não, utiliza estimativas de produção agrícola para dimensionar recursos e realizar cronogramas de execução e seqüênciamento de operações (Barata, 1992; Beauclair \& Penteado, 1984; Chapman \& Leverinton, 1976; Muchow et al., 1998). Segundo a Cooperativa Central dos Produtores de Açúcar e Álcool do Estado de São Paulo - COPERSUCAR (1982), o objetivo primordial da agroindústria sucro-alcooleira é a recuperação máxima da sacarose da cana-de-açúcar ao menor custo possível. Para se atingir este objetivo, depende-se diretamente da produtividade e da qualidade tecnológica da matéria-prima a ser processada, aliada às características e à eficiência da unidade industrial.

O objetivo deste trabalho foi desenvolver modelos capazes de obter previsões de ATR - Açúcar Teórico Recuperável (Conselho dos Produtores de Cana-de-Açúcar, Açúcar e Álcool do Estado de São Paulo - CONSECANA, 1999), em quilogramas de sacarose por tonelada de cana-de-açúcar e TCH - toneladas de cana-de-açúcar por hectare, ao longo da safra, utilizando dados referentes aos fatores de produção como precipitação e temperatura. 


\section{REVISÃO DE LITERATURA}

Segundo Doorembos \& Kassam (1979), a cana-de-açúcar tem como origem à Ásia, provavelmente a Nova Guiné sendo a maior parte das lavouras comerciais localizadas entre as latitudes $35^{\circ} \mathrm{N}$ e $35^{\circ} \mathrm{S}$.

De acordo com Humbert (1968), o ciclo de desenvolvimento da cana-de-açúcar varia desde 10 meses na Louisiana, até dois anos no Hawai, Peru e África do Sul. Nos demais países produtores é de 14 a 18 meses para cana planta e de 12 meses para as socas.

Sendo uma planta muito eficiente em armazenar energia solar, requer que a relação clima-planta, assim como os demais fatores que intervêm no seu desenvolvimento se integrem ao ótimo.

Para Van Dillewijn (1952), o seu crescimento é governado por um complexo de fatores internos e externos, sendo últimos estes especialmente elementos climáticos como precipitação, umidade do ar e temperatura que variam de acordo com as condições das diferentes áreas produtoras.

Para Humbert (1968), bons rendimentos em açúcar somente são observados retardando o crescimento, cujos agentes mais efetivos são as baixas temperaturas e a seca moderada. Desse modo, a temperatura noturna influi mais no crescimento do que a 
diurna e quando as noites são frias, o desenvolvimento é lento e há aumento na concentração de sacarose.

\subsection{Clima da cana-de-açúcar no Brasil}

De acordo com Barbieri \& Villa Nova (1977), a temperatura ótima para a brotação das gemas é de 32 a $38{ }^{\circ} \mathrm{C}$, e para um ótimo crescimento o ambiente deve apresentar médias de temperaturas diurnas entre 22 e $30^{\circ} \mathrm{C}$, porém abaixo de $20{ }^{\circ} \mathrm{C}$ a taxa de crescimento diminui. Para a maturação e colheita, se faz necessário a redução da temperatura para 10 a $20^{\circ} \mathrm{C}$ na região Centro-Sul ou a redução pluviométrica na região Norte-Nordeste, ocorrendo então a diminuição da taxa de crescimento e maior acúmulo de sacarose.

No Brasil, pela grande extensão do seu território encontram-se as mais variadas condições climáticas para a lavoura canavieira, descritas no Quadro 4. Certas áreas segundo Barbieri \& Villa Nova (1977), possuem clima ideal sem restrição alguma, ao passo que outras apresentam restrições térmicas e/ou hídricas moderadas, que permitem a produção econômica da cultura sem exigir recursos e técnicas especiais. Entretanto, há aquelas que as restrições são limitantes, onde somente o cultivo das variedades selecionadas e o emprego de recursos extras, podem corrigir as deficiências hídricas ou técnicas culturais adequadas venham prevenir os efeitos do frio, permitindo uma lavoura canavieira econômica. 


\begin{tabular}{|c|c|c|}
\hline $\begin{array}{c}\text { REGIÃO } \\
\text { CANAVIEIRA }\end{array}$ & $\begin{array}{c}\text { TIPO } \\
\text { CLIMÁTICO } \\
\text { (KOEPPEN) }\end{array}$ & $\begin{array}{l}\text { CARACTERÍSTICAS } \\
\text { REGIONAIS DO CLIMA }\end{array}$ \\
\hline $\begin{array}{l}\text { MATO } \\
\text { GROSSO }\end{array}$ & $\mathrm{Aw}$ & $\begin{array}{l}\text { Clima tropical, com seca nos meses de jun., jul. e ago. Meses } \\
\text { mais chuvosos jan., fev. e mar. Precipitação anual em torno de } \\
1.500 \mathrm{~mm} \text {. Temperatura média anual em torno de } 24^{\circ} \mathrm{C} \text {. }\end{array}$ \\
\hline GOIÁS & Aw & $\begin{array}{l}\text { Clima tropical com seca nos meses de jun., jul. e ago. Meses } \\
\text { mais chuvosos dez., jan. e fev. Precipitação anual em torno de } \\
1.500 \mathrm{~mm} \text {. Temperatura média anual em torno de } 22^{\circ} \mathrm{C} \text {. }\end{array}$ \\
\hline \multirow[t]{2}{*}{ MINAS GERAIS } & Cwa & $\begin{array}{l}\text { Clima subtropical, seco no inverno meses de jun., jul. e ago., e } \\
\text { verão chuvoso meses nov., dez. e jan. Precipitação anual de } \\
1.250 \mathrm{~mm} \text { a } 1.750 \mathrm{~mm} \text {. Temperatura do mês mais quente } \\
\text { superior a } 22^{\circ} \mathrm{C} \text {. }\end{array}$ \\
\hline & Cwbl & $\begin{array}{l}\text { Clima temperado, seco no inverno meses de jun., jul. e ago. } \\
\text { Verão chuvoso nov., dez. e jan. Precipitação anual em torno de } \\
1.500-1.750 \mathrm{~mm} \text {. Temperatura do mês mais quente inferior a } \\
22^{\circ} \mathrm{C} \text {. }\end{array}$ \\
\hline SÃO PAULO & Cwa & $\begin{array}{l}\text { Clima subtropical com seca no inverno meses de jun., jul. e ago. } \\
\text { e verão chuvoso meses nov., dez. e jan. Temperatura do mês } \\
\text { mais quente superior a } 22^{\circ} \mathrm{C} \text {. Precipitação anual entre } 1.250 \\
\text { mm e } 1.500 \mathrm{~mm} \text {. Temperatura média anual entre } 20^{\circ} \text { e } 22^{\circ} \mathrm{C} \text {. }\end{array}$ \\
\hline PARANÁ & $\mathrm{Cfa}$ & $\begin{array}{l}\text { Clima subtropical sempre úmido. Temperatura do mês mais } \\
\text { quente superior a } 22^{\circ} \mathrm{C} \text {. Meses mais secos jun., jul. e ago., } \\
\text { meses mais chuvosos dez., jan. e fev. Precipitação anual em } \\
\text { torno de } 1.250 \mathrm{~mm} \text {. Temperatura média anual em torno de } 20^{\circ} \\
\text { C. }\end{array}$ \\
\hline $\begin{array}{c}\text { SANTA } \\
\text { CATARINA }\end{array}$ & $\mathrm{Cfa}$ & $\begin{array}{l}\text { Clima subtropical sempre úmido. Temperatura do mês mais } \\
\text { quente superior a } 22^{\circ} \text { C. Meses mais secos jun., jul. e ago., } \\
\text { meses mais chuvosos dez., jan. e fev. Precipitação anual entre } \\
\text { de } 1.500 \text { e } 2.000 \mathrm{~mm} \text {. Temperatura média anual entre } 18^{\circ} \text { e } 20^{\circ} \\
\text { C. }\end{array}$ \\
\hline $\begin{array}{l}\text { RIO GRANDE } \\
\text { DO SUL }\end{array}$ & $\mathrm{Cfb}$ & $\begin{array}{l}\text { Clima subtropical sempre úmido. Temperatura do mês mais } \\
\text { quente inferior a } 22^{\circ} \mathrm{C} \text {. Meses mais secos nov., dez. e jan., } \\
\text { meses mais chuvosos ago., set. e out. Precipitação anual em } \\
\text { torno de } 1.500 \mathrm{~mm} \text {. Temperatura média anual entre } 18^{\circ} \text { e } 20^{\circ} \mathrm{C} \text {. }\end{array}$ \\
\hline
\end{tabular}

Fonte: Barbieri \& Villa Nova - PLANALSUCAR: Programa Nacional de Melhoramento da Cana-de-açúcar. Coordenadoria Regional Sul, 1977.

Quadro 4 - Clima da Região Canavieira Centro-Sul do Brasil.

Esses autores citam que a cana-de-açúcar é cultivada em quase todos os estados do Brasil, mas as grandes zonas canavieiras restringem-se principalmente à área 
costeira, entre as latitudes $8^{\circ}$ e $23^{\circ} \mathrm{S}$. A temperatura média anual é de $20^{\circ} \mathrm{C}$ na região Centro - Sul e $26^{\circ} \mathrm{C}$ na região Norte - Nordeste. A precipitação média anual é de 1.250 a $1.750 \mathrm{~mm}$ no Centro - Sul, de 750 a $1.250 \mathrm{~mm}$ no Nordeste e de 1.750 a $2.500 \mathrm{~mm}$ no extremo Norte. Citam ainda que, a região Centro-Sul apresenta boas condições climáticas para o desenvolvimento e maturação da cana-de-açúcar. Nessa região, o principal problema climático é a ocorrência de geadas, principalmente nas áreas situadas entre os meridianos $49^{\circ} 40^{\prime} \mathrm{W}$ e $52^{\circ} 00^{\prime} \mathrm{W}$ e paralelos $22^{\circ}$ e $24^{\circ} \mathrm{S}$, (Sul do Estado de São Paulo e Norte do Estado do Paraná), e no Vale do rio Paranapanema. São causadas por invasões de massas de ar frio proveniente do Sul do continente que às vezes atingem grandes extensões mesmo acima do paralelo $22^{\circ} \mathrm{S}$.

\section{2. Época de plantio da cana-de-açúcar no Brasil}

O plantio da cana-de-açúcar na região Centro-Sul é feito em duas épocas conhecidas como "plantio de cana de ano" e "plantio de cana de ano e meio". O plantio feito em outubro permite a colheita da cana com aproximadamente 12 meses, sendo conhecida como "cana de ano", enquanto que o plantio feito em janeiro - fevereiro, permite a colheita da cana com 18 meses sendo conhecida como "cana de ano e meio".

Castro (1999), descreve que a curva característica do crescimento da cana-deaçúcar de primeiro corte é simétrica para cana de ano, mostrando-se bimodal em cana de ano e meio. Na Figura 1, observa-se que a cana de ano tem seu máximo desenvolvimento de novembro a abril, diminuindo em seguida devido às condições climáticas adversas, podendo ser colhida dependendo do cultivar a partir de julho. A cana de ano e meio tem taxa de crescimento restrita de maio a setembro em função do 
clima, desencadeando o maior desenvolvimento de outubro a abril, principalmente a partir de dezembro, sob condições favoráveis de precipitação.

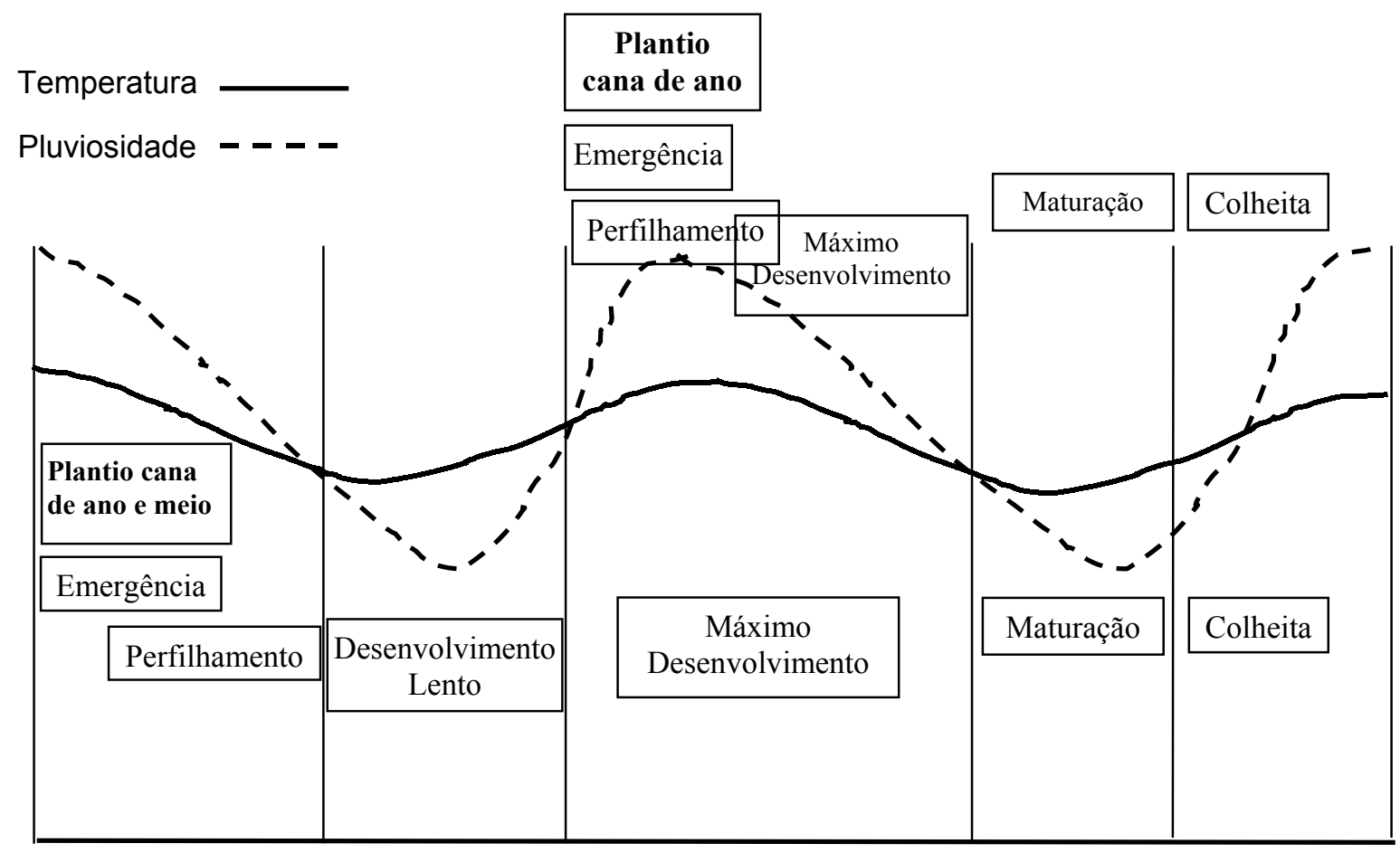

JAN FEV MAR ABR MAI JUN JUL AGO SET OUT NOV DEZ JAN FEV MAR ABR MAI JUN JUL AGO SET OUT NOV DEZ

Figura 1 - Ciclos da cana-de-açúcar e variações na temperatura e pluviosidade da região Centro-Sul do Brasil (Castro, 1999).

$\mathrm{Na}$ organização operacional da lavoura canavieira na região Centro - Sul em especial quanto à colheita de acordo com o Programa Nacional de Melhoramento da Cana-de-Açúcar - PLANALSUCAR (1983), devem ser levados em consideração três aspectos fundamentais:

a) Distribuição das variedades;

b) Distribuição das áreas de corte; 
c) Seleção das áreas de reforma.

Possuindo duas estações distintas durante o ano, o Brasil é o único país no mundo com duas colheitas anuais: uma do Norte - Nordeste, que começa em setembro e continua até abril, e a outra na região Centro - Sul, que vai de maio a dezembro.

\subsection{Fatores que atuam sobre o crescimento, desenvolvimento e maturação da cana- de-açúcar}

O clima é o fator que mais influencia a produtividade da cana-de-açúcar (Barbieri, 1993; Keating et al., 1999; Ometto, 1978, 1980). Os modelos que não particularizam este efeito podem, no máximo, representar uma fração da variação total da produtividade (Beauclair, 1994). Segundo Barbieri (1993), de uma ou de outra forma, estes modelos pretendem correlacionar os efeitos dos dados meteorológicos com a produção e rendimento das culturas. Porém, em alguns trabalhos o clima foi isolado e estudou-se o efeito de outros fatores, como atributos do solo em Beauclair (1991 \& 1994), medidas de crescimento e análises da planta com relação a determinar níveis adequados da cada nutriente para a cultura (Beaufils, 1973; Zambello Júnior \& Orlando Filho, 1980).

Magalhães (1987) cita que dos fatores ambientais a temperatura provavelmente, é o de maior significância para o desempenho da cana. Temperaturas altas, geralmente são bem toleradas pela cultura, desde que haja irrigação ou umidade no solo. Porém, em temperaturas baixas (menores que $21^{\circ} \mathrm{C}$ ) a cultura sofre diminuição na taxa de alongamento dos colmos e acúmulo de sacarose. 
Castro (1999), afirma que a maturação é considerada como um dos aspectos mais importantes na produção da cana-de-açúcar, e que as características varietais são de importância no processo de acúmulo de sacarose que é executado às custas de energia.

Alexander (1973), menciona que as plantas de cana-de-açúcar retardam seu ritmo de crescimento para o acúmulo de mais açúcar em condições naturais específicas de combinação da temperatura ambiente e umidade do solo. Descreve que o processo de maturação fisiológica consiste em frear a taxa de desenvolvimento vegetativo, sem porém afetar significativamente o processo fotossintético, de maneira que haja maior saldo de produtos fotossintetizados e transformados em açúcares para armazenamento nos tecidos da planta. Nessas condições, o clima é definido como o determinante principal das restrições impostas pelo ambiente físico, constituído pela interação dos componentes clima, solo e planta que influenciam respectivamente a época de colheita, o número programado de cortes e a eleição de variedades (Gemente et al., 1986). Para outros autores (Barbieri \& Villa Nova, 1977), o crescimento da cana-de-açúcar é governado também pelas potencialidades genéticas de origem hereditária além do meio ambiente. De modo geral, as condições de todas as estações do ano afetam o desenvolvimento da cana-de-açúcar e o sucesso da cultura, uma vez que se colhem colmos, todo o período vegetativo no decorrer do ciclo está dependente de condições ambientais favoráveis para o seu pleno desenvolvimento. Portanto este trabalho enfocou os fatores temperatura ambiente e umidade do solo, os quais serão relacionados com a maturação e o rendimento. 


\subsubsection{Temperatura ambiente}

O crescimento da cana-de-açúcar está relacionado com a temperatura ambiente, segundo Fauconier \& Bassereau (1975), sendo que o crescimento máximo dá-se entre 30 e $34{ }^{\circ} \mathrm{C}$, enquanto que abaixo de $25^{\circ} \mathrm{C}$ e acima de $38^{\circ} \mathrm{C}$ é muito lento. Barbieri et al. (1978), estabeleceram a temperatura basal para cana em torno de $20^{\circ} \mathrm{C}$, e que em suas várias fases fenológicas, a temperatura continua assumindo grande importância. Assim o florescimento que está ligado ao comprimento do dia, umidade do solo e variedade, também é dependente da temperatura. Valores noturnos acima de $18{ }^{\circ} \mathrm{C}$, baixa umidade e comprimento do dia próximo a 12 horas, na maioria dos casos e dependendo da variedade exposta, há estímulo do florescimento.

O melhor método para correlacionar o desenvolvimento dos vegetais e a temperatura, é o método dos graus-dias, que corresponde a área compreendida entre a temperatura base, abaixo da qual o desenvolvimento é considerado nulo, e a curva da temperatura diária (Villa Nova et al., 1972). Com base nesse conceito, Barbieri et al. (1978) propuseram a seguinte fórmula para o cálculo dos graus-dias para a cultura da cana-de-açúcar:

Para $\mathrm{TM}>\mathrm{Tb}>\mathrm{Tm}:$

$$
\mathrm{GDC}=\frac{(\mathrm{TM}-\mathrm{Tb})^{2}+(\mathrm{TM}-25)^{2}}{2(\mathrm{TM}-\mathrm{Tm})} \mathrm{f} \times \mathrm{n}^{\circ}{ }^{\mathrm{o}} \text { dias do mês; }
$$

Para $\mathrm{Tb}<\mathrm{Tm}$ :

$$
\mathrm{GDC}=\mathrm{Tm}-\mathrm{Tb}+\frac{(\mathrm{TM}-\mathrm{Tm})}{2}+\frac{(\mathrm{TM}-25)^{2}}{2(\mathrm{TM}-\mathrm{Tm})} \mathrm{f} \times \mathrm{n}^{\circ} \text { dias do mês; }
$$

sendo: 


$$
\mathrm{f}=(\mathrm{N} / 24-\mathrm{N})^{2}
$$

$\mathrm{N}=$ comprimento do dia em horas,

$\mathrm{TM}=$ temperatura máxima média mensal $\left({ }^{\circ} \mathrm{C}\right)$,

$\mathrm{Tm}=$ temperatura mínima média mensal $\left({ }^{\circ} \mathrm{C}\right)$,

$\mathrm{Tb}=$ temperatura base $\left({ }^{\circ} \mathrm{C}\right)$.

\subsubsection{Umidade do solo}

A retirada da água pelo sistema radicular da planta pressupõe que no equilíbrio hídrico do sistema solo-raiz resida um dos problemas fundamentais da agricultura. A água em excesso no solo altera os processos químicos e biológicos, limitando a quantidade de oxigênio e acelerando a formação de compostos tóxicos à raiz. Por outro lado, a percolação intensa da água provoca remoção de nutrientes por conseqüência e inibição do crescimento normal da planta. Embora importantes, os excedentes hídricos não apresentam a mesma ordem de grandeza de problemas, quando comparados à seca, que se caracteriza por diferentes formas e intensidades e corresponde à causa principal de decréscimos de produtividade (Ortolani \& Paes de Camargo, 1987).

Trabalhando com evapotranspirógrafo de nível freático constante, equipamento que estabelece as condições ideais de crescimento e desenvolvimento, Barbieri (1981) obteve para a cultura da cana-de-açúcar, um consumo em água de $1300 \mathrm{~mm}$, para uma produção de $464 \mathrm{~kg}$, em $30 \mathrm{~m}^{2}$, que compreende a superfície do aparelho.

Se admitirmos que desses $464 \mathrm{~kg}, 15 \%$ representam fibra, ter-se-á então como caldo o total de $394 \mathrm{~kg}$. Esse caldo de cana possui sólidos, e admitindo que os sólidos totais perfazem 9\%, ter-se-á então, $358 \mathrm{~kg}$ de água que ficou retida na cana. 
Por sua vez, $1300 \mathrm{~mm}$ de altura de água transformada em volume, equivale a 1300 litros de água por metro quadrado de solo, cultivado com a cana-de-açúcar. Logo, o consumo de água pela cultura plantada no evapotranspirógrafo de $30 \mathrm{~m}^{2}$ foi de 39000 litros. Se no processo de evapotranspiração admitir-se que $20 \%$ foi na evaporação da superfície do solo, restam 31200 litros de água transpirada pela planta, provocando uma produção de $464 \mathrm{~kg}$ de cana e uma retenção pela planta de $358 \mathrm{~kg}$, ou litros de água.

Vê-se que em condições ideais, a parcela de água retida pela cana-de-açúcar, que possui um grande armazenamento líquido, corresponde a $1,15 \%$ de toda água que se perde por transpiração. Esse mesmo autor concluiu ainda que a demanda climática ideal de água para a variedade NA 56-79 variou de $0,5 \mathrm{~mm} /$ dia na época da emergência até $6,03 \mathrm{~mm} /$ dia na fase de pico de consumo em dezembro, decaindo para $2,8 \mathrm{~mm} / \mathrm{dia}$ no início da fase de maturação. Outros autores como Doorembos \& Kassam (1979), relatam que dependendo do clima, a necessidade hídrica da cultura encontra-se na faixa de 1500 a $2500 \mathrm{~mm}$ distribuídos de maneira uniforme durante o desenvolvimento. Já Thompson (1967), na África do Sul, verificou uma variação no consumo de água de 5,5 a 6,0 $\mathrm{mm} /$ dia nos meses de janeiro/fevereiro e de 1,8 a 2,3 $\mathrm{mm} /$ dia nos meses de junho/julho. Para as condições climáticas de Tucumán na Argentina, Fogliata (1974) determinou uma evapotranspiração média de dez meses da cana-de-açúcar igual a 4,36 mm/dia, com máxima de $6,09 \mathrm{~mm} /$ dia e mínima de 3,46 mm/dia. Verificou que a cultura necessita de 12,55 a 14,90 mm de água para produzir uma tonelada de cana e 104,9 a 144,2 $\mathrm{mm}$ de água para produzir uma tonelada de açúcar. 


\subsection{Modelos matemáticos utilizando variáveis climáticas}

\subsubsection{O que é um modelo?}

De acordo com Caixeta Filho (2001), são representações idealizadas para situações do mundo real. Apesar da dificuldade para a validação de modelos, sempre haverá indicação do nível de sucesso do processo da modelagem. Thornley (1976), relata que são equações ou o conjunto delas, podendo representar quantitativamente as suposições e hipóteses idealizadas sobre o sistema real.

Do mesmo modo para Aris (1994), cita que são equações matemáticas que representam uma série de fenômenos, que pode ser uma entidade física, química, biológica, social ou conceitual. A palavra modelo deriva de "modus" (uma medida), e implica em mudanças de escala em suas interpretações.

A evolução dos modelos pode ser simplificadamente descrita da seguinte forma (Figura 2):

Figura 2 - Evolução dos modelos.

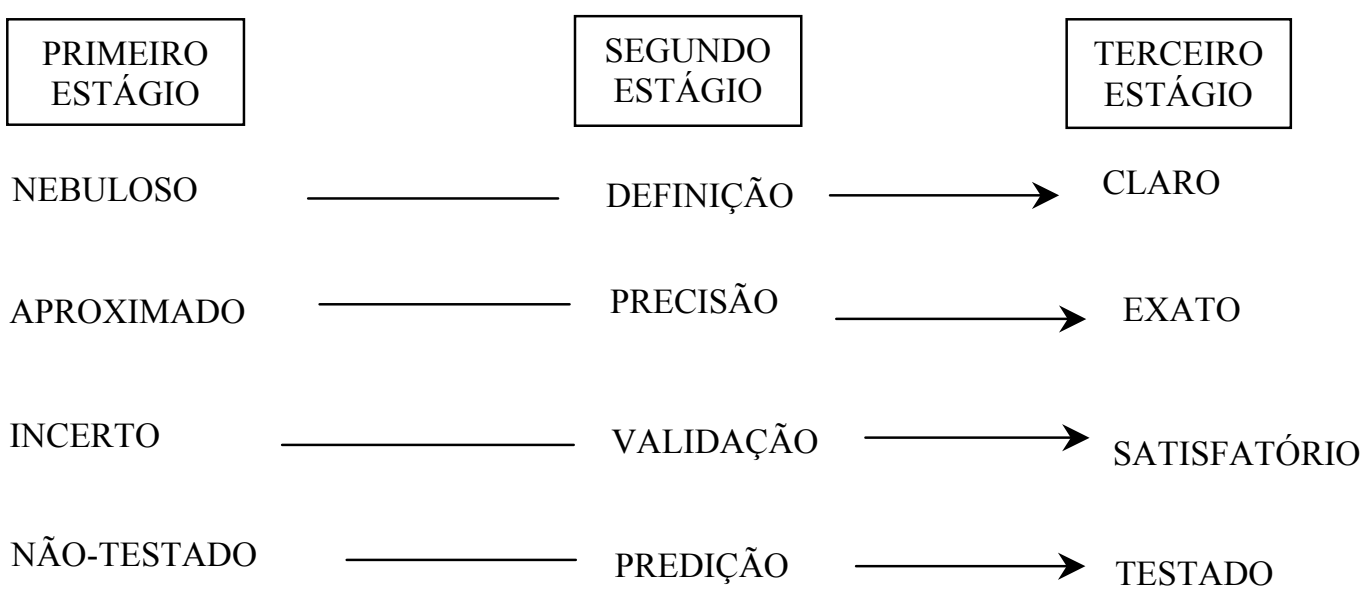

Fonte: USDA, (1978). 
O primeiro estágio consiste em definir o problema e formular hipóteses alternativas. O segundo estágio está no desenvolvimento de experimentos para provar as hipóteses e relatam ainda a performance dos experimentos envolvidos. No terceiro estágio, realizar-se-á o teste de hipótese com os resultados experimentais.

Os modelos matemáticos podem ser positivos (observam vantagens comparativas quanto à reprodução adequada de séries históricas), tendo como exemplos o empírico-descritivo, mecanicista-explicativo, qualitativo e quantitativo ou normativos (impõe um determinado padrão, um comportamento), como exemplo a programação linear (Caixeta Filho, 2001).

\subsubsection{Exemplos de alguns modelos utilizados em cana-de-açúcar}

A importância das informações referentes ao comportamento futuro da cultura em termos de maturação (acúmulo de sacarose) para definição do manejo de variedades pode ser verificado no exemplo descrito por Beauclair \& Penteado (1984), os quais afirmaram que o procedimento usual para determinar a época ideal de corte para as áreas cultivadas consiste inicialmente na seleção de áreas a serem amostradas para análise tecnológica, onde os parâmetros de maturação são considerados. Em seguida escolhemse para o corte, os locais com os maiores valores de ATR. Para mostrar que este procedimento nem sempre é o melhor, utilizou-se um exemplo simplificado (Gráfico 1).

Neste exemplo, observa-se que após a seleção de duas variedades, "A" e "B", a decisão usual seria o corte da variedade "B" em maio, restando para junho a variedade "A". O total de açúcar colhido neste caso seria de $210 \mathrm{Kg}$ de açúcar por tonelada de cana. Já a decisão capaz de maximizar a quantidade total de açúcar deste período seria o corte da variedade "A" em maio, restando para junho a variedade "B". Desta forma, ter- 
se-ia um total de $215 \mathrm{Kg}$ de açúcar por tonelada de cana, aumentando assim o lucro do empreendimento, já que nenhum insumo extra foi aplicado.

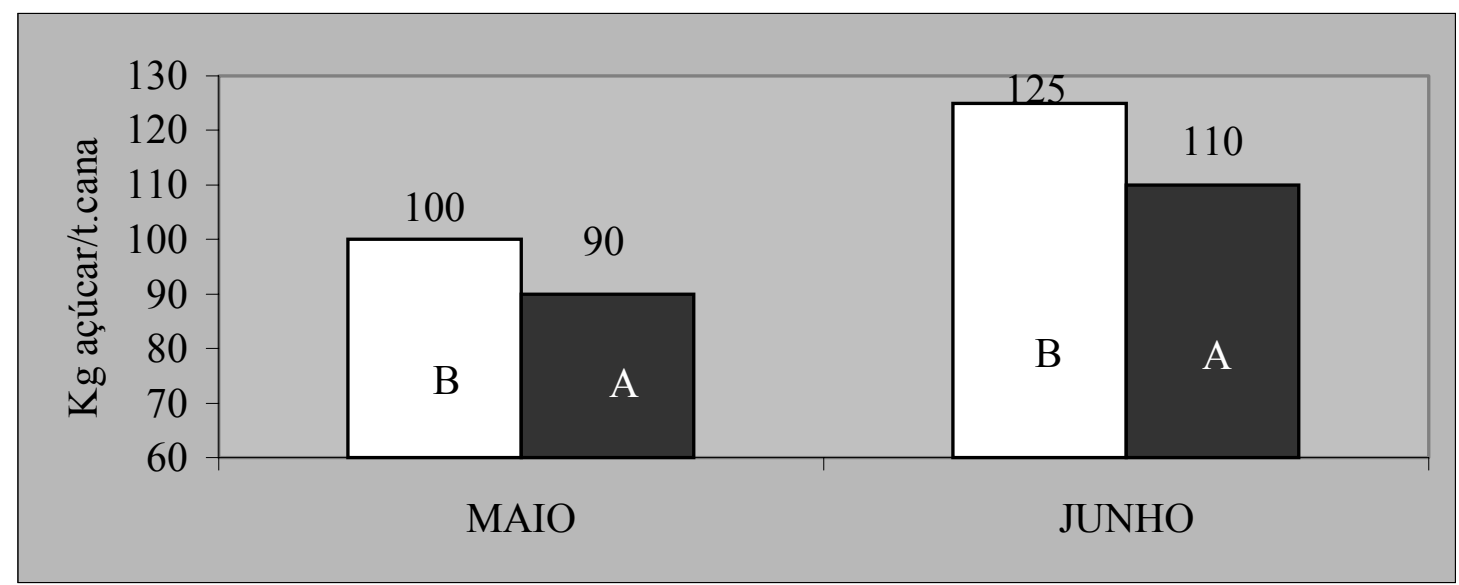

Gráfico 1. Situação teórica da evolução do ATR de duas variedades em função do mês de safra.

Este exemplo auxilia a compreensão da complexidade do problema real, que comporta um número muito maior de áreas aptas para o corte, cada uma com uma combinação de parâmetros diferentes, e, portanto cada uma com um potencial de produção de açúcar diferente, demonstrando a importância do conhecimento da qualidade futura da cana para que a decisão certa de manejo seja tomada.

Rojas (1991), analisou e expressou matematicamente a influência de vários parâmetros climáticos (precipitação, evapotranspiração e temperaturas máximas e mínimas) sobre a produtividade da cana-de-açúcar (final) e utilizando a ferramenta de regressão linear múltipla pelo método "STEPWISE" obteve a seguinte equação matemática:

$$
\mathrm{Y}=61,5439+1,6247 \mathrm{X}_{1}-0,0353 \mathrm{X}_{2}+0,0397 \mathrm{X}_{3} ; \quad \mathrm{R}^{2}=0,81
$$


onde:

$$
\begin{aligned}
& Y=\text { toneladas de cana-de-açúcar por hectare, } \\
& \mathrm{X}_{1}=\text { Precipitação }(\mathrm{mm}) \text { em janeiro, } \\
& \mathrm{X}_{2}=\text { Precipitação }(\mathrm{mm}) \text { em maio, } \\
& \mathrm{X}_{3}=\text { Precipitação }(\mathrm{mm}) \text { em outubro. }
\end{aligned}
$$

Um modelo de previsão de produtividade também foi apresentado em um trabalho realizado na África do Sul, onde Culverwell (1984) analisou dados climáticos, épocas de corte e teores de sacarose utilizando um método denominado de Serviço de Processamento de Recordes de Produtividade (FRPS), e concluiu ser este uma ferramenta importante no gerenciamento da lavoura canavieira.

Outro trabalho realizado por Hoekstra (1984), simulou operações mês a mês de colheita para as áreas com cana-de-açúcar em conjunto com a capacidade de moagem da usina. Dados passados e a expectativa futura de chuva foram usadas numa equação empíricas, onde se calculou a produtividade.

Alguns usos para os modelos de produtividade foram propostos por Boote et al. (1996), como avaliar os riscos de produção considerando séries climáticas históricas para uma região, otimização de data de plantio, densidade de plantio, espaçamento, escolha de variedade e aplicação de fertilizantes para diferentes tipos de solo.

Na Austrália, Pointing \& Taylor (1985), utilizando modelos de produtividade, desenvolveram um sistema computacional para o controle de corte e moagem.

Mishoe et al. (1979), usou um modelo fisiológico de crescimento da cana-deaçúcar baseado no balanço de carbono, maximizando a biomassa. 


\section{MATERIAL E MÉTODOS}

Este projeto foi desenvolvido no Departamento de Produção Vegetal da ESALQ/USP - Setor de Agricultura e na Usina Açucareira Bortolo Carolo que está localizada no município de Pontal - Estado de São Paulo, nas seguintes coordenadas: $21^{\circ} 00^{\prime}$ Latitude $\mathrm{S}$ e $48^{\circ} 02^{\prime} 23^{\prime \prime}$ Longitude $\mathrm{W}$, com temperatura média de $22,4^{\circ} \mathrm{C}$, precipitação média anual de $1.598 \mathrm{~mm}$ e altitude média de $515 \mathrm{~m}$ (Sociedade dos Técnicos Açucareiros e Alcooleiros do Brasil - STAB, 1991).

Os dados das safras 1999/2000, 2000/2001 e 2001/2002 foram analisados considerando a produtividade (ATR e TCH), idade do canavial, solo, variedades e manejo, e com os dados testou-se modelos estatísticos de previsão de produtividade utilizando o programa computacional SAS "Statistical Analysis System" versão 6.11 (SAS Institute, 1989).

A cana mais rica em sacarose é encontrada, via de regra, em regiões de estações climáticas acentuadamente secas e relativamente frias. Onde não há deficiência hídrica, é necessário que a temperatura média seja inferior a $21^{\circ} \mathrm{C}$ por três meses para que ocorra um repouso vegetativo e iniciando o processo de maturação. Todavia, a literatura não relata trabalhos relacionando a influência da queda de temperatura na maturação, apenas relata que a amplitude térmica poderá atuar como fator favorável à maturação (Miocque, 1980; Saes et al., 1990). 
A Figura 3 demonstra como será calculado este fator.

Figura 3 - Graus-dias negativos $\left({ }^{\circ} \mathrm{C}\right)$.

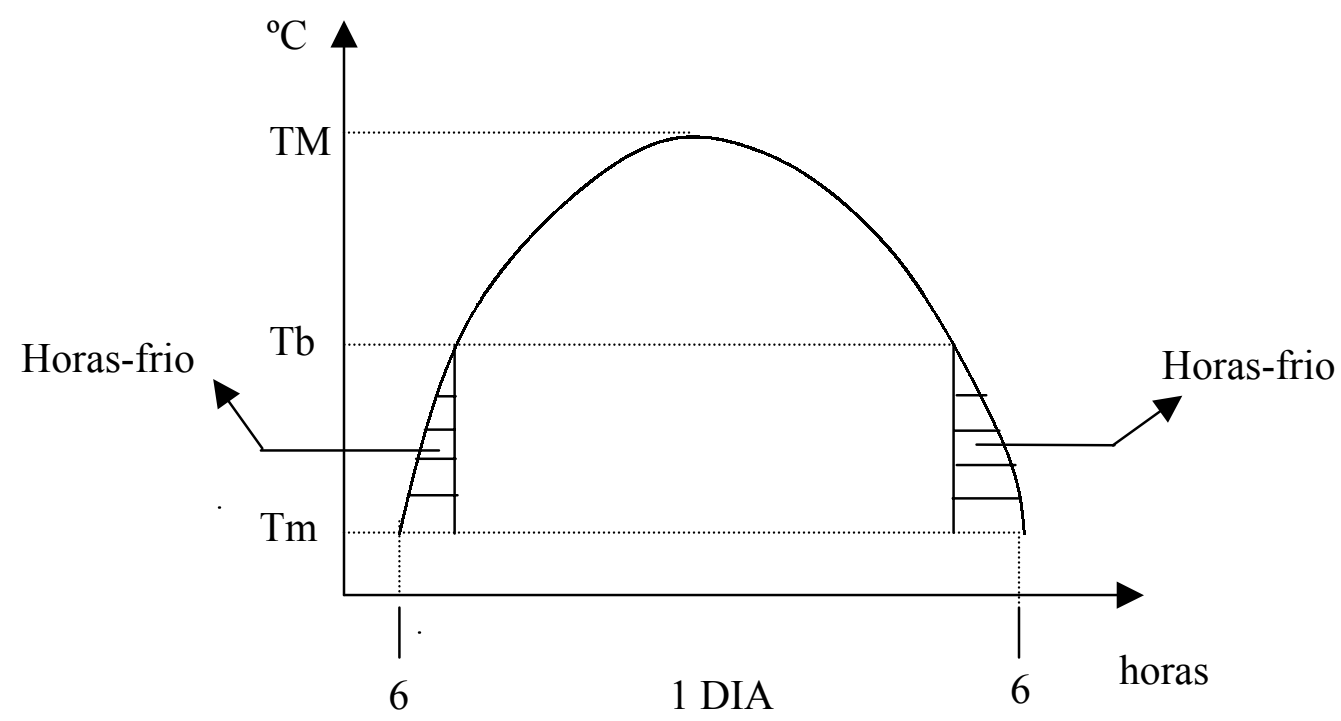

As duas áreas serão representadas da seguinte forma:

Para $\mathrm{Tb}>\mathrm{Tm}$

Graus-dias negativos $=(\underline{\mathrm{Tb}-\mathrm{Tm}})^{2} \times \mathrm{n} .^{\mathrm{o}}$ dias do mês;

$2(\mathrm{TM}-\mathrm{Tm})$

Para $\mathrm{Tb} \leq \mathrm{Tm}$, Graus-dias negativos $=0$

onde:

$\mathrm{TM}=$ temperatura máxima média mensal $\left({ }^{\circ} \mathrm{C}\right)$,

$\mathrm{Tm}$ = temperatura mínima média mensal $\left({ }^{\circ} \mathrm{C}\right)$,

$\mathrm{Tb}=$ temperatura base $\left({ }^{\circ} \mathrm{C}\right)$.

O modelo agroclimático utilizado no presente trabalho é definido por uma expressão matemática que relaciona as variáveis dependentes ATR e TCH (Y) com as 
variáveis independentes definidas como precipitação, graus-dias e graus-dias negativo dos cinco meses anteriores a colheita de cada talhão da seguinte forma:

$$
\mathrm{Y}=\mathrm{a}+\mathrm{b}_{1} \mathrm{~mm} 1+\mathrm{b}_{2} \mathrm{~mm} 2+\mathrm{b}_{3} \mathrm{~mm} 3+\ldots+\mathrm{b}_{15} \text { frio5; }
$$

onde:

$\mathrm{Y}=$ variáveis dependentes dos modelos (ATR e TCH), $\mathrm{mm} 1=$ precipitação do mês anterior à colheita do talhão $(\mathrm{mm})$, $\mathrm{mm} 2$ = precipitação do segundo mês anterior à colheita do talhão $(\mathrm{mm})$, mm3 = precipitação do terceiro mês anterior à colheita do talhão $(\mathrm{mm})$, $\mathrm{mm} 4$ = precipitação do quarto mês anterior à colheita do talhão $(\mathrm{mm})$, mm5 = precipitação do quinto mês anterior à colheita do talhão $(\mathrm{mm})$, $\mathrm{Gd} 1$ = graus-dias do mês anterior à colheita do talhão $\left({ }^{\circ} \mathrm{C}\right)$, $\mathrm{Gd} 2$ = graus-dias do segundo mês anterior à colheita do talhão $\left({ }^{\circ} \mathrm{C}\right)$, $\mathrm{Gd} 3$ = graus-dias do terceiro mês anterior à colheita do talhão $\left({ }^{\circ} \mathrm{C}\right)$, $\mathrm{Gd} 4$ = graus-dias do quarto mês anterior à colheita do talhão $\left({ }^{\circ} \mathrm{C}\right)$, Gd5 = graus-dias do quinto mês anterior à colheita do talhão $\left({ }^{\circ} \mathrm{C}\right)$, frio 1 = graus-dias negativos do mês anterior à colheita do talhão $\left({ }^{\circ} \mathrm{C}\right)$, frio2 $=$ graus-dias negativos do segundo mês anterior à colheita do talhão $\left({ }^{\circ} \mathrm{C}\right)$, frio3 = graus-dias negativos do terceiro mês anterior à colheita do talhão $\left({ }^{\circ} \mathrm{C}\right)$, frio4 $=$ graus-dias negativos do quarto mês anterior à colheita do talhão $\left({ }^{\circ} \mathrm{C}\right)$, frio5 $=$ graus-dias negativos do quinto mês anterior à colheita do talhão $\left({ }^{\circ} \mathrm{C}\right)$. A determinação dos parâmetros $b_{1}, b_{2}, b_{3}, \ldots, b_{14}$ e $b_{15}$ da equação adotada foi feita utilizando o procedimento "REG" pelo método "STEPWISE", onde este seleciona as variáveis independentes que entrarão no modelo através da regressão linear múltipla. 
Em todos os procedimentos, a análise de variância da regressão linear múltipla foi testada com o teste F (Spiegel, 1972), até o nível de 10\% de probabilidade de erro na rejeição da hipótese nula. Este nível é utilizado normalmente em trabalhos de regressão com variáveis aleatórias (Hoffman \& Vieira, 1977).

Como indicador da precisão dos modelos, utilizou-se o parâmetro denominado de coeficiente de determinação $\left(\mathrm{R}^{2}\right)$ e o índice de concordância de Willmott (1981).

$$
\begin{aligned}
& \mathrm{R}^{2}=\mathrm{SSR} / \mathrm{SST} ; \\
& \mathrm{Id}=1-\frac{\sum(\mathrm{Sj}-\mathrm{Oj})^{2}}{\sum(|\mathrm{Sj}-\overline{\mathrm{O}}|+|\mathrm{Oj}-\overline{\mathrm{O}}|)^{2}},
\end{aligned}
$$

onde:

$\mathrm{R}^{2}=$ coeficiente de determinação,

$\mathrm{SSR}=$ soma de quadrados da regressão,

$\mathrm{SST}=$ soma de quadrados totais.

Id = índice de concordância de Willmott,

$\mathrm{Sj}$ = variável estimada,

Oj = variável real,

$\overline{\mathrm{O}}=$ média da variável real.

Na simulação dos modelos e comparação entre o ATR real e o ATR estimado, utilizou-se o teste do qui-quadrado sendo o ajustamento de freqüências observadas a proporções previstas por teorias ou por hipóteses convenientes (Pimentel Gomes, 1990).

O cálculo é feito pela fórmula:

$$
\chi^{2}=\frac{\sum(\mathrm{fo}-\mathrm{fe})^{2}}{\mathrm{fe}}
$$

onde: 
fo = freqüência observada,

fe $=$ freqüência esperada.

O nível de significância estatística será de 5\%. 


\section{RESULTADOS E DISCUSSÃO}

Nos Apêndices nas Tabelas 1, 2 e 3 encontram-se os dados da Usina Açucareira Bortolo Carolo das safras 1999/2000, 2000/2001 e 2001/2002 previamente subdivididos pela maturação (precoce, média ou tardia) e estágio da cultura (ano, ano e meio ou soca).

Com relação ao solo, a Usina Açúcareira Bortolo Carolo apresenta 78\% dos talhões em LR (Latossolo Roxo). Buscou-se então selecionar apenas talhões com este tipo de solo.

Níveis de adubação, calagem e gessagem, aplicação de maturadores, pragas e doenças não foram considerados nos modelos, apenas considerou-se uma C.A.D. (capacidade de água disponível) igual a $100 \mathrm{~mm}$ para os Latossolos Roxos.

A seguir, encontram-se os dados climáticos da região de Ribeirão Preto dos anos de 1998, 1999, 2000 e 2001 além do cálculo dos graus-dias e graus-dias negativos que foram utilizados nos modelos:

INSTITUTO AGRONÔMICO - SEÇÃO DE CLIMATOLOGIA AGRÍCOLA ESTAÇÃO EXPERIMENTAL DE RIBEIRÃO PRETO
LAT.: 21 13' S
LONG.: 48 54' w
ALT.: $562 \mathrm{~m}$

DADOS MENSAIS 
Tabela 4. Umidade do solo considerada (mm): C.A.D. $=100 \mathrm{~mm}$.

\begin{tabular}{ccccccccccccc}
\hline ANO & JAN & FEV & MAR & ABR & MAI & JUN & JUL & AGO & SET & OUT & NOV & DEZ \\
\hline 1998 & 100 & 100 & 100 & 44,4 & 62,0 & 1,8 & 0,5 & 43,6 & 22,9 & 100 & 100 & 100 \\
1999 & 100 & 100 & 100 & 93,6 & 18,8 & 23,9 & 0,5 & 0 & 90 & 36,5 & 73,8 & 100 \\
2000 & 100 & 100 & 100 & 0,2 & 0,9 & 0,2 & 39 & 49,3 & 76 & 41,9 & 100 & 100 \\
2001 & 82,7 & 100 & 100 & 36,9 & 100 & 1 & 3 & 33 & 52 & 100 & 100 & 100 \\
\hline
\end{tabular}

Tabela 5. Temperatura média máxima $\left({ }^{\circ} \mathrm{C}\right)$.

\begin{tabular}{cccccccccccccc}
\hline ANO & JAN & FEV & MAR & ABR & MAI & JUN & JUL & AGO & SET & OUT & NOV & DEZ & ANO \\
\hline 1998 & 31,1 & 30,6 & 30,9 & 29,6 & 25,9 & 25,4 & 27,7 & 28,0 & 30,1 & 29,1 & 29,9 & 29,6 & 29,0 \\
1999 & 30,0 & 30,3 & 30,0 & 28,8 & 26,0 & 26,1 & 27,9 & 28,7 & 30,5 & 30,5 & 29,7 & 29,6 & 29,0 \\
2000 & 29,4 & 29,4 & 29,3 & 29,5 & 27,4 & 27,6 & 25,9 & 29 & 28,5 & 33,1 & 30,1 & 29,8 & 29,1 \\
2001 & 31 & 31,5 & 30,8 & 30,3 & 26,1 & 25,5 & 27,5 & 28,2 & 28,9 & 29,2 & 29,7 & 28,8 & 29,0 \\
\hline
\end{tabular}

Tabela 6. Temperatura média mínima $\left({ }^{\circ} \mathrm{C}\right)$.

\begin{tabular}{cccccccccccccc}
\hline ANO & JAN & FEV & MAR & ABR & MAI & JUN & JUL & AGO & SET & OUT & NOV & DEZ & ANO \\
\hline 1998 & 20,4 & 20,7 & 19,7 & 17,8 & 14,6 & 13,5 & 13 & 16,5 & 18,2 & 18,7 & 18,5 & 19,9 & 17,6 \\
1999 & 20,7 & 20,0 & 19,7 & 16,5 & 13,7 & 13,7 & 15,4 & 14,2 & 16,9 & 17,5 & 17,5 & 19,6 & 17,1 \\
2000 & 19,9 & 20,2 & 19,6 & 16,5 & 13,9 & 14,1 & 11,5 & 14,7 & 16,3 & 19 & 18,4 & 19 & 16,9 \\
2001 & 18,9 & 19,9 & 19,6 & 18,4 & 14,4 & 13,6 & 14,2 & 15,2 & 16,9 & 18,2 & 19,7 & 19,4 & 17,4 \\
\hline
\end{tabular}

Passos para o cálculo dos graus-dias $\left({ }^{\circ} \mathrm{C}\right)$ :

Tabela 7. Duração máxima diária da insolação $(\mathrm{N})$ em horas - $15^{\circ}$ dia do mês (Barbieri \& Tuon, 1993).

\begin{tabular}{ccccccccccccc}
\hline LAT & JAN & FEV & MAR & ABR & MAI & JUN & JUL & AGO & SET & OUT & NOV & DEZ \\
\hline $22^{\circ}$ & 13,4 & 12,8 & 12,2 & 11,6 & 11,1 & 10,8 & 10,9 & 11,3 & 12 & 12,6 & 13,2 & 13,5 \\
\hline
\end{tabular}

Tabela 8. Cálculo do fator $\mathrm{f}$.

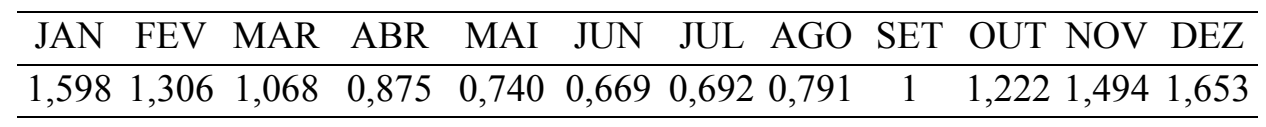


Tabela 9. Graus-dias $\left({ }^{\circ} \mathrm{C}\right)$.

\begin{tabular}{ccccccccccccc}
\hline ANO & JAN & FEV & MAR & ABR & MAI & JUN & JUL & AGO & SET & OUT & NOV & DEZ \\
\hline 1998 & 371 & 264,5 & 227 & 126 & 36 & 25 & 48,5 & 78 & 161 & 181 & 240 & 299 \\
1999 & 332 & 238 & 201 & 98 & 34,5 & 31 & 61 & 75,5 & 155 & 205 & 213 & 290 \\
2000 & 281 & 221,5 & 179 & 112 & 51 & 48 & 26,5 & 83,1 & 103,8 & 318,7 & 245,2 & 282,5 \\
2001 & 321,4 & 275 & 222,1 & 148 & 37,7 & 26 & 50 & 73 & 118 & 176 & 260 & 250 \\
\hline
\end{tabular}

Tabela 10. Graus-dias negativos $\left({ }^{\circ} \mathrm{C}\right)$.

\begin{tabular}{ccccccccccccc}
\hline ANO & JAN & FEV & MAR & ABR & MAI & JUN & JUL & AGO & SET & OUT & NOV & DEZ \\
\hline 1998 & 0 & 0 & 0,1 & 6,2 & 40 & 53,2 & 51,7 & 16,5 & 4 & 2,5 & 2,9 & 0 \\
1999 & 0 & 0 & 0,1 & 15 & 50 & 48 & 26,2 & 36 & 10,6 & 7,4 & 7,6 & 0,2 \\
2000 & 0 & 0 & 0,2 & 14,1 & 42,7 & 38,6 & 77,7 & 30,4 & 16,8 & 1,1 & 3,3 & 1,4 \\
2001 & 1,5 & 0 & 0,2 & 3,2 & 41,5 & 51,6 & 39,2 & 27,4 & 12 & 4,5 & 0,1 & 0,5 \\
\hline
\end{tabular}

Com relação à umidade do solo considerada nos modelos, esta foi comparada mensalmente com a série histórica da precipitação na região de Ribeirão Preto, sendo exposta na Tabela 11 nos Apêndices.

Com os índices mensais em ordem decrescente, o método de Kimbal citado por Villela \& Mattos (1975) é aplicado gerando probabilidades iguais ou maiores que o evento ocorrido, exposto na Tabela 12.

$$
\mathrm{P}>\mathrm{h}=\left(1-\mathrm{P}_{\mathrm{o}}\right) \times \frac{\mathrm{n} .^{\mathrm{o}} \text { na ordem }}{\mathrm{n} .^{\mathrm{o}} \text { total }+1} \times 100
$$

onde:

$$
\begin{aligned}
& \mathrm{P}>\mathrm{h}=\text { probabilidade igual ou maior que o evento ocorrido, } \\
& \mathrm{Po}=1 / \mathrm{n}^{\circ}{ }^{\mathrm{o}} \text { total. }
\end{aligned}
$$


Tabela 12. Probabilidades iguais ou maiores que o evento ocorrido (em \%).

\begin{tabular}{ccccccccccccc}
\hline ANO & JAN & FEV & MAR & ABR & MAI & JUN & JUL & AGO & SET & OUT & NOV & DEZ \\
\hline 1998 & 96 & 86 & 80 & 68 & 35 & 71 & 68 & 18 & 61 & 63 & 80 & 94 \\
1999 & 96 & 86 & 80 & 26 & 64 & 44 & 68 & 70 & 17 & 94 & 89 & 94 \\
2000 & 96 & 86 & 80 & 95 & 89 & 77 & 21 & 17 & 24 & 93 & 80 & 94 \\
2001 & 100 & 86 & 80 & 79 & 15 & 74 & 60 & 21 & 33 & 63 & 80 & 94 \\
\hline
\end{tabular}

Observa-se pela Tabela 12, a grande heterogeneidade dos dados de chuva nos anos de 1999 e 2000 os quais foram usados na elaboração dos modelos de previsão, se comparado com o ano de 2001 que será o ano de simulação dos modelos. Este fato poderá vir a interferir na calibração e validação dos modelos, pois apenas dois anos de observações foram utilizados.

Os modelos de maturação (ATR) mais promissores através da saída do pacote estatístico SAS "Statistical Analysis System" pelo método "STEPWISE", indicando cada etapa das análises, assim como os quadros parciais e os dados referentes à entrada de cada variável no modelo até o ajuste final, quando são apresentados os dados das estimativas dos parâmetros das equações dos modelos de cada análise, estão apresentados nos Apêndices.

Nestas análises estatísticas, as variáveis selecionadas pelo modelo indicam que existe um efeito destes parâmetros na quantidade de açúcar por tonelada de cana. A magnitude deste efeito, no entanto, é dada pelos valores do $\mathrm{R}^{2}$ (coeficiente de determinação) no modelo final encontrado, já citado anteriormente. Estes valores podem ser considerados como o percentual da variação da variável dependente (ATR), podendo ser explicada pelo modelo definido. 
Os Resultados 1 e 2 apresentados nos Apêndices, retratam as análises estatísticas realizadas tendo como variável dependente o ATR. Como variáveis independentes, os parâmetros de clima foram introduzidos (precipitação, graus-dias e graus-dias negativos).

O Resultado 1, referente à primeira análise estatística revelou um efeito significativo para as variáveis $\mathrm{mm} 2, \mathrm{~mm} 4$ e frio4, correspondendo a precipitação do segundo mês anterior à colheita do talhão, precipitação do quarto mês anterior à colheita do talhão e aos graus-dias negativos do quarto mês anterior à colheita. Nota-se que o conceito graus-dias negativos adotado neste trabalho foi de extrema valia na seleção das variáveis independentes do modelo, como o sinal positivo do parâmetro estimado para a variável frio4, indicando um efeito benéfico na variável ATR. Nesta mesma análise, o sinal negativo do parâmetro estimado para a variável mm2 indica um efeito depressivo no ATR. Fisiologicamente, o sinal positivo do parâmetro estimado para a variável mm4 é explicado, pois uma seca drástica anterior à colheita não é benéfica, ocorrendo o fechamento dos estômatos para economia de água e por conseqüência diminuição da transpiração, trocas gasosas, assimilação de $\mathrm{CO}_{2}$ e acúmulo de sacarose. Portanto, a falta de água na planta afeta a produção de sacarose. $\mathrm{O}$ valor do $\mathrm{R}^{2}=0,6943 *$ é relativamente alto, explicando cerca de $69 \%$ da variação do ATR, sendo o restante $31 \%$ fatores que não foram considerados no modelo como a própria diferença varietal a qual influencia a época de maturação. Como o modelo apresenta a rejeição da hipótese nula (valor de F é estatisticamente significativo), o efeito das variáveis selecionadas deve ser considerado. 
Com isso, o modelo pode fornecer valores de ATR com dois meses de antecedência da colheita das canas de ano para as variedades plantadas na Usina Açúcareira Bortolo Carolo.

O Resultado 2, referente à segunda análise estatística também revelou um efeito significativo para as variáveis $\mathrm{Gd} 2, \mathrm{~mm} 1$, frio2, $\mathrm{mm} 5, \mathrm{Gd} 1$, frio4 e mm4 indicando os graus-dias do segundo mês anterior à colheita, precipitação do mês anterior à colheita, graus-dias negativos do segundo mês anterior à colheita, precipitação do quinto mês anterior à colheita, graus-dias do mês anterior à colheita, graus-dias negativos do quarto mês anterior à colheita e precipitação do quarto mês anterior à colheita. Os sinais dos parâmetros estimados das variáveis independentes indicam ao mesmo tempo, a contribuição da variável frio4 no ATR e o efeito depressivo da variável frio2 no ATR. Por este fato, o modelo pode não estar adequado ao fornecimento de valores estimados para cana de ano e meio. Isto será comprovado ou não na simulação para a safra 2001/2002. Com relação ao coeficiente de determinação $R^{2}=0,7574 *$ obtido, este é um valor alto explicando cerca de $76 \%$ da variação do ATR, sendo o restante $24 \%$ fatores que não foram considerados no modelo como a própria diferença varietal já citada anteriormente, a qual influencia a época de maturação. Como o modelo apresenta a rejeição da hipótese nula (valor de $\mathrm{F}$ é estatisticamente significativo), o efeito das variáveis selecionadas deve ser considerado. Este modelo considerado pode fornecer valores de ATR com apenas um mês de antecedência da colheita das canas de ano e meio para as variedades plantadas na Usina Açúcareira Bortolo Carolo, sendo de extrema valia no planejamento de corte, pois o tempo de planejamento numa usina geralmente é escasso. 
Portanto, os modelos de maturação (ATR) para cana de ano eq. (12) e cana de ano e meio eq. (13) são apresentados a seguir:

$\mathrm{ATR}=133,86601-0,38572 \mathrm{~mm} 2+0,32466 \mathrm{~mm} 4+0,24406$ frio4; $\mathrm{R}^{2}=0,6943$ (12) onde:

ATR = Açúcar Teórico Recuperável (em Kg de açúcar por tonelada de cana), mm2 = precipitação do segundo mês anterior à colheita do talhão (em mm), mm4 = precipitação do quarto mês anterior à colheita do talhão (em mm), frio4 = graus-dias negativos do quarto mês anterior à colheita do talhão (em $\left.{ }^{\circ} \mathrm{C}\right)$.

\section{$\mathrm{ATR}=138,87880+0,21102 \mathrm{~mm} 1+0,12318 \mathrm{~mm} 4+0,25010 \mathrm{mm5}+\mathbf{0 , 0 8 1 6 3} \mathrm{Gd} 1-$ 0,34190 Gd2 - 0,36126 frio2 + 0,40344 frio4; $\mathbf{R}^{2}=0,7574$} onde:

ATR = Açúcar Teórico Recuperável (em Kg de açúcar por tonelada de cana), $\mathrm{mm} 1$ = precipitação do mês anterior à colheita do talhão (em mm), mm4 = precipitação do quarto mês anterior à colheita do talhão (em mm), mm5 = precipitação do quinto mês anterior à colheita do talhão (em mm), $\mathrm{Gd1}$ = graus-dias do mês anterior à colheita do talhão $\left(\mathrm{em}^{\circ} \mathrm{C}\right)$, $\mathrm{Gd} 2$ = graus-dias do segundo mês anterior à colheita do talhão $\left(\mathrm{em}{ }^{\circ} \mathrm{C}\right)$, frio2 = graus-dias negativos do segundo mês anterior à colheita do talhão $\left(\mathrm{em}^{\circ} \mathrm{C}\right)$, frio4 = graus-dias negativos do quarto mês anterior à colheita do talhão (em $\left.{ }^{\circ} \mathrm{C}\right)$.

Com relação aos modelos de maturação (ATR) para socas precoces, médias e tardias, estes não se mostraram promissores indicando um $\mathrm{R}^{2}$ de 0,$36 ; 0,48$ e 0,45 
respectivamente e não foram apresentados. É provável que a variação na época de corte dentro dos grupos de maturação, diferentes estágios das socas, aplicação de maturadores e apenas dois anos de safra, contribuam no alto percentual de variação da variável dependente, pois explicam apenas 36, 48 e $45 \%$ da variação do ATR, indicando a existência de outros fatores influenciando a maturação e que não foram considerados nos modelos.

Os modelos de produtividade (TCH) analisados apresentaram um $\mathrm{R}^{2}$ baixo para as canas de ano $(0,31)$ e cana de ano e meio $(0,39)$, porém os resultados estatísticos (ver Apêndices) indicaram a precipitação como variável de maior peso nos modelos, reafirmando a importância da umidade do solo na produção de colmos.

As equações dos modelos de produtividade (TCH) para cana de ano eq. (14) e cana de ano e meio eq. (15) são apresentadas a seguir:

$\mathrm{TCH}=64,21145+0,27273 \mathrm{~mm} 4$;

$$
\mathbf{R}^{2}=\mathbf{0 , 3 1 2 5}
$$

onde:

$\mathrm{TCH}=$ tonelada de cana-de-açúcar por hectare $\left(\mathrm{t} \cdot \mathrm{ha}^{-1}\right)$, $\mathrm{mm} 4$ = precipitação do quarto mês anterior à colheita do talhão (em mm).

$\mathrm{TCH}=35,72306+0,57487 \mathrm{~mm} 1+0,22957 \mathrm{~mm} 2+0,29839 \mathrm{~mm} 4+0,89310 \mathrm{~mm} 5-$ 0,34098 Gd4;

$$
\mathbf{R}^{2}=0,3932
$$

$\mathrm{TCH}=$ tonelada de cana-de-açúcar por hectare $\left(\mathrm{t} \cdot \mathrm{ha}^{-1}\right)$,

$\mathrm{mm} 1$ = precipitação do mês anterior à colheita do talhão (em mm), $\mathrm{mm} 2$ = precipitação do segundo mês anterior à colheita do talhão (em mm), $\mathrm{mm} 4$ = precipitação do quarto mês anterior à colheita do talhão $(\mathrm{em} \mathrm{mm})$, 
mm5 = precipitação do quinto mês anterior à colheita do talhão (em mm), Gd4 = graus-dias do quarto mês anterior à colheita do talhão $\left(\mathrm{em}^{\circ} \mathrm{C}\right)$.

Para as socas precoces, médias e tardias esses valores foram ainda menores 0,09; 0,08 e 0,04 respectivamente não sendo apresentados, indicando que a variação na época de corte dentro dos grupos de maturação, diferentes estágios das socas, diferentes épocas de plantio, dois anos de safra analisados, adubação, pragas e doenças, calagem e gessagem atuam diretamente na produtividade da cana-de-açúcar e estes fatores não foram considerados. Isto confirma indiretamente a filosofia dos "blueprints", onde a interação dos fatores assume importância maior do que um efeito ou fator isolado (Cooke, 1982).

Após a elaboração dos modelos, realizaram-se simulações para validar os modelos promissores, gerando produtividades estimadas ao longo da safra, comparando com as produtividades reais da safra 2001/2002.

\subsection{Simulações para validação dos modelos promissores}

Utilizando os dados climáticos da região de Riberão Preto na safra de 2001/2002, obtivemos valores do ATR estimado de acordo com os modelos, sendo comparados com os valores do ATR real através do teste qui-quadrado.

Nos dados de ATR para cana de ano, obtêm-se um valor de $\chi^{2}=95,66$. Consultando a tabela (HOFFMAN, 1980) para $\alpha<0,05$ e G.L. $=74$ o valor é $\chi^{2} \cong 96$. Como o valor de qui-quadrado calculado é menor que o tabelado não há diferença estatística significativa ao nível de 5\% entre os dados, aceitando-se Ho e a hipótese de freqüências iguais para dados reais e estimados. 
No Gráfico 2, os dados reais e estimados são melhores visualizados:

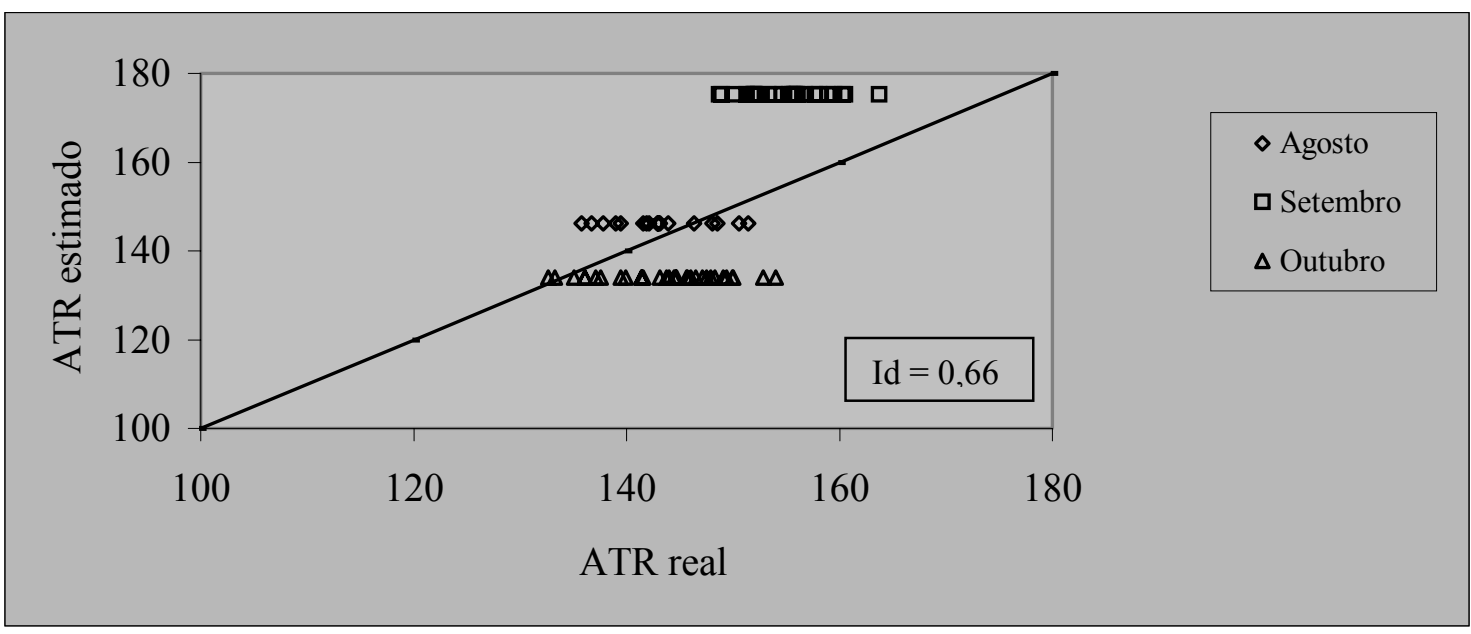

Gráfico 2. Simulação entre o ATR estimado e o ATR real para cana de ano.

Nos dados de ATR para cana de ano e meio também se aplicou o teste quiquadrado, obtendo um valor de $\chi^{2}=280,14$. Consultando a tabela para $\alpha<0,05$ e G.L. $=$ 213 o valor é $\chi^{2} \cong 240$. Como o valor de qui-quadrado calculado supera o valor tabelado diz-se que há diferença estatística significativa ao nível de 5\%, rejeitando a hipótese de freqüências iguais para ATR real e ATR estimado em cana de ano e meio. No Gráfico 3, os dados reais e estimados para cana de ano e meio são melhores visualizados:

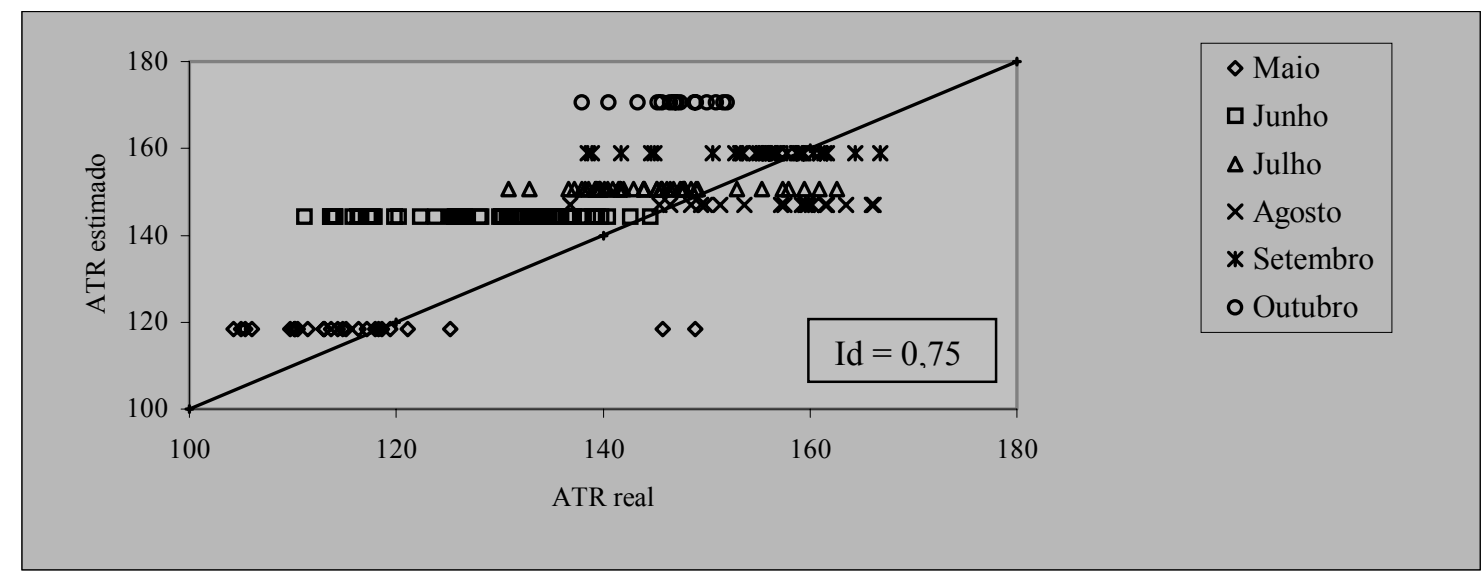

Gráfico 3. Simulação entre o ATR estimado e o ATR real para cana de ano e meio. 
Nos modelos de produtividade o teste qui-quadrado também foi aplicado sendo para cana de ano $\chi^{2}=355,55$. Como o valor de qui-quadrado calculado supera o valor tabelado diz-se que há diferença estatística significativa ao nível de 5\%, rejeitando a hipótese de freqüências iguais para TCH real e TCH estimado em cana de ano. Para cana de ano e meio o valor de qui-quadrado calculado é $\chi^{2}=2983,27$ superando o valor tabelado, havendo diferença estatística entre o TCH real e o TCH estimado ao nível de 5\%. Nos Gráficos 4 e 5, a simulação para os modelos de produtividade é melhor visualizada.

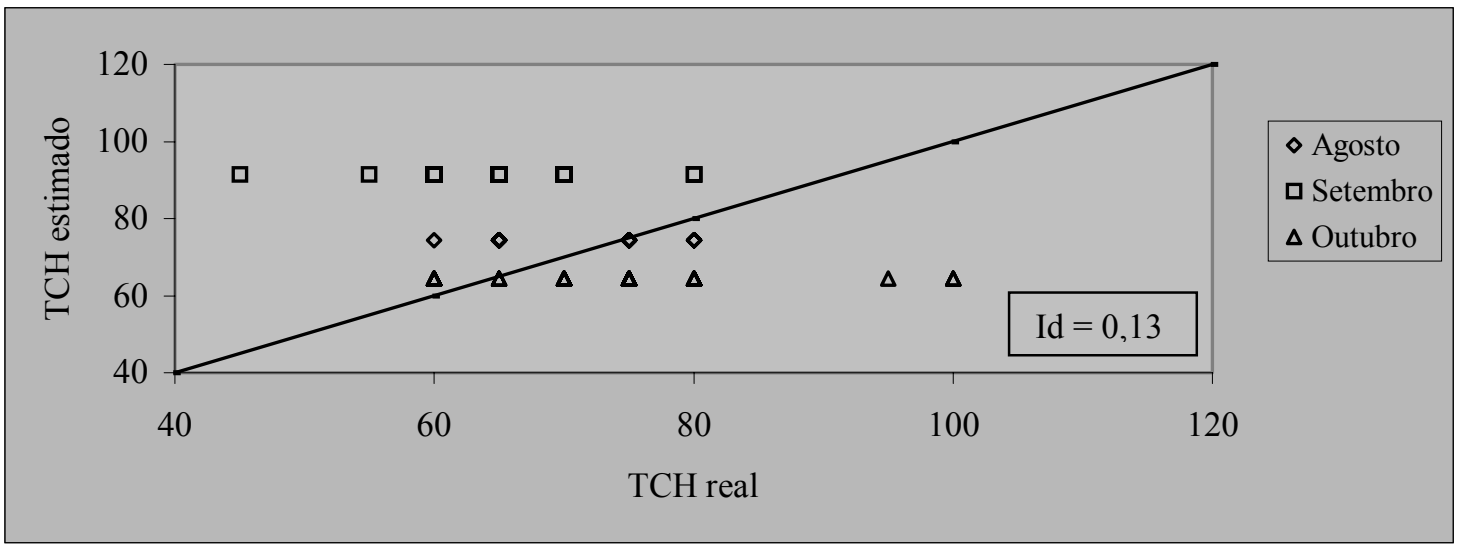

Gráfico 4. Simulação entre o TCH estimado e o TCH real para cana de ano.

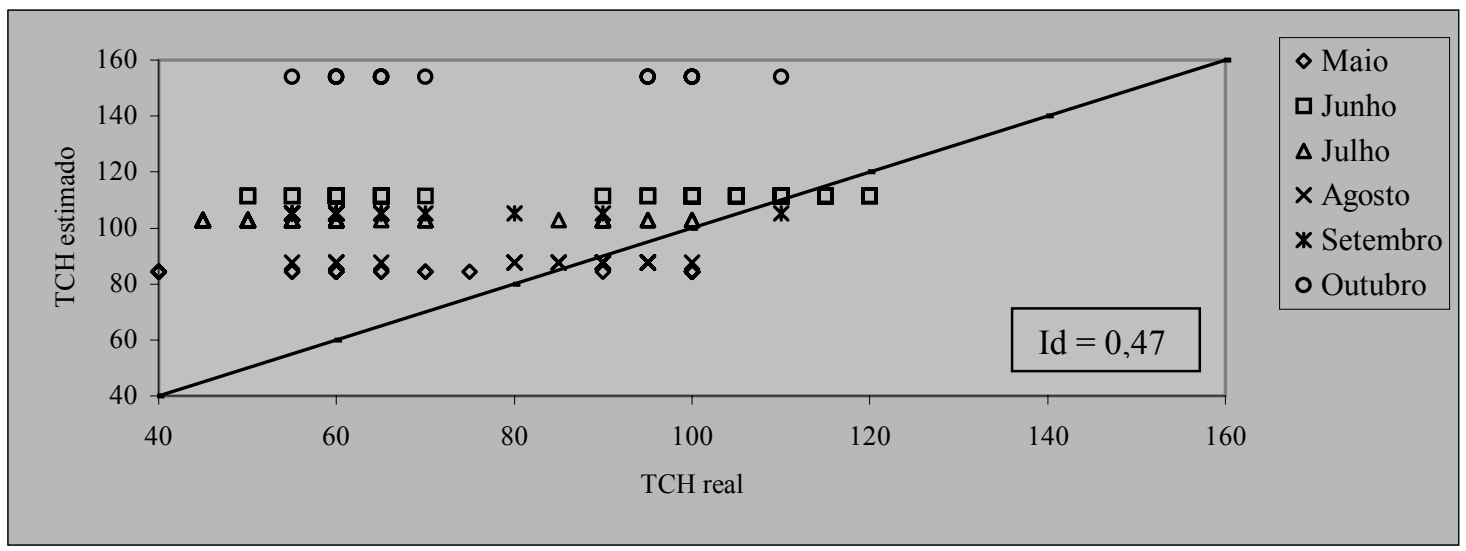

Gráfico 5. Simulação entre o TCH estimado e o TCH real para cana de ano e meio. 


\section{CONCLUSÕES}

- Pode-se confirmar e quantificar a influência da precipitação, graus-dias e graus-dias negativos na maturação e produtividade da cana-de-açúcar.

- O modelo de maturação para cana de ano mostrou-se mais confiável quando comparado com o modelo de maturação para cana de ano e meio, após a realização da simulação para a safra 2001/2002.

- A introdução do fator graus-dias negativos foi de suma importância, pois teve grande influência nos modelos de maturação.

- Os modelos de produtividade não se mostraram confiáveis após a realização da simulação para a safra 2001/2002. 


\section{REFERÊNCIAS BIBLIOGRÁFICAS}

AÇÚCAREIRA BORTOLO CAROLO. STAB. Açúcar, Álcool e Subprodutos, Piracicaba, v.10, n.2, p.4-9, nov./dez. 1991.

ALEXANDER, A.G. Sugarcane physiology: a comprehensive study of the Saccharum source-to-sink system. Amsterdam: Elsevier, 1973. 752p.

ANUÁRIO ESTATÍSTICO DO BRASIL. Rio de Janeiro, v.58, p.3-27, 1998.

ARIS, R. Mathematical modeling techniques. New York: Dover, 1994. 269p.

BARATA, M.Q.F. Otimização econômica do corte e reforma de canaviais. Piracicaba, 1992. 124p. Dissertação (Mestrado) - Escola Superior de Agricultura "Luiz de Queiroz", Universidade de São Paulo.

BARBIERI, V. Medidas e estimativas de consumo hídrico em cana-de-açúcar (Saccharum spp.). Piracicaba, 1981. 82p. Dissertação (Mestrado) - Escola Superior de Agricultura "Luiz de Queiroz", Universidade de São Paulo.

BARBIERI, V. Condicionamento climático da produtividade potencial da cana-deaçúcar (Saccharum spp.): Um modelo matemático-fisiológico de estimativa. Piracicaba, 1993. 140p. Tese (Doutorado) - Escola Superior de Agricultura "Luiz de Queiroz", Universidade de São Paulo.

BARBIERI, V.; TUON, R.L. Metodologia para estimativa da produção potencial de algumas culturas. Piracicaba: ESALQ, 1992. 17p. 
BARBIERI, V.; VILLA NOVA, N. A. Climatologia e a cana-de-açúcar. In: PLANALSUCAR - Coordenadoria Regional Sul - COSUL, Araras, p. 1-22, 1977.

BARBIERI, V.; BACCHI, O.O.S.; VILLA NOVA, N.A. Análise do fator temperatura média do ar no desenvolvimento da cana-de-açúcar. /Apresentado no 1. Congresso de Agrometeorologia, Mossoró, 1978/.

BEAUCLAIR, E.G.F. de Relações entre algumas propriedades químicas do solo e a produtividade da cana-de-açúcar (Saccharum spp.), através de regressão linear múltipla. Piracicaba, 1991. 90p. Dissertação (Mestrado) - Escola Superior de Agricultura "Luiz de Queiroz", Universidade de São Paulo.

BEAUCLAIR, E.G.F. de Produtividade da cana-de-açúcar em função de alguns macronutrientes presentes no caldo e no solo. Piracicaba, 1994. 98p. Tese (Doutorado) - Escola Superior de Agricultura "Luiz de Queiroz", Universidade de São Paulo.

BEAUCLAIR, E.G.F. de; PENTEADO, C.R. Cronograma de corte da cana-de-açúcar através da programação linear. In: SEMINÁRIO DA TECNOLOGIA AGRONÔMICA 2., Piracicaba, 1984. Cronograma de corte da cana-de-açúcar através da programação linear. Piracicaba: Centro de Tecnologia Copersucar, 1984. p. 424-434.

BEAUFILS, E.R. Diagnosis and recommendations integrated system (DRIS); a general scheme for experimentation and calibration based on principles developed from research in plant nutrition. Soil Science Bulletin, v.1, p.1-32, 1973.

BOOTE, K.J.; JONES, J.W.; PICKERING, N.B. Potential Uses and Limitations of Crop Models. Agronomy Journal, v. 88, p. 704-716, sep./oct. 1996. 
CAIXETA-FILHO, J.V. Pesquisa operacional: técnicas de otimização aplicadas a sistemas agroindustriais. São Paulo: Atlas, 2001. 171p.

CASTRO, P.R.C. Maturadores químicos em cana-de-açúcar. In: SEMANA DA CANADE-AÇÚCAR DE PIRACICABA - SECAPI 4., Piracicaba, 1999. Anais. Piracicaba: Saccharum, 1999. p. 12-16.

CHAPMAN, L.S.; LEVERINGTON, K.G. Optimising harvest schedules in the Mackay area. Bureau of Sugar Experiment Stations: Mackay and Brisbane, Conference 43., p. 33-38, 1976.

CONSECANA. Manual de instruções. Piracicaba: CONSECANA, 1999. 92p.

COOKE, G.W. Valor dos "blueprints" em pesquisa e consultoria. Informações Agronômicas, Instituto Internacional da Potassa, São Paulo: v.18, p.1-6, 1982.

COPERSUCAR. Amostragem e análise da cana-de-açúcar: Cooperativa Central dos Produtores de Açúcar e Álcool do Estado de São Paulo. São Paulo, 1980. 37 p.

COPERSUCAR. Controle de produção integrado aplicado à cana-de-açúcar: Sistema Copi. In: SEMINÁRIO DA TECNOLOGIA AGRONÔMICA 1., Piracicaba, 1982. Controle de produção integrado aplicado à cana-de-açúcar: Sistema Copi. Piracicaba: Centro de Tecnologia Copersucar, 1982. p. 193-209.

CULVERWELL, T.L. Field records as an aid to the management of sugarcane crops. PROCEEDINGS OF THE SOUTH AFRICAN SUGAR TECHNOLOGISTS' ASSOCIATION, p. 179-181, June 1984.

DOOREMBOS, J.; KASSAM, A. H. Efectos del agua sobre el rendimiento de los cultivos. Roma: FAO, 1979. 212p. (Riego y Drenaje 33). 
ESTADOS UNIDOS. Concepts for Using Modeling as a Research Tool. Department of Agriculture: Agricultural Research Service, 1978. 18p.

FAO PRODUCTION YEARBOOK. FAO Statistics Series, v.52, n.148, p.150-151, 1998.

FAUCONIER, R.; BASSEREAU, D. La caña de azúcar. Barcelona: Editorial Blume, 1975. 433p.

FOGLIATA, F.A. Sugarcane irrigation in Tucumán. In: INTERNATIONAL SOCIETY SugARCAnE TECHNOlOgists., 15., Proceedings, Buenos Ayres: Heyne \& Gibson, 1974 p. 665-667.

GEMENTE, A.C.; PINAZZA, A.H.; BRUGNARO, C.; GUIMARÃES, E.; OLIVEIRA NETO, G.R. de; KRUGLIANSKAS, I.; SBRAGIA, R. Planejamento agrícola. In: BRUGNARO, C.; SBRAGIA, R. Gerência agrícola em destilarias de álcool. 2. ed. Piracicaba: IAA/PLANALSUCAR, 1986. p. 29-83 (Coleção PLANALSUCAR, 1).

HOEKSTRA, R.G. Program for simulating yields of crushing and harvesting operations. PROCEEDINGS OF THE SOUTH AFRICAN SUGAR TECHNOLOGISTS' ASSOCIATION, p. 1-8, June 1984.

HOFFMAN, R. Estatística para economistas. São Paulo: Pioneira, 1980. 379p.

HOFFMAN, R.; VIEIRA, S. Análise de regressão - Uma introdução a econometria. São Paulo: Hucitec, 1977. 379 p.

HUMBERT, R.P. The growing of sugarcane. Amsterdam: Elsevier, 1968. 779p. KEATING, B.A.; ROBERTSON, M.J.; MUCHOW, R.C.; HUTH, N.I. Modelling sugarcane production systems I. Development and performance of the sugarcane module. Field Crops Research, v.61, n.3, p. 253-271, May 1999. 
MACHADO, E. C. Fisiologia da produção da cana-de-açúcar. Crescimento. In: PARANHOS, S. B. Cana-de-açúcar: Cultivo e utilização. Campinas: Fundação Cargill, 1987. v. 1, p. 56-87, 1987.

MAGALHÃES, A.C.N. Ecofisiologia da cana-de-açúcar: aspectos do metabolismo do carbono na planta. In: P. R. C. CASTRO; S. O. FERREIRA; T. YAMADA (Ed.) Ecofisiologia da Produção Agrícola, Piracicaba: Potafos, 1987. p. 113-118.

MIOCQUE, M. Maturação da cana-de-açúcar. Sugar y Azucar do Brasil, n. 4, p.1-8, 1980.

MISHOE, J.W.; JONES, J.W.; GASCHO, G.J. Harvesting Scheduling of Sugarcane for Optimum Biomass Production. Transactions of the ASAE, v. 22, n. 6, p. 1299-1304, 1979.

MUCHOW, R.C.; HIGGINS, A.J.; RUDD, A.V.; FORD, A.W. Optimizing harvest date in sugar production: a case study for the Mossman mill region in Australia II. Sensitivity to crop age and crop class distribution. Field Crops Research, v.57, n.3, p. 243-251, June 1998.

OMETTO, J.C. An equation for the estimation of agro-industrial sugarcane yield in the Piracicaba region. In: INTERNATIONAL SOCIETY SUGARCANE TECHNOLOGISTS., 16., São Paulo, 1978 Proceedings. São Paulo: ISSCT, 1978 p. 899-905.

OMETTO, J.C. Parâmetros meteorológicos e a cultura da cana-de-açúcar. Piracicaba: ESALQ, 1980. 17p.

ORLANDO FILHO, S. (coord) Nutrição e adubação da cana-de-açúcar no Brasil. Piracicaba: Planalsucar, 1983.369p. 
ORTOLANI, A.A.; PAES de CAMARGO, M.B. Influência dos fatores climáticos na produção. In: CASTRO, P.R.C; FERREIRA, S.O.; YAMADA, T. (Ed.) Ecofisiologia da Produção Agrícola, Piracicaba: Potafos, 1987. 249p.

PIMENTEL GOMES, F. Curso de Estatística Experimental. Piracicaba: Nobel, 1990. 469 p.

PINAZZA, A.H. Implicações da gerência agrícola nas usinas e destilarias. Brasil Açúcareiro, v. 103, p.26-27, jul./dez. 1985.

POINTING, E.M.; TAYLOR, G.N. Development of computer controlled harvest allotment at Proserpine mill. Proceedings of Australian Society of Sugarcane Technologists, v.70, p. 23-29, 1985.

ROJAS, O.E. Predicción de Rendimientos de Caña de Azúcar (Saccharum spp.) en Guanacaste, Costa Rica. Turrialba, v.41, n.3, 1991, p.376-380.

SAES, L.A.; CAMARGO, A.P. de; SILVA, F.C. da; CESAR, M.A.A.; MORAES, R.S. de; SAKAI, E. Avaliação preliminar do potencial agronômico de algumas variedades de cana-de-açúcar no município de Pariquera-Açú no Vale do Ribeira. STAB. Açúcar, Álcool e Subprodutos, Piracicaba, v.5/6, n.1, p.26-35, maio/ago., 1990.

SAS INSTITUTE. SAS Language and Procedures: Usage, Version 6. Cary, NC: Sas Institute, 1989. 638p.

SENSOR RURAL. SEADE, n.6, p.56-58, maio/jun., 1998.

SPIEGEL, M.R. Estatística. São Paulo: McGraw-Hill do Brasil, 1972. 580p. 
THOMPSON, G.D. The relationship of potential evapotranspiration of sugarcane environment factors. In: INTERNATIONAL SOCIETY SUGARCANE TECHNOlOGiSTS., 12., Puerto Rico. Proceedings, Amsterdam: Elsevier, p. 3-9, 1967.

THORNLEY, J.H.M. Mathematical models in plant physiology: a quantitative approach to problems in plant and crop physiology. London: Academic Press., 1976. $318 \mathrm{p}$.

VAN DILLEWIJN, C. Botany of sugarcane. Waltham: The Chronica Botanica, 1952. $371 \mathrm{p}$.

VILlA NOVA, N. A.; PEDRO JÚNIOR, M. J.; PEREIRA, A. R.; OMETTO, J. C. Estimativa de graus-dias acumulados acima de qualquer temperatura base, em função das temperaturas máxima e mínima. Caderno de Ciência da Terra, v. 30, n.8, p.1-8, 1972.

VILlELA, S.M.; MATTOS, A. Hidrologia aplicada. São Paulo: Mc Graw - Hill, 1975. 245p.

WILLMOTT, C.J. On the validation of model. Physical geography, v.2, n.2, p.184-194, 1981.

ZAMBELLO JÚNIOR, E.; ORLANDO FILHO, J. Diagnosis and recommendations integrated system (DRIS) applied to various sugarcane tissues. In: INTERNATIONAL SOCIETY SUGARCANE TECHNOLOGISTS., 17., Manila, 1980. Proceedings. Manila: ISSCT, 1980. v. 1, p. 446-457. 
APÊNDICES 
Tabela 1. SAFRA 1999/2000.

\begin{tabular}{|c|c|c|c|c|c|c|c|c|}
\hline $\begin{array}{c}\text { Precoce } \\
\text { Talhão }\end{array}$ & $\begin{array}{c}\text { ano } \\
\text { Estágio }\end{array}$ & Corte & Variedade & Solo & Corte/Anterior & Corte/Atual & $\mathrm{TCH}$ & ATR \\
\hline 8 & $\mathrm{a}$ & 1 & RB83-5486 & LR & $\mathrm{Jul} / 98$ & Ago/99 & 79 & 160,58 \\
\hline 9 & $\mathrm{a}$ & 1 & RB83-5486 & LR & $\mathrm{Jul} / 98$ & Ago/99 & 72 & 161,17 \\
\hline 10 & $\mathrm{a}$ & 1 & RB83-5486 & LR & $\mathrm{Jul} / 98$ & Ago/99 & 105 & 154,22 \\
\hline 11 & $\mathrm{a}$ & 1 & RB83-5486 & LR & $\mathrm{Jul} / 98$ & Ago/99 & 100 & 159,27 \\
\hline 130 & $\mathrm{a}$ & 1 & RB83-5486 & LR & Set/98 & Out/99 & 45 & 157,22 \\
\hline 132 & $\mathrm{a}$ & 1 & RB83-5486 & LR & Ago/98 & Out/99 & 87 & 153,87 \\
\hline 133 & $\mathrm{a}$ & 1 & RB83-5486 & LR & Set/98 & Out/99 & 79 & 148,72 \\
\hline 134 & $\mathrm{a}$ & 1 & RB83-5486 & LR & Set/98 & Out/99 & 80 & 160,98 \\
\hline 390 & $\mathrm{a}$ & 1 & RB83-5486 & LR & Ago/98 & Out/99 & 73 & 155,30 \\
\hline 392 & $\mathrm{a}$ & 1 & RB83-5486 & LR & $\mathrm{Ago} / 98$ & Out/99 & 78 & 156,17 \\
\hline 3100 & $\mathrm{a}$ & 1 & RB83-5486 & LR & Ago/98 & Out/99 & 74 & 155,47 \\
\hline 3101 & $\mathrm{a}$ & 1 & RB83-5486 & LR & Ago/98 & Out/99 & 89 & 156,53 \\
\hline 3102 & $\mathrm{a}$ & 1 & RB83-5486 & LR & Ago/98 & Out/99 & 83 & 158,03 \\
\hline 3103 & $\mathrm{a}$ & 1 & RB83-5486 & LR & Ago/98 & Out/99 & 84 & 151,28 \\
\hline 2098 & $\mathrm{a}$ & 1 & RB83-5486 & LR & Ago/98 & Out/99 & 51 & 154,72 \\
\hline 2099 & $\mathrm{a}$ & 1 & RB83-5486 & LR & Jun/98 & Out/99 & 81 & 153,74 \\
\hline 2105 & $\mathrm{a}$ & 1 & RB83-5486 & LR & Ago/98 & Out/99 & 53 & 157,19 \\
\hline 3200 & $\mathrm{a}$ & 1 & SP80-1842 & LR & Ago/98 & Out/99 & 59 & 135,95 \\
\hline 3203 & $\mathrm{a}$ & 1 & SP80-1842 & LR & Ago/98 & Out/99 & 57 & 142,90 \\
\hline Precoce & ano e & meio & & & & & & \\
\hline Talhão & Estágio & Corte & Variedade & Solo & Corte/Anterior & Corte/Atual & $\mathrm{TCH}$ & ATR \\
\hline 131 & $\mathrm{~m}$ & 1 & RB83-5486 & LR & Mai/98 & Out/99 & 64 & 156,51 \\
\hline 389 & $\mathrm{~m}$ & 1 & RB83-5486 & LR & Mai/98 & Out/99 & 84 & 153,62 \\
\hline 391 & $\mathrm{~m}$ & 1 & RB83-5486 & LR & Mai/98 & Out/99 & 59 & 152,40 \\
\hline 753 & $\mathrm{~m}$ & 1 & RB83-5486 & LR & Fev/98 & Jun/99 & 112 & 146,55 \\
\hline 754 & $\mathrm{~m}$ & 1 & RB83-5486 & LR & Fev/98 & Jun/99 & 120 & 148,56 \\
\hline 2580 & $\mathrm{~m}$ & 1 & RB83-5486 & LR & Jan/98 & Mai/99 & 175 & 135,91 \\
\hline 2581 & $\mathrm{~m}$ & 1 & RB83-5486 & LR & Jan/98 & Mai/99 & 95 & 133,55 \\
\hline 2582 & $\mathrm{~m}$ & 1 & RB83-5486 & LR & Jan/98 & Mai/99 & 123 & 140,84 \\
\hline 2583 & $\mathrm{~m}$ & 1 & RB83-5486 & LR & $\mathrm{Jan} / 98$ & Mai/99 & 129 & 136,50 \\
\hline 2584 & $\mathrm{~m}$ & 1 & RB83-5486 & LR & Jan/98 & Mai/99 & 127 & 134,74 \\
\hline 2585 & $\mathrm{~m}$ & 1 & RB83-5486 & LR & Jan/98 & Mai/99 & 126 & 139,09 \\
\hline 2586 & $\mathrm{~m}$ & 1 & RB83-5486 & LR & Jan/98 & Mai/99 & 111 & 139,16 \\
\hline 2667 & $\mathrm{~m}$ & 1 & RB83-5486 & LR & Fev/98 & Mai/99 & 102 & 129,58 \\
\hline 2668 & $\mathrm{~m}$ & 1 & RB83-5486 & LR & Fev/98 & Mai/99 & 105 & 134,20 \\
\hline 2669 & $\mathrm{~m}$ & 1 & RB83-5486 & LR & Fev/98 & Mai/99 & 103 & 133,45 \\
\hline 2670 & $\mathrm{~m}$ & 1 & RB83-5486 & LR & Fev/98 & Mai/99 & 104 & 134,76 \\
\hline 2671 & $\mathrm{~m}$ & 1 & RB83-5486 & LR & Fev/98 & Mai/99 & 102 & 131,65 \\
\hline 2672 & $\mathrm{~m}$ & 1 & RB83-5486 & LR & Fev/98 & Mai/99 & 102 & 131,27 \\
\hline 1204 & $\mathrm{~m}$ & 1 & RB83-5486 & LR & Mar/98 & Mai/99 & 92 & 144,91 \\
\hline 382 & $\mathrm{~m}$ & 1 & SP80-1842 & LR & Mai/98 & Set/99 & 89 & 158,63 \\
\hline 821 & $\mathrm{~m}$ & 1 & RB82-5336 & LR & $\mathrm{Abr} / 98$ & Set/99 & 93 & 136,07 \\
\hline 822 & $\mathrm{~m}$ & 1 & RB82-5336 & LR & Abr/98 & Jun/99 & 99 & 138,43 \\
\hline 823 & $\mathrm{~m}$ & 1 & RB82-5336 & LR & $\mathrm{Abr} / 98$ & Jun/99 & 97 & 140,66 \\
\hline $4 \mathrm{~A}$ & $\mathrm{~m}$ & 1 & SP80-1836 & LR & Mar/98 & Ago/99 & 119 & 153,43 \\
\hline
\end{tabular}




\begin{tabular}{|c|c|c|c|c|c|c|c|c|}
\hline Talhão & Estágio & Corte & Variedade & Solo & Corte/Anterior & Corte/Atual & $\mathrm{TCH}$ & ATR \\
\hline 678 & $\mathrm{~m}$ & 1 & RB83-5054 & LR & Fev/98 & Set/99 & 127 & 151,61 \\
\hline 686 & $\mathrm{~m}$ & 1 & RB83-5054 & LR & Fev/98 & Set/99 & 156 & 159,26 \\
\hline Média & ano $\mathrm{e}$ & meio & & & & & & \\
\hline Talhão & Estágio & Corte & Variedade & Solo & Corte/Anterior & Corte/Atual & $\mathrm{TCH}$ & ATR \\
\hline 360 & $\mathrm{~m}$ & 1 & RB85-5536 & LR & Mar/98 & Jul/99 & 89 & 153,56 \\
\hline 370 & $\mathrm{~m}$ & 1 & RB85-5536 & LR & Mar/98 & $\mathrm{Jul} / 99$ & 98 & 150,82 \\
\hline 500 & $\mathrm{~m}$ & 1 & RB85-5536 & LR & $\mathrm{Abr} / 98$ & Jul/99 & 79 & 161,10 \\
\hline 501 & $\mathrm{~m}$ & 1 & RB85-5536 & LR & Mar/98 & $\mathrm{Jul} / 99$ & 92 & 162,61 \\
\hline 930 & $\mathrm{~m}$ & 1 & RB85-5536 & LR & Mar/98 & Jun/99 & 124 & 134,55 \\
\hline 931 & $\mathrm{~m}$ & 1 & RB85-5536 & LR & Mar/98 & Jun/99 & 108 & 137,29 \\
\hline 932 & $\mathrm{~m}$ & 1 & RB85-5536 & LR & Mar/98 & Jun/99 & 94 & 138,25 \\
\hline 933 & $\mathrm{~m}$ & 1 & RB85-5536 & LR & Mar/98 & Mai/99 & 100 & 142,09 \\
\hline 934 & $\mathrm{~m}$ & 1 & RB85-5536 & LR & Mar/98 & Mai/99 & 101 & 142,56 \\
\hline 1050 & $\mathrm{~m}$ & 1 & RB85-5536 & LR & Fev/98 & Jun/99 & 97 & 150,09 \\
\hline 1051 & $\mathrm{~m}$ & 1 & RB85-5536 & LR & Fev/98 & Jun/99 & 95 & 152,15 \\
\hline 3950 & $\mathrm{~m}$ & 1 & RB85-5536 & LR & Fev/98 & Jun/99 & 81 & 150,57 \\
\hline 305 & $\mathrm{~m}$ & 1 & RB85-5536 & LR & Abr/98 & $\mathrm{Jul} / 99$ & 116 & 159,82 \\
\hline 306 & $\mathrm{~m}$ & 1 & RB85-5536 & LR & Abr/98 & Jul/99 & 113 & 150,67 \\
\hline 307 & $\mathrm{~m}$ & 1 & RB85-5536 & LR & Abr/98 & Jul/99 & 128 & 153,69 \\
\hline 308 & $\mathrm{~m}$ & 1 & RB85-5536 & LR & Abr/98 & Ago/99 & 108 & 158,96 \\
\hline 309 & $\mathrm{~m}$ & 1 & RB85-5536 & LR & Abr/98 & Ago/99 & 105 & 167,95 \\
\hline 310 & $\mathrm{~m}$ & 1 & RB85-5536 & LR & Abr/98 & Jul/99 & 115 & 151,10 \\
\hline 311 & $\mathrm{~m}$ & 1 & RB85-5536 & LR & Abr/98 & Jul/99 & 100 & 152,34 \\
\hline 316 & $\mathrm{~m}$ & 1 & RB85-5536 & LR & Abr/98 & Jul/99 & 127 & 148,21 \\
\hline 317 & $\mathrm{~m}$ & 1 & RB85-5536 & LR & $\mathrm{Abr} / 98$ & Ago/99 & 126 & 165,31 \\
\hline 480 & $\mathrm{~m}$ & 1 & SP81-3250 & LR & Fev/98 & Jun/99 & 82 & 148,96 \\
\hline 1550 & $\mathrm{~m}$ & 1 & SP81-3250 & LR & Mar/98 & Mai/99 & 105 & 125,08 \\
\hline 1551 & $\mathrm{~m}$ & 1 & SP81-3250 & LR & Mar/98 & Mai/99 & 127 & 123,36 \\
\hline 1553 & $\mathrm{~m}$ & 1 & SP81-3250 & LR & Mar/98 & Mai/99 & 175 & 124,26 \\
\hline 1600 & $\mathrm{~m}$ & 1 & SP81-3250 & LR & Fev/98 & Jul/99 & 102 & 147,45 \\
\hline 2050 & $\mathrm{~m}$ & 1 & SP81-3250 & LR & Fev/98 & Mai/99 & 108 & 142,89 \\
\hline 2051 & $\mathrm{~m}$ & 1 & SP81-3250 & LR & Fev/98 & Mai/99 & 171 & 142,09 \\
\hline 2053 & $\mathrm{~m}$ & 1 & SP81-3250 & LR & Fev/98 & Mai/99 & 112 & 144,26 \\
\hline 2055 & $\mathrm{~m}$ & 1 & SP81-3250 & LR & Fev/98 & Mai/99 & 105 & 135,37 \\
\hline 2056 & $\mathrm{~m}$ & 1 & SP81-3250 & LR & Fev/98 & Mai/99 & 134 & 141,24 \\
\hline 2057 & $\mathrm{~m}$ & 1 & SP81-3250 & LR & Fev/98 & Mai/99 & 125 & 138,29 \\
\hline 3600 & $\mathrm{~m}$ & 1 & SP81-3250 & LR & Fev/98 & Jun/99 & 114 & 142,55 \\
\hline 3601 & $\mathrm{~m}$ & 1 & SP81-3250 & LR & Fev/98 & Jun/99 & 166 & 138,65 \\
\hline 5000 & $\mathrm{~m}$ & 1 & SP81-3250 & LR & Mar/98 & Mai/99 & 61 & 121,70 \\
\hline 5001 & $\mathrm{~m}$ & 1 & SP81-3250 & LR & Mar/98 & Mai/99 & 178 & 128,95 \\
\hline 300 & $\mathrm{~m}$ & 1 & SP81-3250 & LR & Abr/98 & Jul/99 & 56 & 154,27 \\
\hline 301 & $\mathrm{~m}$ & 1 & SP81-3250 & LR & Abr/98 & Jul/99 & 123 & 157,97 \\
\hline 302 & $\mathrm{~m}$ & 1 & SP81-3250 & LR & Abr/98 & Jul/99 & 166 & 162,89 \\
\hline 303 & $\mathrm{~m}$ & 1 & SP81-3250 & LR & Abr/98 & Jul/99 & 128 & 160,36 \\
\hline 304 & $\mathrm{~m}$ & 1 & SP81-3250 & LR & Abr/98 & Ago/99 & 134 & 162,40 \\
\hline 318 & $\mathrm{~m}$ & 1 & SP81-3250 & LR & $\mathrm{Abr} / 98$ & Ago/99 & 120 & 161,82 \\
\hline 319 & $\mathrm{~m}$ & 1 & SP81-3250 & LR & Abr/98 & Set/99 & 119 & 171,10 \\
\hline 320 & $\mathrm{~m}$ & 1 & SP81-3250 & LR & Abr/98 & Set/99 & 119 & 171,28 \\
\hline 321 & $\mathrm{~m}$ & 1 & SP81-3250 & LR & Abr/98 & Set/99 & 128 & 171,41 \\
\hline 643 & $\mathrm{~m}$ & 1 & SP81-3250 & LR & Fev/98 & Jul/99 & 102 & 148,82 \\
\hline
\end{tabular}


Tabela 1. SAFRA 1999/2000.

Média ano e meio

Talhão Estágio Corte

(501

2501

312

313

314

315

3250

3251

3252

3253

3254

3255

3256

3951

$\begin{array}{ll}\mathrm{m} & 1 \\ \mathrm{~m} & 1\end{array}$

Variedade

RB85-5113

Solo

Corte/Anterior Cor

Corte/Atual

$\mathrm{TCH}$

ATR

RB85-5113 LR

RB85-5113 LR

Mar/98

Out/99

158,56

$\mathrm{Abr} / 98$

$\mathrm{Jul} / 99$

124

149,59

RB85-5113 LR

Abr/98

Jul/99

148

146,95

RB85-5113 LR

Abr/98

Jul/99

123

148,15

RB84-5257 LR

Abr/98

Jul/99

117

150,21

RB84-5257 LR

Abr/98

Set/99

128

170,83

RB84-5257 LR

Out/99

112

155,63

RB84-5257 LR

Abr/98

Out/99

108

165,53

RB84-5257 LR

Abr/98

Out/99

110

152,73

RB84-5257 LR

Abr/98

Set/99

109

168,37

RB84-5257 LR

Abr/98

Out/99

134

164,61

SP80-1816 LR

$\mathrm{Abr} / 98$
$\mathrm{Fev} / 98$

Out/99

84

165,78

$\mathrm{m}$

Jun/99

143,74

Tardia ano e meio

Talhão Estágio Corte

$5355 \mathrm{~A}$

$\mathrm{m} \quad 1$

Variedade

Solo Corte/Anterior

Corte/Atual

$\mathrm{TCH}$

ATR

RB72-454 LR

Mar/98

Ago/99

52

168,79

\begin{tabular}{|c|c|c|c|c|c|c|c|c|}
\hline Precoce & soca & & & & & & & \\
\hline Talhão & Estágio & Corte & Variedade & Solo & Corte/Anterior & Corte/Atual & $\mathrm{TCH}$ & ATR \\
\hline 82 & $\mathrm{~s}$ & 2 & RB83-5486 & LR & Out/98 & Jun/99 & 85 & 143,96 \\
\hline 83 & $\mathrm{~s}$ & 2 & RB83-5486 & LR & Ago/98 & Jun/99 & 110 & 144,46 \\
\hline 84 & $\mathrm{~s}$ & 2 & RB83-5486 & LR & Jun/98 & Jun/99 & 111 & 135,64 \\
\hline 85 & $\mathrm{~s}$ & 2 & RB83-5486 & LR & Jun/98 & Mai/99 & 113 & 126,95 \\
\hline 601 & $\mathrm{~s}$ & 3 & RB83-5486 & LR & Mai/98 & Mai/99 & 100 & 132,40 \\
\hline 720 & $\mathrm{~s}$ & 4 & RB83-5486 & LR & Jun/98 & Mai/99 & 92 & 131,49 \\
\hline 747 & $\mathrm{~s}$ & 3 & RB83-5486 & LR & $\mathrm{Jul} / 98$ & Jun/99 & 66 & 148,38 \\
\hline 751 & $\mathrm{~s}$ & 3 & RB83-5486 & LR & Jun/98 & Jun/99 & 98 & 149,11 \\
\hline 886 & $\mathrm{~s}$ & 2 & RB83-5486 & LR & Ago/98 & Jun/99 & 126 & 148,75 \\
\hline 888 & $\mathrm{~s}$ & 2 & RB83-5486 & LR & Mai/98 & Jun/99 & 79 & 136,27 \\
\hline 1200 & $\mathrm{~s}$ & 2 & RB83-5486 & LR & $\mathrm{Jul} / 98$ & Jul/99 & 91 & 153,89 \\
\hline 1201 & $\mathrm{~s}$ & 2 & RB83-5486 & LR & $\mathrm{Jul} / 98$ & Jul/99 & 88 & 159,05 \\
\hline 1202 & $\mathrm{~s}$ & 2 & RB83-5486 & LR & Jun/98 & $\mathrm{Jul} / 99$ & 93 & 159,70 \\
\hline 1203 & $\mathrm{~s}$ & 2 & RB83-5486 & LR & Mar/98 & Mai/99 & 98 & 139,22 \\
\hline 86 & $\mathrm{~s}$ & 2 & SP80-1842 & LR & Out/98 & $\mathrm{Jul} / 99$ & 49 & 143,98 \\
\hline 87 & $\mathrm{~s}$ & 2 & SP80-1842 & LR & Out/98 & Jul/99 & 69 & 138,43 \\
\hline 88 & $\mathrm{~s}$ & 2 & SP80-1842 & LR & Out/98 & $\mathrm{Jul} / 99$ & 84 & 133,70 \\
\hline 89 & $\mathrm{~s}$ & 2 & SP80-1842 & LR & Out/98 & Jul/99 & 129 & 136,51 \\
\hline 419 & $\mathrm{~s}$ & 3 & SP80-1842 & LR & Nov/98 & Jul/99 & 80 & 151,51 \\
\hline 3050 & $\mathrm{~s}$ & 2 & SP80-1842 & LR & Set $/ 98$ & Jun/99 & 108 & 125,82 \\
\hline 3051 & $\mathrm{~s}$ & 2 & SP80-1842 & LR & Set/98 & Jun/99 & 101 & 123,88 \\
\hline $1800 \mathrm{~A}$ & $\mathrm{~s}$ & 3 & SP80-1842 & LR & Mai/98 & $\mathrm{Jul} / 99$ & 85 & 144,22 \\
\hline 722 & $\mathrm{~s}$ & 4 & RB82-5336 & LR & Mai/98 & Mai/99 & 77 & 121,37 \\
\hline 723 & $\mathrm{~s}$ & 4 & RB82-5336 & LR & Mai/98 & Mai/99 & 72 & 121,20 \\
\hline 540 & $\mathrm{~s}$ & 5 & RB76-5418 & LR & Mai/98 & Jul/99 & 78 & 142,03 \\
\hline 541 & $\mathrm{~s}$ & 5 & RB76-5418 & LR & Mai/98 & Jul/99 & 85 & 145,74 \\
\hline 543 & $\mathrm{~s}$ & 5 & RB76-5418 & LR & Mai/98 & Jul/99 & 60 & 141,85 \\
\hline 544 & $\mathrm{~s}$ & 5 & RB76-5418 & LR & Mai/98 & Jul/99 & 77 & 140,52 \\
\hline 545 & $\mathrm{~s}$ & 5 & RB76-5418 & LR & Mai/98 & Jul/99 & 64 & 143,19 \\
\hline 546 & $\mathrm{~s}$ & 5 & RB76-5418 & LR & Mai/98 & Jun/99 & 69 & 138,83 \\
\hline 547 & $\mathrm{~s}$ & 5 & RB76-5418 & LR & Mai/98 & Jun/99 & 79 & 137,79 \\
\hline
\end{tabular}


Tabela 1. SAFRA 1999/2000.

\begin{tabular}{|c|c|c|c|c|c|c|c|c|}
\hline Precoce & soca & & & & & & & \\
\hline Talhão & Estágio & Corte & Variedade & Solo & Corte/Anterior & Corte/Atual & $\mathrm{TCH}$ & ATR \\
\hline 2118 & $\mathrm{~s}$ & 4 & RB76-5418 & LR & Mai/98 & Mai/99 & 66 & 133,40 \\
\hline 2119 & $\mathrm{~s}$ & 4 & RB76-5418 & LR & Mai/98 & Mai/99 & 71 & 130,25 \\
\hline 2120 & $\mathrm{~s}$ & 4 & RB76-5418 & LR & Mai/98 & Mai/99 & 56 & 128,48 \\
\hline 2121 & $\mathrm{~s}$ & 4 & RB76-5418 & LR & Mai/98 & Mai/99 & 51 & 129,60 \\
\hline 4500 & $\mathrm{~s}$ & 5 & RB76-5418 & LR & Mai/98 & Mai/99 & 52 & 128,27 \\
\hline 4501 & $\mathrm{~s}$ & 5 & RB76-5418 & LR & Mai/98 & Mai/99 & 48 & 127,70 \\
\hline 4502 & $\mathrm{~s}$ & 5 & RB76-5418 & LR & Mai/98 & Mai/99 & 59 & 129,36 \\
\hline 4503 & $\mathrm{~s}$ & 5 & RB76-5418 & LR & Mai/98 & Mai/99 & 46 & 129,42 \\
\hline 4504 & $\mathrm{~s}$ & 5 & RB76-5418 & LR & Mai/98 & Mai/99 & 61 & 128,15 \\
\hline 4505 & $\mathrm{~s}$ & 5 & RB76-5418 & LR & Mai/98 & Mai/99 & 57 & 130,33 \\
\hline 1609 & $\mathrm{~s}$ & 6 & SP71-6163 & LR & Jun/98 & Jun/99 & 57 & 137,96 \\
\hline 1610 & $\mathrm{~s}$ & 6 & SP71-6163 & LR & Jun/98 & Jun/99 & 49 & 142,20 \\
\hline 1611 & $\mathrm{~s}$ & 6 & SP71-6163 & LR & Jun/98 & Jun/99 & 56 & 135,05 \\
\hline 1612 & $\mathrm{~s}$ & 6 & SP71-6163 & LR & Jun/98 & Jun/99 & 53 & 136,72 \\
\hline 1613 & $\mathrm{~s}$ & 6 & SP71-6163 & LR & Jun/98 & Jun/99 & 61 & 134,20 \\
\hline 3357 & $\mathrm{~s}$ & 6 & SP71-6163 & LR & Set/98 & Jul/99 & 56 & 144,68 \\
\hline 3358 & $\mathrm{~s}$ & 6 & SP71-6163 & LR & Set $/ 98$ & $\mathrm{Jul} / 99$ & 46 & 143,52 \\
\hline 3901 & $\mathrm{~s}$ & 6 & SP71-6163 & LR & Set $/ 98$ & $\mathrm{Jul} / 99$ & 49 & 132,34 \\
\hline 3902 & $\mathrm{~s}$ & 6 & SP71-6163 & LR & Set $/ 98$ & Jul/99 & 48 & 135,73 \\
\hline 3903 & $\mathrm{~s}$ & 6 & SP71-6163 & LR & Set/98 & $\mathrm{Jul} / 99$ & 31 & 140,49 \\
\hline 3904 & $\mathrm{~s}$ & 6 & SP71-6163 & LR & Set/98 & $\mathrm{Jul} / 99$ & 25 & 138,14 \\
\hline 4450 & $\mathrm{~s}$ & 5 & SP71-6163 & LR & Mai/98 & Jun/99 & 91 & 131,54 \\
\hline 4451 & $\mathrm{~s}$ & 5 & SP71-6163 & LR & Mai/98 & Jun/99 & 82 & 132,79 \\
\hline 4452 & $\mathrm{~s}$ & 5 & SP71-6163 & LR & Mai/98 & Jun/99 & 84 & 134,93 \\
\hline 4453 & $\mathrm{~s}$ & 5 & SP71-6163 & LR & Mai/98 & Mai/99 & 82 & 132,86 \\
\hline 4454 & $\mathrm{~s}$ & 5 & SP71-6163 & LR & Mai/98 & Mai/99 & 48 & 128,56 \\
\hline 4455 & $\mathrm{~s}$ & 5 & SP71-6163 & LR & Mai/98 & Mai/99 & 47 & 129,93 \\
\hline 4456 & $\mathrm{~s}$ & 5 & SP71-6163 & LR & Mai/98 & Jun/99 & 86 & 133,41 \\
\hline 4457 & $\mathrm{~s}$ & 5 & SP71-6163 & LR & Mai/98 & Jun/99 & 94 & 135,41 \\
\hline 4458 & $\mathrm{~s}$ & 5 & SP71-6163 & LR & Mai/98 & Mai/99 & 82 & 131,25 \\
\hline 4459 & $\mathrm{~s}$ & 5 & SP71-6163 & LR & Mai/98 & Mai/99 & 84 & 135,02 \\
\hline 4460 & $\mathrm{~s}$ & 5 & SP71-6163 & LR & Mai/98 & Jun/99 & 83 & 131,56 \\
\hline 4461 & $\mathrm{~s}$ & 5 & SP71-6163 & LR & Mai/98 & Mai/99 & 55 & 131,82 \\
\hline 4462 & $\mathrm{~s}$ & 5 & SP71-6163 & LR & Mai/98 & Mai/99 & 48 & 131,29 \\
\hline 4463 & $\mathrm{~s}$ & 5 & SP71-6163 & LR & Mai/98 & Mai/99 & 60 & 131,09 \\
\hline 4464 & $\mathrm{~s}$ & 5 & SP71-6163 & LR & Mai/98 & Mai/99 & 50 & 129,93 \\
\hline 4465 & $\mathrm{~s}$ & 5 & SP71-6163 & LR & Mai/98 & Mai/99 & 90 & 129,01 \\
\hline 4466 & $\mathrm{~s}$ & 5 & SP71-6163 & LR & Mai/98 & Mai/99 & 90 & 128,96 \\
\hline 4467 & $\mathrm{~s}$ & 5 & SP71-6163 & LR & Mai/98 & Mai/99 & 86 & 127,15 \\
\hline 4468 & $\mathrm{~s}$ & 5 & SP71-6163 & LR & Mai/98 & Mai/99 & 88 & 128,31 \\
\hline 4469 & $\mathrm{~s}$ & 5 & SP71-6163 & LR & Mai/98 & Mai/99 & 95 & 130,43 \\
\hline 4700 & $\mathrm{~s}$ & 5 & SP71-6163 & LR & Mai/98 & Jun/99 & 100 & 136,03 \\
\hline 4701 & $\mathrm{~s}$ & 5 & SP71-6163 & LR & Jun/98 & Jun/99 & 87 & 133,35 \\
\hline 4702 & $\mathrm{~s}$ & 5 & SP71-6163 & LR & Mai/98 & Jun/99 & 107 & 140,42 \\
\hline 4703 & $\mathrm{~s}$ & 5 & SP71-6163 & LR & Mai/98 & Jun/99 & 93 & 138,06 \\
\hline 4704 & $\mathrm{~s}$ & 5 & SP71-6163 & LR & Mai/98 & Jun/99 & 93 & 141,60 \\
\hline 4705 & $\mathrm{~s}$ & 5 & SP71-6163 & LR & Jun/98 & Jun/99 & 95 & 133,60 \\
\hline 4706 & $\mathrm{~s}$ & 5 & SP71-6163 & LR & Jun/98 & Jun/99 & 106 & 139,94 \\
\hline 4707 & $\mathrm{~s}$ & 5 & SP71-6163 & LR & Jun/98 & Jun/99 & 102 & 133,54 \\
\hline 4708 & $\mathrm{~s}$ & 5 & SP71-6163 & LR & Jun/98 & Jun/99 & 95 & 135,43 \\
\hline 4709 & $\mathrm{~s}$ & 5 & SP71-6163 & LR & Jun/98 & Jun/99 & 91 & 132,21 \\
\hline
\end{tabular}




\begin{tabular}{|c|c|c|c|c|c|c|c|c|}
\hline Talhão & Estágio & Corte & Variedade & Solo & Corte/Anterior & Corte/Atual & $\mathrm{TCH}$ & ATR \\
\hline 4710 & $\mathrm{~s}$ & 5 & SP71-6163 & LR & Jun/98 & Jun/99 & 90 & 133,56 \\
\hline 4711 & $\mathrm{~s}$ & 5 & SP71-6163 & LR & Jun/98 & Jun/99 & 83 & 135,07 \\
\hline 4712 & $\mathrm{~s}$ & 5 & SP71-6163 & LR & Jun/98 & Jun/99 & 80 & 138,73 \\
\hline 4713 & $\mathrm{~s}$ & 5 & SP71-6163 & LR & Jun/98 & Jun/99 & 92 & 142,01 \\
\hline 4714 & $\mathrm{~s}$ & 5 & SP71-6163 & LR & Jun/98 & Jun/99 & 82 & 141,79 \\
\hline 4715 & $\mathrm{~s}$ & 5 & SP71-6163 & LR & Jun/98 & Jun/99 & 85 & 142,15 \\
\hline 4716 & $\mathrm{~s}$ & 5 & SP71-6163 & LR & Jun/98 & Jun/99 & 99 & 138,88 \\
\hline 4717 & $\mathrm{~s}$ & 5 & SP71-6163 & LR & Jun/98 & Jun/99 & 97 & 137,92 \\
\hline 4718 & $\mathrm{~s}$ & 5 & SP71-6163 & LR & Jun/98 & Jun/99 & 90 & 139,91 \\
\hline 4719 & $\mathrm{~s}$ & 5 & SP71-6163 & LR & Jun/98 & Jun/99 & 88 & 142,43 \\
\hline 4720 & $\mathrm{~s}$ & 5 & SP71-6163 & LR & Jun/98 & Jun/99 & 61 & 138,64 \\
\hline 4721 & $\mathrm{~s}$ & 5 & SP71-6163 & LR & Jun/98 & Jun/99 & 107 & 139,55 \\
\hline 4722 & $\mathrm{~s}$ & 5 & SP71-6163 & LR & Jun/98 & Jun/99 & 90 & 139,25 \\
\hline 4800 & $\mathrm{~s}$ & 5 & SP71-6163 & LR & Jun/98 & Jun/99 & 62 & 128,33 \\
\hline 4801 & $\mathrm{~s}$ & 5 & SP71-6163 & LR & Jun/98 & Jun/99 & 59 & 143,13 \\
\hline 4802 & $\mathrm{~s}$ & 5 & SP71-6163 & LR & Jun/98 & Jun/99 & 66 & 136,30 \\
\hline 2083 & $\mathrm{~s}$ & 7 & SP71-6163 & LR & Jun/98 & $\mathrm{Jul} / 99$ & 85 & 141,30 \\
\hline 726 & $\mathrm{~s}$ & 5 & SP79-2312 & LR & Mai/98 & Mai/99 & 43 & 121,52 \\
\hline 727 & $\mathrm{~s}$ & 5 & SP79-2312 & LR & Mai/98 & Mai/99 & 42 & 122,20 \\
\hline 728 & $\mathrm{~s}$ & 5 & SP79-2312 & LR & Mai/98 & Mai/99 & 41 & 130,01 \\
\hline 2150 & $\mathrm{~s}$ & 3 & RB82-5336 & LR & Jun/98 & Mai/99 & 68 & 136,63 \\
\hline 2151 & $\mathrm{~s}$ & 3 & RB82-5336 & LR & Jun/98 & Mai/99 & 77 & 135,98 \\
\hline 2152 & $\mathrm{~s}$ & 3 & RB82-5336 & LR & Jun/98 & Mai/99 & 70 & 138,38 \\
\hline 2153 & $\mathrm{~s}$ & 3 & RB82-5336 & LR & Jun/98 & Mai/99 & 73 & 135,16 \\
\hline 2154 & $\mathrm{~s}$ & 3 & RB82-5336 & LR & Jun/98 & Mai/99 & 65 & 134,84 \\
\hline 2155 & $\mathrm{~s}$ & 3 & RB82-5336 & LR & Jun/98 & Mai/99 & 64 & 134,10 \\
\hline 2158 & $\mathrm{~s}$ & 3 & RB82-5336 & LR & Jun/98 & Mai/99 & 79 & 134,30 \\
\hline 2636 & $\mathrm{~s}$ & 4 & SP77-5181 & LR & Jun/98 & Mai/99 & 82 & 140,78 \\
\hline 2637 & $\mathrm{~s}$ & 4 & SP77-5181 & LR & Jun/98 & Mai/99 & 85 & 148,82 \\
\hline 2638 & $\mathrm{~s}$ & 4 & SP77-5181 & LR & Jun/98 & Mai/99 & 82 & 144,53 \\
\hline 2639 & $\mathrm{~s}$ & 4 & SP77-5181 & LR & Jun/98 & Mai/99 & 117 & 134,87 \\
\hline
\end{tabular}

$\begin{array}{ccccccccc}\begin{array}{c}\text { Média } \\ \text { Talhão }\end{array} & \begin{array}{c}\text { soca } \\ \text { Estágio }\end{array} & \text { Corte } & \text { Variedade } & \text { Solo } & \text { Corte/Anterior } & \text { Corte/Atual } & \text { TCH } & \text { ATR } \\ 3 & \text { S } & 3 & \text { SP70-1284 } & \text { LR } & \text { Ago/98 } & \text { Ago/99 } & 89 & 155,62 \\ 22 & \text { S } & 9 & \text { SP70-1284 } & \text { LR } & \text { Set/98 } & \text { Ago/99 } & 65 & 156,84 \\ 23 & \text { S } & 7 & \text { SP70-1284 } & \text { LR } & \text { Set/98 } & \text { Ago/99 } & 72 & 151,61 \\ 24 & \text { S } & 7 & \text { SP70-1284 } & \text { LR } & \text { Set/98 } & \text { Ago/99 } & 69 & 148,05 \\ 25 & \text { S } & 5 & \text { SP70-1284 } & \text { LR } & \text { Set/98 } & \text { Ago/99 } & 96 & 156,84 \\ 135 & \text { S } & 8 & \text { SP70-1284 } & \text { LR } & \text { Mai/98 } & \text { Ago/99 } & 73 & 151,09 \\ 3104 & \text { S } & 3 & \text { SP70-1284 } & \text { LR } & \text { Ago/98 } & \text { Ago/99 } & 52 & 161,15 \\ 3412 & \text { S } & 2 & \text { SP70-1284 } & \text { LR } & \text { Set/98 } & \text { Set/99 } & 82 & 161,98 \\ 3414 & \text { S } & 2 & \text { SP70-1284 } & \text { LR } & \text { Set/98 } & \text { Set/99 } & 51 & 150,50 \\ 3415 & \text { S } & 2 & \text { SP70-1284 } & \text { LR } & \text { Set/98 } & \text { Set/99 } & 119 & 154,56 \\ 3416 & \text { S } & 3 & \text { SP70-1284 } & \text { LR } & \text { Set/98 } & \text { Set/99 } & 69 & 158,31 \\ 3417 & \text { S } & 2 & \text { SP70-1284 } & \text { LR } & \text { Set/98 } & \text { Set/99 } & 64 & 151,62 \\ 3418 & \text { S } & 2 & \text { SP70-1284 } & \text { LR } & \text { Set/98 } & \text { Set/99 } & 123 & 156,43 \\ 3419 & \text { S } & 3 & \text { SP70-1284 } & \text { LR } & \text { Set/98 } & \text { Set/99 } & 118 & 154,00 \\ 3420 & \text { S } & 3 & \text { SP70-1284 } & \text { LR } & \text { Set/98 } & \text { Set/99 } & 74 & 148,74 \\ 3421 & \text { S } & 2 & \text { SP70-1284 } & \text { LR } & \text { Set/98 } & \text { Set/99 } & 118 & 144,68 \\ 3422 & \text { S } & 2 & \text { SP70-1284 } & \text { LR } & \text { Set/98 } & \text { Set/99 } & 126 & 154,26\end{array}$


Tabela 1. SAFRA 1999/2000.

\begin{tabular}{|c|c|c|c|c|c|c|c|c|}
\hline Média & $\begin{array}{c}\text { soca } \\
\text { Fstáoio }\end{array}$ & Corte & Voriododo & Solo & Corte/Anterior & & TCH & ATR \\
\hline 3423 & $\begin{array}{l}\text { Lstagio } \\
\text { S }\end{array}$ & 2 & SP70-1284 & LR & Set/98 & Set/99 & 129 & $\begin{array}{c}\text { A1R } \\
147,95\end{array}$ \\
\hline 3424 & s & 2 & SP70-1284 & LR & Set/98 & Set/99 & 48 & 148,99 \\
\hline $3414 \mathrm{~A}$ & $\mathrm{~s}$ & 2 & SP70-1284 & LR & Set/98 & Set/99 & 47 & 150,50 \\
\hline $3418 \mathrm{~A}$ & $\mathrm{~s}$ & 2 & SP70-1284 & LR & Set/98 & Set/99 & 107 & 156,43 \\
\hline $3421 \mathrm{~A}$ & $\mathrm{~s}$ & 2 & SP70-1284 & LR & Set/98 & Set/99 & 93 & 144,68 \\
\hline $3422 \mathrm{~A}$ & $\mathrm{~s}$ & 2 & SP70-1284 & LR & Set/98 & Set/99 & 117 & 154,26 \\
\hline 2325 & $\mathrm{~s}$ & 3 & RB85-5536 & LR & Set/98 & $\mathrm{Ago} / 99$ & 71 & 159,26 \\
\hline 2326 & $\mathrm{~s}$ & 3 & RB85-5536 & LR & Mar/98 & Ago/99 & 67 & 165,40 \\
\hline 2327 & $\mathrm{~s}$ & 3 & RB85-5536 & LR & Mar/98 & Ago/99 & 56 & 164,60 \\
\hline 2328 & $\mathrm{~s}$ & 3 & RB85-5536 & LR & Out/98 & Ago/99 & 118 & 163,28 \\
\hline 2900 & $\mathrm{~s}$ & 2 & RB85-5536 & LR & Set/98 & Ago/99 & 89 & 158,31 \\
\hline 2901 & $\mathrm{~s}$ & 2 & RB85-5536 & LR & Set/98 & Ago/99 & 75 & 160,40 \\
\hline $2328 \mathrm{~A}$ & $\mathrm{~s}$ & 3 & RB85-5536 & LR & Nov/98 & $\mathrm{Ago} / 99$ & 72 & 163,28 \\
\hline 5350 & $\mathrm{~s}$ & 2 & RB85-5536 & LR & Ago/98 & Ago/99 & 97 & 171,84 \\
\hline 5400 & $\mathrm{~s}$ & 2 & RB85-5536 & LR & Nov/98 & Set/99 & 65 & 149,39 \\
\hline 5401 & $\mathrm{~s}$ & 2 & RB85-5536 & LR & Mar/98 & Ago/99 & 63 & 161,99 \\
\hline 5402 & $\mathrm{~s}$ & 2 & RB85-5536 & LR & Mar/98 & Ago/99 & 68 & 155,29 \\
\hline 1621 & $\mathrm{~s}$ & 3 & SP81-3250 & LR & Jun/98 & Jul/99 & 97 & 142,68 \\
\hline 1624 & $\mathrm{~s}$ & 3 & SP81-3250 & LR & Jun/98 & $\mathrm{Jul} / 99$ & 98 & 145,31 \\
\hline 456 & $\mathrm{~s}$ & 5 & SP79-1011 & LR & Ago/98 & $\mathrm{Jul} / 99$ & 106 & 144,82 \\
\hline 457 & $\mathrm{~s}$ & 5 & SP79-1011 & LR & Ago/98 & Jul/99 & 76 & 142,8 \\
\hline 459 & $\mathrm{~s}$ & 5 & SP79-1011 & LR & $\mathrm{Jul} / 98$ & $\mathrm{Jul} / 99$ & 93 & 145,2 \\
\hline 530 & $\mathrm{~s}$ & 5 & SP79-1011 & LR & Set/98 & $\mathrm{Jul} / 99$ & 74 & 135,5 \\
\hline 531 & $\mathrm{~s}$ & 5 & SP79-1011 & LR & Set/98 & $\mathrm{Jul} / 99$ & 90 & 140,48 \\
\hline 532 & $\mathrm{~s}$ & 5 & SP79-1011 & LR & Set/98 & $\mathrm{Jul} / 99$ & 81 & 141,65 \\
\hline 562 & $\mathrm{~s}$ & 5 & SP79-1011 & LR & Set/98 & Set/99 & 91 & 145,47 \\
\hline 563 & $\mathrm{~s}$ & 5 & SP79-1011 & LR & Jul/98 & $\mathrm{Jul} / 99$ & 63 & 133,13 \\
\hline 564 & $\mathrm{~s}$ & 5 & SP79-1011 & LR & $\mathrm{Jul} / 98$ & $\mathrm{Jul} / 99$ & 88 & 135,75 \\
\hline 565 & $\mathrm{~s}$ & 5 & SP79-1011 & LR & Jul/98 & $\mathrm{Jul} / 99$ & 70 & 140,2 \\
\hline 566 & $\mathrm{~s}$ & 5 & SP79-1011 & LR & $\mathrm{Jul} / 98$ & Jul/99 & 80 & 147,0 \\
\hline 567 & $\mathrm{~s}$ & 5 & SP79-1011 & LR & $\mathrm{Jul} / 98$ & $\mathrm{Jul} / 99$ & 89 & 128,8 \\
\hline 568 & $\mathrm{~s}$ & 5 & SP79-1011 & LR & Set/98 & Set/99 & 84 & 164,38 \\
\hline 697 & $\mathrm{~s}$ & 4 & SP79-1011 & LR & $\mathrm{Jul} / 98$ & Jul/99 & 66 & 134,91 \\
\hline 698 & $\mathrm{~s}$ & 4 & SP79-1011 & LR & $\mathrm{Jul} / 98$ & Jul/99 & 84 & 130,92 \\
\hline 699 & $\mathrm{~s}$ & 4 & SP79-1011 & LR & $\mathrm{Jul} / 98$ & Jul/99 & 78 & 132,59 \\
\hline 700 & $\mathrm{~s}$ & 4 & SP79-1011 & LR & $\mathrm{Jul} / 98$ & $\mathrm{Jul} / 99$ & 77 & 130,47 \\
\hline 808 & $\mathrm{~s}$ & 5 & SP79-1011 & LR & Jul/98 & Jul/99 & 96 & 147,2 \\
\hline 1102 & $\mathrm{~s}$ & 4 & SP79-1011 & LR & Set/98 & Set/99 & 53 & 168,5 \\
\hline 1103 & $\mathrm{~s}$ & 4 & SP79-1011 & LR & Set/98 & Set/99 & 79 & 160,66 \\
\hline 1104 & $\mathrm{~s}$ & 4 & SP79-1011 & LR & Set/98 & Set/99 & 68 & 142,51 \\
\hline 1105 & $\mathrm{~s}$ & 4 & SP79-1011 & LR & Set/98 & Set/99 & 69 & 147,77 \\
\hline 1106 & $\mathrm{~s}$ & 4 & SP79-1011 & LR & Nov/98 & Set/99 & 72 & 156,63 \\
\hline 2052 & $\mathrm{~s}$ & 2 & SP79-1011 & LR & Nov/98 & Set/99 & 73 & 140,36 \\
\hline 2054 & $\mathrm{~s}$ & 2 & SP79-1011 & LR & Nov/98 & Set/99 & 65 & 135,2 \\
\hline 2508 & $\mathrm{~s}$ & 4 & SP79-1011 & LR & Set/98 & Ago/99 & 85 & 150,4 \\
\hline 2709 & $\mathrm{~s}$ & 2 & SP79-1011 & LR & Ago/98 & $\mathrm{Ago} / 99$ & 69 & 151,80 \\
\hline 2710 & $\mathrm{~s}$ & 2 & SP79-1011 & LR & $\mathrm{Jul} / 98$ & Ago/99 & 77 & 160,58 \\
\hline 4671 & $\mathrm{~s}$ & 4 & SP79-1011 & LR & Out/98 & $\mathrm{Jul} / 99$ & 69 & 143,23 \\
\hline 4672 & $\mathrm{~s}$ & 4 & SP79-1011 & LR & Out/98 & $\mathrm{Jul} / 99$ & 70 & 153,3 \\
\hline 4673 & $\mathrm{~s}$ & 4 & SP79-1011 & LR & Out/98 & Jul/99 & 80 & 150,2 \\
\hline 4674 & $\mathrm{~S}$ & 4 & SP79-1011 & LR & Out/98 & $\mathrm{Jul} / 99$ & 89 & \\
\hline
\end{tabular}




\begin{tabular}{|c|c|c|c|c|c|c|c|c|}
\hline Talhão & Estágio & Corte & Variedade & Solo & Corte/Anterior & Corte/Atual & $\mathrm{TCH}$ & ATR \\
\hline 4764 & $\mathrm{~s}$ & 4 & SP79-1011 & LR & Out/98 & Set/99 & 54 & 160,52 \\
\hline 651 & $\mathrm{~s}$ & 3 & SP79-1011 & LR & Dez/98 & Set/99 & 70 & 140,93 \\
\hline 652 & $\mathrm{~s}$ & 3 & SP79-1011 & LR & Dez/98 & Set/99 & 60 & 143,32 \\
\hline 653 & $\mathrm{~s}$ & 3 & SP79-1011 & LR & Nov/98 & Set/99 & 71 & 140,69 \\
\hline 654 & $\mathrm{~s}$ & 3 & SP79-1011 & LR & Ago/98 & Set/99 & 83 & 140,10 \\
\hline 655 & $\mathrm{~s}$ & 3 & SP79-1011 & LR & $\mathrm{Ago} / 98$ & Jul/99 & 87 & 140,37 \\
\hline 656 & $\mathrm{~s}$ & 3 & SP79-1011 & LR & Dez/98 & Set/99 & 27 & 149,37 \\
\hline 657 & $\mathrm{~s}$ & 3 & SP79-1011 & LR & Dez/98 & Set/99 & 27 & 152,81 \\
\hline 658 & $\mathrm{~s}$ & 2 & SP79-1011 & LR & Ago/98 & Jul/99 & 80 & 144,17 \\
\hline 659 & $\mathrm{~s}$ & 2 & SP79-1011 & LR & Jun/98 & Jul/99 & 72 & 143,54 \\
\hline 662 & $\mathrm{~s}$ & 2 & SP79-1011 & LR & Jun/98 & Jul/99 & 71 & 138,63 \\
\hline 663 & $\mathrm{~s}$ & 2 & SP79-1011 & LR & Jun/98 & Jul/99 & 67 & 137,32 \\
\hline 664 & $\mathrm{~s}$ & 2 & SP79-1011 & LR & Dez/98 & Set/99 & 55 & 153,62 \\
\hline 665 & $\mathrm{~s}$ & 2 & SP79-1011 & LR & Dez/98 & Set/99 & 56 & 147,49 \\
\hline 666 & $\mathrm{~s}$ & 2 & SP79-1011 & LR & Dez/98 & Set/99 & 67 & 147,82 \\
\hline 668 & $\mathrm{~s}$ & 2 & SP79-1011 & LR & $\mathrm{Ago} / 98$ & Jul/99 & 77 & 154,27 \\
\hline 669 & $\mathrm{~s}$ & 2 & SP79-1011 & LR & Ago/98 & Jul/99 & 63 & 161,83 \\
\hline 670 & $\mathrm{~s}$ & 2 & SP79-1011 & LR & Fev/98 & Jul/99 & 54 & 139,97 \\
\hline 780 & $\mathrm{~s}$ & 4 & SP79-1011 & LR & Set/98 & Set/99 & 73 & 153,89 \\
\hline 781 & $\mathrm{~s}$ & 4 & SP79-1011 & LR & Set/98 & Ago/99 & 84 & 164,73 \\
\hline 782 & $\mathrm{~s}$ & 4 & SP79-1011 & LR & Set/98 & Set/99 & 113 & 157,62 \\
\hline 5357 & $\mathrm{~s}$ & 3 & SP79-1011 & LR & Nov/98 & Ago/99 & 41 & 160,64 \\
\hline 4600 & $\mathrm{~s}$ & 5 & SP70-1143 & LR & Out/98 & Set/99 & 54 & 155,10 \\
\hline 4601 & $\mathrm{~s}$ & 5 & SP70-1143 & LR & Out/98 & Ago/99 & 55 & 145,73 \\
\hline 4606 & $\mathrm{~s}$ & 5 & SP70-1143 & LR & Out/98 & Set/99 & 64 & 160,21 \\
\hline 4607 & $\mathrm{~s}$ & 5 & SP70-1143 & LR & Out/98 & Set/99 & 57 & 161,92 \\
\hline 351 & $\mathrm{~s}$ & 5 & SP70-1143 & LR & Out/98 & Set/99 & 56 & 158,43 \\
\hline 2073 & $\mathrm{~s}$ & 4 & SP70-1143 & LR & Jun/98 & Jul/99 & 77 & 141,84 \\
\hline 2074 & $\mathrm{~s}$ & 3 & SP70-1143 & LR & Jun/98 & Jul/99 & 61 & 140,78 \\
\hline 2075 & $\mathrm{~s}$ & 3 & SP70-1143 & LR & Jun/98 & $\mathrm{Jul} / 99$ & 115 & 144,02 \\
\hline 2076 & $\mathrm{~s}$ & 4 & SP70-1143 & LR & Jun/98 & Jul/99 & 81 & 141,03 \\
\hline 2077 & $\mathrm{~s}$ & 3 & SP70-1143 & LR & Jun/98 & Jul/99 & 85 & 135,11 \\
\hline 2078 & $\mathrm{~s}$ & 3 & SP70-1143 & LR & Jun/98 & Jul/99 & 52 & 149,97 \\
\hline 2084 & $\mathrm{~s}$ & 3 & SP70-1143 & LR & Jun/98 & Jul/99 & 97 & 142,77 \\
\hline 2085 & $\mathrm{~s}$ & 3 & SP70-1143 & LR & Jun/98 & Jul/99 & 83 & 141,46 \\
\hline 2096 & $\mathrm{~s}$ & 3 & SP70-1143 & LR & Jun/98 & Jul/99 & 88 & 139,16 \\
\hline 1625 & $\mathrm{~s}$ & 3 & RB85-5113 & LR & Set/98 & Jul/99 & 87 & 150,37 \\
\hline 3000 & $\mathrm{~s}$ & 2 & RB84-5257 & LR & Out/98 & Set/99 & 60 & 161,24 \\
\hline
\end{tabular}

\begin{tabular}{|c|c|c|c|c|c|c|c|c|}
\hline Tardia & soca & & & & & & & \\
\hline Talhão & Estágio & Corte & Variedade & Solo & Corte/Anterior & Corte/Atual & $\mathrm{TCH}$ & $\begin{array}{l}\text { ATR } \\
14723\end{array}$ \\
\hline 386 & $\mathrm{~s}$ & 7 & RB72-454 & LR & Out/98 & Set/99 & 50 & 147,23 \\
\hline 387 & $\mathrm{~s}$ & 7 & RB72-454 & LR & Dez/98 & Set/99 & 31 & 134,99 \\
\hline 388 & $\mathrm{~s}$ & 7 & RB72-454 & LR & Dez/98 & Set/99 & 41 & 138,21 \\
\hline 533 & $\mathrm{~s}$ & 5 & RB72-454 & LR & Nov/98 & Set/99 & 51 & 149,87 \\
\hline 534 & $\mathrm{~s}$ & 5 & RB72-454 & LR & Set/98 & Set/99 & 52 & 153,51 \\
\hline 535 & $\mathrm{~s}$ & 5 & RB72-454 & LR & Nov/98 & Set/99 & 61 & 139,74 \\
\hline 536 & $\mathrm{~s}$ & 5 & RB72-454 & LR & Set/98 & Set/99 & 39 & 125,50 \\
\hline 537 & $\mathrm{~s}$ & 5 & RB72-454 & LR & Nov/98 & Set/99 & 75 & 153,45 \\
\hline 538 & $\mathrm{~s}$ & 5 & RB72-454 & LR & Nov/98 & Set/99 & 102 & 153,15 \\
\hline 548 & $\mathrm{~s}$ & 5 & RB72-454 & LR & Nov/98 & Set/99 & 72 & 153,25 \\
\hline
\end{tabular}


Tabela 1. SAFRA 1999/2000.

Tardia soca

Talhão Estágio Corte

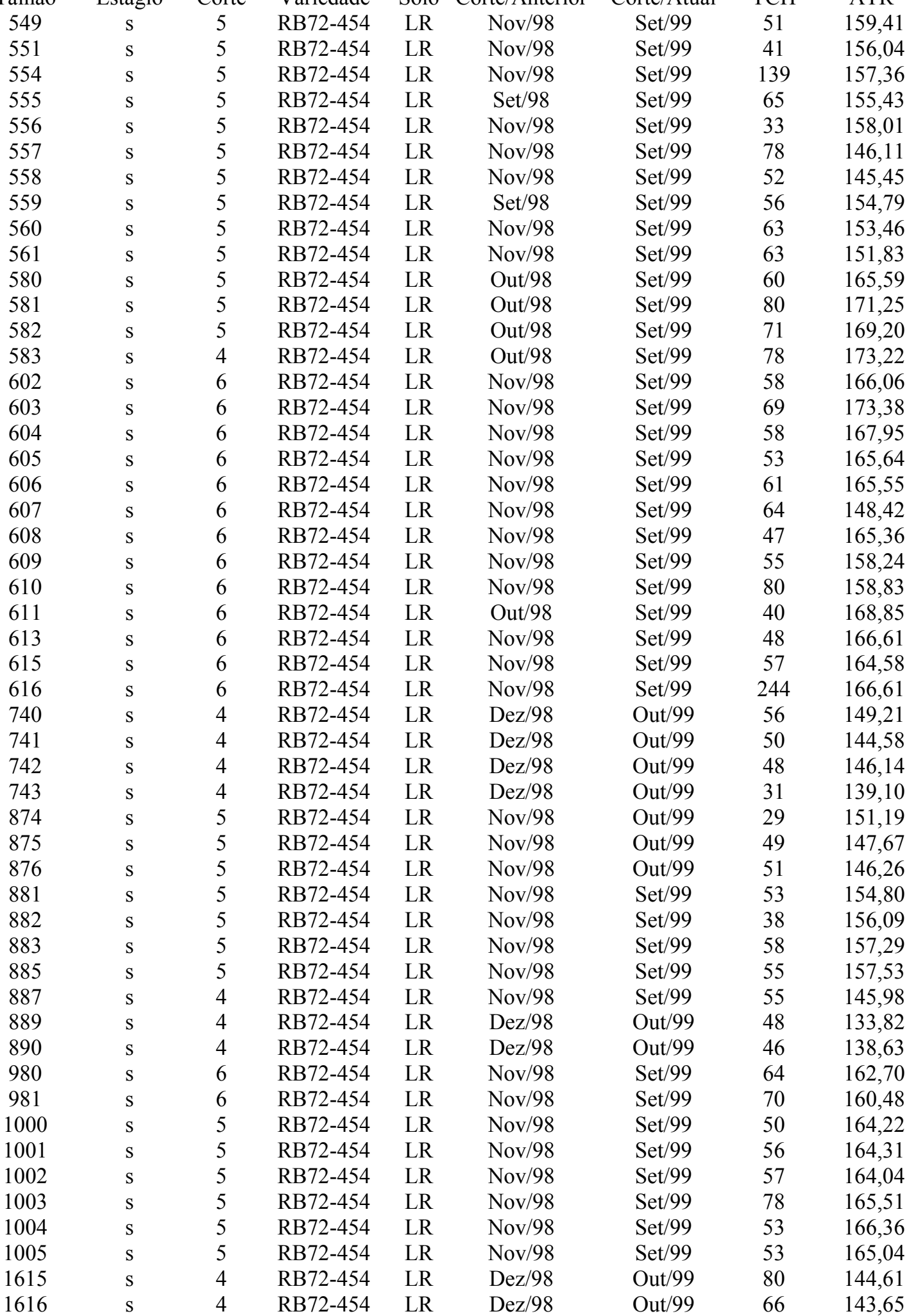


Tabela 1. SAFRA 1999/2000.

\begin{tabular}{|c|c|c|c|c|c|c|c|c|}
\hline $\begin{array}{l}\text { Tardia } \\
\text { Talhão }\end{array}$ & $\begin{array}{l}\text { soca } \\
\text { Estáaio }\end{array}$ & Corte & & Soll & & & & ATR \\
\hline $\begin{array}{c}\text { Talhão } \\
1617\end{array}$ & $\begin{array}{c}\text { Estág10 } \\
\mathrm{s}\end{array}$ & 4 & $\begin{array}{l}\text { Variedade } \\
\text { RB72-454 }\end{array}$ & $\begin{array}{l}\text { Solo } \\
\text { LR }\end{array}$ & Nov/98 & $\begin{array}{l}\text { Corte/Atual } \\
\text { Out/99 }\end{array}$ & $\begin{array}{l}1 \mathrm{CH} \\
40\end{array}$ & $\begin{array}{l}\text { A1R } \\
148,18\end{array}$ \\
\hline 1618 & $\mathrm{~s}$ & 4 & RB72-454 & LR & Dez/98 & Out/99 & 54 & 148,80 \\
\hline 1619 & $\mathrm{~s}$ & 4 & RB72-454 & LR & Dez/98 & Out/99 & 84 & 134,65 \\
\hline 1620 & $\mathrm{~s}$ & 4 & RB72-454 & LR & Dez/98 & Out/99 & 41 & 126,93 \\
\hline 1640 & $\mathrm{~s}$ & 2 & RB72-454 & LR & Dez/98 & Out/99 & 42 & 143,67 \\
\hline 1641 & $\mathrm{~s}$ & 2 & RB72-454 & LR & Dez/98 & Out/99 & 37 & 140,80 \\
\hline 1642 & $\mathrm{~s}$ & 2 & RB72-454 & LR & Dez/98 & Out/99 & 34 & 131,67 \\
\hline 1643 & $\mathrm{~s}$ & 2 & RB72-454 & LR & Dez/98 & Out/99 & 89 & 134,36 \\
\hline 1644 & $\mathrm{~s}$ & 2 & RB72-454 & LR & Dez/98 & Out/99 & 64 & 127,79 \\
\hline 2034 & $\mathrm{~s}$ & 5 & RB72-454 & LR & Set/98 & Out/99 & 68 & 152,83 \\
\hline 2035 & $\mathrm{~s}$ & 5 & RB72-454 & LR & Set $/ 98$ & Out/99 & 64 & 151,96 \\
\hline 2036 & $\mathrm{~s}$ & 5 & RB72-454 & LR & Set $/ 98$ & Out/99 & 60 & 149,86 \\
\hline 2300 & $\mathrm{~s}$ & 5 & RB72-454 & LR & Dez/98 & Out/99 & 29 & 147,61 \\
\hline 2301 & $\mathrm{~s}$ & 5 & RB72-454 & LR & Dez/98 & Out/99 & 35 & 152,33 \\
\hline 2450 & $\mathrm{~s}$ & 4 & RB72-454 & LR & Out/98 & Set/99 & 71 & 156,38 \\
\hline 2454 & $\mathrm{~s}$ & 4 & RB72-454 & LR & Out/98 & Set/99 & 73 & 157,93 \\
\hline 2457 & $\mathrm{~s}$ & 4 & RB72-454 & LR & Out $/ 98$ & Set/99 & 75 & 157,19 \\
\hline 2458 & $\mathrm{~s}$ & 4 & RB72-454 & LR & Out/98 & Set/99 & 62 & 155,26 \\
\hline 2459 & $\mathrm{~s}$ & 4 & RB72-454 & LR & Nov/98 & Set/99 & 72 & 158,00 \\
\hline 2460 & $\mathrm{~s}$ & 4 & RB72-454 & LR & Out/98 & Set/99 & 46 & 163,67 \\
\hline 2662 & $\mathrm{~s}$ & 3 & RB72-454 & LR & Dez/98 & Out/99 & 60 & 138,95 \\
\hline 2663 & $\mathrm{~s}$ & 3 & RB72-454 & LR & Dez/98 & Out/99 & 37 & 144,57 \\
\hline 2664 & $\mathrm{~s}$ & 3 & RB72-454 & LR & Dez/98 & Out/99 & 67 & 145,82 \\
\hline 2665 & $\mathrm{~s}$ & 3 & RB72-454 & LR & Dez/98 & Out/99 & 45 & 136,49 \\
\hline 2666 & $\mathrm{~s}$ & 3 & RB72-454 & LR & Dez/98 & Out/99 & 46 & 147,63 \\
\hline 2680 & $\mathrm{~s}$ & 3 & RB72-454 & LR & Nov/98 & Out/99 & 44 & 142,32 \\
\hline 2681 & $\mathrm{~s}$ & 3 & RB72-454 & LR & Dez/98 & Out/99 & 49 & 140,62 \\
\hline 2682 & $\mathrm{~s}$ & 3 & RB72-454 & LR & Dez/98 & Out/99 & 43 & 145,03 \\
\hline 2683 & $\mathrm{~s}$ & 3 & RB72-454 & LR & Dez/98 & Out/99 & 56 & 147,82 \\
\hline 2684 & $\mathrm{~s}$ & 3 & RB72-454 & LR & Dez/98 & Out/99 & 35 & 139,14 \\
\hline 3315 & $\mathrm{~s}$ & 6 & RB72-454 & LR & Dez/98 & Out/99 & 38 & 148,10 \\
\hline 3406 & $\mathrm{~s}$ & 6 & RB72-454 & LR & Dez/98 & Set/99 & 44 & 144,65 \\
\hline 3407 & $\mathrm{~s}$ & 6 & RB72-454 & LR & Dez/98 & Set/99 & 18 & 144,70 \\
\hline 3409 & $\mathrm{~s}$ & 6 & RB72-454 & LR & Dez/98 & Set/99 & 41 & 142,22 \\
\hline 3474 & $\mathrm{~s}$ & 5 & RB72-454 & LR & Out/98 & Set/99 & 61 & 172,06 \\
\hline 3475 & $\mathrm{~s}$ & 5 & RB72-454 & LR & Out/98 & Set/99 & 51 & 178,38 \\
\hline 3476 & $\mathrm{~s}$ & 5 & RB72-454 & LR & Set/98 & Set/99 & 46 & 172,84 \\
\hline 3477 & $\mathrm{~s}$ & 5 & RB72-454 & LR & Set $/ 98$ & Set/99 & 57 & 176,44 \\
\hline 3650 & $\mathrm{~s}$ & 6 & RB72-454 & LR & Dez/98 & Set/99 & 50 & 158,23 \\
\hline 3651 & $\mathrm{~s}$ & 6 & RB72-454 & LR & Dez/98 & Out/99 & 44 & 150,98 \\
\hline 3652 & $\mathrm{~s}$ & 6 & RB72-454 & LR & Dez/98 & Out/99 & 66 & 149,69 \\
\hline 3653 & $\mathrm{~s}$ & 6 & RB72-454 & LR & Dez/98 & Out/99 & 42 & 155,40 \\
\hline 4351 & $\mathrm{~s}$ & 5 & RB72-454 & LR & Dez/98 & Set/99 & 39 & 167,69 \\
\hline 4352 & $\mathrm{~s}$ & 5 & RB72-454 & LR & Dez/98 & Set/99 & 54 & 161,90 \\
\hline 4353 & $\mathrm{~s}$ & 4 & RB72-454 & LR & Out/97 & Set/99 & 88 & 150,66 \\
\hline 4552 & $\mathrm{~s}$ & 5 & RB72-454 & LR & Dez/98 & Set/99 & 58 & 148,34 \\
\hline 4608 & $\mathrm{~s}$ & 5 & RB72-454 & LR & Out $/ 98$ & Set/99 & 52 & 159,41 \\
\hline 4609 & $\mathrm{~s}$ & 5 & RB72-454 & LR & Out/98 & Set/99 & 34 & 153,87 \\
\hline 4610 & $\mathrm{~s}$ & 5 & RB72-454 & LR & Out $/ 98$ & Out/99 & 40 & 157,25 \\
\hline 4611 & $\mathrm{~s}$ & 5 & RB72-454 & LR & Out/98 & Out/99 & 30 & 158,94 \\
\hline 4614 & $\mathrm{~s}$ & 5 & RB72-454 & LR & Out $/ 98$ & Set/99 & 42 & 167,42 \\
\hline
\end{tabular}


Tabela 1. SAFRA 1999/2000.

\begin{tabular}{|c|c|c|c|c|c|c|c|c|}
\hline Tardia & soca & & & & & & & \\
\hline $\begin{array}{c}\text { Talhão } \\
4615\end{array}$ & Estágio & Corte & Variedade & Solo & Corte/Anterior & $\begin{array}{c}\text { Corte/Atual } \\
\text { Set/99 }\end{array}$ & $\begin{array}{c}\mathrm{TCH} \\
50\end{array}$ & $\begin{array}{l}\text { ATR } \\
16422\end{array}$ \\
\hline $\begin{array}{l}4615 \\
4617\end{array}$ & $\begin{array}{l}\mathrm{s} \\
\mathrm{s}\end{array}$ & $\begin{array}{l}5 \\
5\end{array}$ & $\begin{array}{l}\text { RB72-454 } \\
\text { RB72-454 }\end{array}$ & $\begin{array}{l}\text { LR } \\
\text { LR }\end{array}$ & $\begin{array}{l}\text { Out } / 98 \\
\text { Out/98 }\end{array}$ & $\begin{array}{l}\text { Set/99 } \\
\text { Set/99 }\end{array}$ & $\begin{array}{l}59 \\
71\end{array}$ & $\begin{array}{l}164,22 \\
162.24\end{array}$ \\
\hline 4618 & $\mathrm{~s}$ & 5 & RB72-454 & LR & Out $/ 98$ & Set/99 & 69 & 169,20 \\
\hline 4619 & $\mathrm{~s}$ & 5 & RB72-454 & LR & Out $/ 98$ & Set/99 & 43 & 156,27 \\
\hline 4620 & $\mathrm{~s}$ & 5 & RB72-454 & LR & Out/98 & Set/99 & 37 & 161,33 \\
\hline 5150 & $\mathrm{~s}$ & 5 & RB72-454 & LR & Dez/98 & Out/99 & 79 & 149,59 \\
\hline 5151 & $\mathrm{~s}$ & 4 & RB72-454 & LR & Dez/98 & Out/99 & 71 & 154,03 \\
\hline 5152 & $\mathrm{~s}$ & 5 & RB72-454 & LR & Dez/98 & Out/99 & 55 & 147,82 \\
\hline 5200 & $\mathrm{~s}$ & 5 & RB72-454 & LR & Dez/98 & Out/99 & 52 & 150,81 \\
\hline 2079 & $\mathrm{~s}$ & 5 & RB72-454 & LR & Nov/98 & Out/99 & 51 & 162,02 \\
\hline 2086 & $\mathrm{~s}$ & 5 & RB72-454 & LR & Nov/98 & Out/99 & 104 & 160,41 \\
\hline 2087 & $\mathrm{~s}$ & 5 & RB72-454 & LR & Nov/98 & Out/99 & 41 & 165,59 \\
\hline 2097 & $\mathrm{~s}$ & 5 & RB72-454 & LR & Nov/98 & Out/99 & 77 & 151,08 \\
\hline 2100 & $\mathrm{~s}$ & 4 & RB72-454 & LR & Nov/98 & Out/99 & 54 & 163,29 \\
\hline 2104 & $\mathrm{~s}$ & 4 & RB72-454 & LR & Nov/98 & Out/99 & 85 & 162,74 \\
\hline 2550 & $\mathrm{~s}$ & 5 & RB72-454 & LR & Nov/98 & Set/99 & 78 & 167,62 \\
\hline 462 & $\mathrm{~s}$ & 8 & SP71-1406 & LR & Out/98 & Out/99 & 43 & 144,45 \\
\hline 463 & $\mathrm{~s}$ & 8 & SP71-1406 & LR & Out $/ 98$ & Out/99 & 54 & 142,77 \\
\hline 464 & $\mathrm{~s}$ & 8 & SP71-1406 & LR & Out $/ 98$ & Out/99 & 56 & 141,94 \\
\hline 465 & $\mathrm{~s}$ & 8 & SP71-1406 & LR & Out $/ 98$ & Out/99 & 65 & 144,30 \\
\hline 853 & $\mathrm{~s}$ & 2 & SP71-1406 & LR & Nov/98 & Out/99 & 58 & 157,71 \\
\hline 1255 & $\mathrm{~s}$ & 8 & SP71-1406 & LR & Out/98 & Out/99 & 51 & 140,20 \\
\hline 1256 & $\mathrm{~s}$ & 8 & SP71-1406 & LR & Out $/ 98$ & Out/99 & 49 & 143,71 \\
\hline 1257 & $\mathrm{~s}$ & 8 & SP71-1406 & LR & Out $/ 98$ & Out/99 & 77 & 140,14 \\
\hline 1622 & $\mathrm{~s}$ & 3 & RB80-6043 & LR & Dez/98 & Out/99 & 56 & 138,91 \\
\hline 4931 & $\mathrm{~s}$ & 3 & RB80-6043 & LR & Out $/ 98$ & Out/99 & 64 & 138,48 \\
\hline 4932 & $\mathrm{~s}$ & 3 & RB80-6043 & LR & Out/98 & Out/99 & 69 & 138,09 \\
\hline 684 & $\mathrm{~s}$ & 2 & IAC82-3092 & LR & Fev/98 & Set/99 & 115 & 151,15 \\
\hline
\end{tabular}


Tabela 2. SAFRA 2000/2001.

\begin{tabular}{|c|c|c|c|c|}
\hline Precoce & Variedade & $\begin{array}{c}\text { Estágio/mês plantio } \\
\text { dia análise/mês análise } \\
\text { ano análise }\end{array}$ & $\mathrm{TCH}$ & ATR \\
\hline 540 & RB83-5486 & a1208102000 & 70 & 130,22 \\
\hline 541 & RB83-5486 & a1208102000 & 70 & 125,34 \\
\hline 848 & RB83-5486 & a1217092000 & 65 & 117,15 \\
\hline 849 & RB83-5486 & a1210082000 & 60 & 129,32 \\
\hline 850 & RB83-5486 & a1211102000 & 65 & 127,36 \\
\hline 851 & RB83-5486 & a1211102000 & 60 & 136,65 \\
\hline 852 & RB83-5486 & a1217092000 & 60 & 129,49 \\
\hline 3400 & RB83-5486 & a1111102000 & 60 & 124,58 \\
\hline 3401 & RB83-5486 & a1114082000 & 60 & 139,37 \\
\hline 3402 & RB83-5486 & a1115082000 & 50 & 139,93 \\
\hline 3403 & RB83-5486 & a1114082000 & 60 & 148,77 \\
\hline 3404 & RB83-5486 & a1111102000 & 60 & 109,40 \\
\hline 3406 & RB83-5486 & a1113082000 & 60 & 122,28 \\
\hline 3900 & RB83-5486 & a0914092000 & 80 & 132,03 \\
\hline 463 & SP80-1842 & a1103082000 & 75 & 143,12 \\
\hline 464 & SP80-1842 & a1 103082000 & 75 & 145,07 \\
\hline 465 & SP80-1842 & a1 104082000 & 75 & 145,55 \\
\hline 466 & SP80-1842 & a1 104082000 & 75 & 131,55 \\
\hline 467 & SP80-1842 & a1 104082000 & 75 & 138,99 \\
\hline 468 & SP80-1842 & a1 104082000 & 65 & 140,97 \\
\hline 602 & SP80-1842 & a1 105102000 & 60 & 131,29 \\
\hline 603 & SP80-1842 & a1 105102000 & 60 & 125,14 \\
\hline 604 & SP80-1842 & a1 106102000 & 60 & 111,65 \\
\hline 605 & SP80-1842 & a1106102000 & 60 & 119,09 \\
\hline 606 & SP80-1842 & a1111102000 & 60 & 131,02 \\
\hline 607 & SP80-1842 & a1111102000 & 60 & 125,05 \\
\hline 608 & SP80-1842 & a1111102000 & 60 & 123,59 \\
\hline 609 & SP80-1842 & a1112102000 & 60 & 117,06 \\
\hline 613 & SP80-1842 & a1119092000 & 70 & 148,08 \\
\hline 614 & SP80-1842 & a1119092000 & 70 & 137,19 \\
\hline 615 & SP80-1842 & a1119092000 & 65 & 130,60 \\
\hline 616 & SP80-1842 & a1119092000 & 60 & 147,10 \\
\hline 617 & SP80-1842 & a1119092000 & 60 & 139,83 \\
\hline 618 & SP80-1842 & a1119092000 & 60 & 125,18 \\
\hline 619 & SP80-1842 & a1119092000 & 65 & 127,24 \\
\hline 1608 & SP80-1842 & a1 107092000 & 70 & 134,15 \\
\hline 1609 & SP80-1842 & a1 109102000 & 70 & 127,79 \\
\hline 1610 & SP80-1842 & a1 109102000 & 70 & 124,54 \\
\hline 1611 & SP80-1842 & a1108102000 & 70 & 130,16 \\
\hline 1612 & SP80-1842 & a1102082000 & 70 & 130,02 \\
\hline 824 & RB82-5336 & a1 125082000 & 60 & 139,99 \\
\hline 825 & RB82-5336 & a1125082000 & 60 & 139,73 \\
\hline 1613 & SP71-6163 & a1 109102000 & 70 & 119,22 \\
\hline Média & ano & $\begin{array}{l}\text { Estágio/mês plantio } \\
\text { dia análise/mês análise }\end{array}$ & & \\
\hline Talhão & Variedade & ano análise & $\mathrm{TCH}$ & ATR \\
\hline 980 & RB85-5536 & a1115092000 & 60 & 133,85 \\
\hline
\end{tabular}


Tabela 2. SAFRA 2000/2001.

$\begin{array}{ccccc}\text { Média } & \text { ano } & \begin{array}{c}\text { Estágio/mês plantio } \\ \text { dia análise/mês análise }\end{array} & \\ \text { Talhão } & \text { Variedade } & \text { ano análise } & \text { TCH } & \text { ATR } \\ 981 & \text { RB85-5536 } & \text { a1115092000 } & 65 & 117,74 \\ 4250 & \text { RB85-5536 } & \text { a1115092000 } & 60 & 128,66 \\ 4251 & \text { RB85-5536 } & \text { a1111102000 } & 60 & 116,31 \\ 4252 & \text { RB85-5536 } & \text { a1115092000 } & 60 & 121,72 \\ 3350 & \text { RB85-5536 } & \text { a1123082000 } & 60 & 140,71 \\ 3351 & \text { RB85-5536 } & \text { a1105092000 } & 60 & 133,89 \\ 3352 & \text { RB85-5536 } & \text { a1130082000 } & 60 & 132,06 \\ 3353 & \text { RB85-5536 } & \text { a1129082000 } & 60 & 125,69 \\ 3354 & \text { RB85-5536 } & \text { a1129082000 } & 60 & 129,98 \\ 521 & \text { RB84-5257 } & \text { a1211102000 } & 60 & 127,16 \\ 522 & \text { RB84-5257 } & \text { a1209092000 } & 65 & 134,61 \\ 523 & \text { RB84-5257 } & \text { a1211092000 } & 65 & 131,34 \\ 524 & \text { RB84-5257 } & \text { a1211102000 } & 60 & 134,11 \\ 727 & \text { RB84-5257 } & \text { a1220082000 } & 65 & 130,87 \\ 855 & \text { RB84-5257 } & \text { a1107082000 } & 75 & 139,40 \\ 856 & \text { RB84-5257 } & \text { a1106082000 } & 75 & 146,33 \\ 857 & \text { RB84-5257 } & \text { a1107082000 } & 70 & 135,83 \\ 858 & \text { RB84-5257 } & \text { a1107082000 } & 70 & 136,01 \\ 1715 & \text { RB84-5257 } & \text { a1116082000 } & 60 & 139,48 \\ 1716 & \text { RB84-5257 } & \text { a1116082000 } & 60 & 141,48 \\ 4000 & \text { RB84-5257 } & \text { a1227092000 } & 60 & 119,62 \\ 4001 & \text { RB84-5257 } & \text { a1228092000 } & 60 & 127,59 \\ 4002 & \text { RB84-5257 } & \text { a1228092000 } & 60 & 109,77 \\ 809 & \text { SP80-1816 } & \text { a1208102000 } & 65 & 112,46\end{array}$

Precoce ano e meio Estágio/mês plantio

dia análise/mês análise

$\begin{array}{cc}\text { Talhão } & \text { Variedade } \\ 720 & \text { RB83-5486 } \\ 946 & \text { RB83-5486 } \\ 947 & \text { RB83-5486 } \\ 948 & \text { RB83-5486 } \\ 949 & \text { RB83-5486 } \\ 3230 & \text { RB83-5486 } \\ 3231 & \text { RB83-5486 } \\ 3550 & \text { RB83-5486 } \\ 3551 & \text { RB83-5486 } \\ 2200 & \text { SP80-1842 } \\ 4050 & \text { SP80-1842 } \\ 4051 & \text { SP80-1842 } \\ 4052 & \text { SP80-1842 } \\ 4053 & \text { SP80-1842 } \\ 722 & \text { RB82-5336 } \\ 723 & \text { RB82-5336 } \\ 3850 & \text { RB82-5336 } \\ 3851 & \text { RB82-5336 } \\ 2500 & \text { RB76-5418 } \\ 704 & \text { SP71-6163 } \\ 705 & \text { SP71-6163 } \\ 2302 & \text { SP71-6163 }\end{array}$

$\begin{array}{ccc}\text { ano análise } & \text { TCH } & \text { ATR } \\ \text { m0913052000 } & 75 & 128,59 \\ \text { m0210102000 } & 85 & 144,24 \\ \text { m0210102000 } & 85 & 133,17 \\ \text { m0218092000 } & 90 & 134,86 \\ \text { m0228052000 } & 90 & 140,87 \\ \text { m0210102000 } & 90 & 141,21 \\ \text { m0201082000 } & 90 & 141,93 \\ \text { m0210052000 } & 90 & 131,56 \\ \text { m0210052000 } & 90 & 125,15 \\ \text { m0228052000 } & 85 & 127,41 \\ \text { m0202102000 } & 75 & 137,30 \\ \text { m0202102000 } & 70 & 136,57 \\ \text { m0226092000 } & 60 & 131,88 \\ \text { m0226092000 } & 70 & 138,64 \\ \text { m0913052000 } & 70 & 122,07 \\ \text { m0913052000 } & 70 & 124,99 \\ \text { m0304102000 } & 100 & 140,68 \\ \text { m0305102000 } & 90 & 136,80 \\ \text { m1105092000 } & 45 & 141,82 \\ \text { m0920062000 } & 30 & 132,20 \\ \text { m0920062000 } & 30 & 134,55 \\ \text { m1207102000 } & 40 & 143,42\end{array}$


Tabela 2. SAFRA 2000/2001.

Precoce ano e meio Estágio/mês plantio dia análise/mês análise

$\begin{array}{cc}\text { Talhão } & \text { Variedade } \\ 2502 & \text { SP71-6163 } \\ 2503 & \text { SP71-6163 } \\ 2504 & \text { SP71-6163 } \\ 2505 & \text { SP71-6163 } \\ 2506 & \text { SP71-6163 } \\ 2507 & \text { SP71-6163 } \\ 2510 & \text { SP77-5181 } \\ 2511 & \text { SP77-5181 } \\ 2512 & \text { SP77-5181 } \\ 2513 & \text { SP77-5181 } \\ 2515 & \text { SP77-5181 } \\ 2516 & \text { SP77-5181 } \\ 2517 & \text { SP77-5181 } \\ 2518 & \text { SP77-5181 } \\ 2514 & \text { RB85-5453 }\end{array}$

ano análise
$\mathrm{m} 1106092000$
$\mathrm{~m} 1106092000$
$\mathrm{~m} 1125092000$
$\mathrm{~m} 1125092000$
$\mathrm{~m} 1125092000$
$\mathrm{~m} 1125092000$
$\mathrm{~m} 1114062000$
$\mathrm{~m} 1114062000$
$\mathrm{~m} 1114062000$
$\mathrm{~m} 1114062000$
$\mathrm{~m} 1115062000$
$\mathrm{~m} 1115062000$
$\mathrm{~m} 1115062000$
$\mathrm{~m} 1115062000$
$\mathrm{~m} 1115062000$

$\begin{array}{cc}\text { TCH } & \text { ATR } \\ 40 & 135,69 \\ 50 & 138,42 \\ 50 & 137,94 \\ 45 & 136,93 \\ 40 & 138,92 \\ 40 & 134,19 \\ 70 & 147,96 \\ 65 & 139,50 \\ 65 & 144,42 \\ 55 & 137,95 \\ 70 & 141,90 \\ 60 & 136,34 \\ 60 & 144,27 \\ 60 & 142,97 \\ 70 & 140,54\end{array}$

Média ano e meio

Estágio/mês plantio

Talhão Variedade dia análise/mês análise

$23 \quad$ SP70-1284

$24 \quad$ SP70-1284

$25 \quad$ SP70-1284

$4200 \quad$ RB85-5536

$400 \quad$ RB85-5536

$404 \quad$ RB85-5536

$405 \quad$ RB85-5536

406 RB85-5536

$430 \quad$ RB85-5536

$431 \quad$ RB85-5536

432 RB85-5536

433 RB85-5536

$434 \quad$ RB85-5536

$435 \quad$ RB85-5536

$436 \quad$ RB85-5536

$437 \quad$ RB85-5536

$438 \quad$ RB85-5536

$2000 \quad$ RB85-5536

$2001 \quad$ RB85-5536

$2002 \quad$ RB85-5536

$2008 \quad$ RB85-5536

2009 RB85-5536

2868 SP81-3250

$2869 \quad$ SP81-3250

$407 \quad$ SP81-3250

$408 \quad$ SP81-3250

$409 \quad$ SP81-3250

$410 \quad$ SP81-3250

$440 \quad$ SP81-3250

$441 \quad$ SP81-3250

$442 \quad$ SP81-3250

$\begin{array}{ccc}\text { ano análise } & \text { TCH } & \text { ATR } \\ \mathrm{m} 1208052000 & 70 & 126,56 \\ \mathrm{~m} 1209062000 & 60 & 130,30 \\ \mathrm{~m} 1218092000 & 75 & 130,31 \\ \mathrm{~m} 0206062000 & 90 & 139,88 \\ \mathrm{~m} 0304072000 & 100 & 151,24 \\ \mathrm{~m} 0303072000 & 90 & 149,32 \\ \mathrm{~m} 0310072000 & 95 & 158,06 \\ \mathrm{~m} 0303072000 & 90 & 150,36 \\ \mathrm{~m} 0328062000 & 100 & 131,76 \\ \mathrm{~m} 0328062000 & 105 & 145,16 \\ \mathrm{~m} 0328062000 & 110 & 140,86 \\ \mathrm{~m} 0328062000 & 100 & 153,00 \\ \mathrm{~m} 0330062000 & 100 & 142,51 \\ \mathrm{~m} 0328062000 & 110 & 140,23 \\ \mathrm{~m} 0329062000 & 105 & 140,96 \\ \mathrm{~m} 0329062000 & 95 & 144,14 \\ \mathrm{~m} 0329062000 & 90 & 143,54 \\ \mathrm{~m} 0312052000 & 105 & 129,12 \\ \mathrm{~m} 0313052000 & 105 & 127,21 \\ \mathrm{~m} 0313052000 & 110 & 123,96 \\ \mathrm{~m} 0312052000 & 90 & 123,13 \\ \mathrm{~m} 0312052000 & 90 & 121,91 \\ \mathrm{~m} 0211052000 & 115 & 131,48 \\ \mathrm{~m} 0209052000 & 120 & 129,76 \\ \mathrm{~m} 0303072000 & 95 & 153,08 \\ \mathrm{~m} 0303072000 & 100 & 151,09 \\ \mathrm{~m} 0304072000 & 100 & 145,11 \\ \mathrm{~m} 0304072000 & 105 & 148,91 \\ \mathrm{~m} 0330062000 & 110 & 136,73 \\ \mathrm{~m} 0330062000 & 110 & 130,83 \\ \mathrm{~m} 0301072000 & 105 & 141,23\end{array}$


Tabela 2. SAFRA 2000/2001.

\begin{tabular}{|c|c|c|c|c|}
\hline Média & ano e meio & $\begin{array}{l}\text { Estágio/mês plantio } \\
\text { dia análise/mês análise }\end{array}$ & & \\
\hline Talhão & Variedade & ano análise & $\mathrm{TCH}$ & ATR \\
\hline 444 & SP81-3250 & m0301072000 & 100 & 150,50 \\
\hline 445 & SP81-3250 & m0302072000 & 100 & 144,55 \\
\hline 446 & SP81-3250 & m0301072000 & 100 & 132,82 \\
\hline 447 & SP81-3250 & m0301072000 & 100 & 126,86 \\
\hline 448 & SP81-3250 & m0301072000 & 100 & 139,16 \\
\hline 449 & SP81-3250 & m0302072000 & 100 & 145,73 \\
\hline 450 & SP81-3250 & m0302072000 & 105 & 149,28 \\
\hline 451 & SP81-3250 & m0302072000 & 105 & 154,43 \\
\hline 3304 & SP81-3250 & m0309062000 & 95 & 134,25 \\
\hline 4761 & SP81-3250 & m0309062000 & 110 & 133,99 \\
\hline 4762 & SP81-3250 & m0310062000 & 110 & 134,95 \\
\hline 4850 & SP81-3250 & $\mathrm{m} 0310052000$ & 95 & 124,50 \\
\hline 4851 & SP81-3250 & $\mathrm{m} 0310052000$ & 100 & 129,02 \\
\hline 4852 & SP81-3250 & $\mathrm{m} 0310052000$ & 100 & 123,21 \\
\hline 694 & SP79-1011 & m0915062000 & 55 & 138,80 \\
\hline 695 & SP79-1011 & m0914062000 & 55 & 133,46 \\
\hline 696 & SP79-1011 & m0914062000 & 55 & 134,82 \\
\hline 697 & SP79-1011 & m0913062000 & 70 & 132,81 \\
\hline 698 & SP79-1011 & m0913062000 & 70 & 132,33 \\
\hline 699 & SP79-1011 & m0914062000 & 70 & 127,82 \\
\hline 700 & SP79-1011 & m0914062000 & 70 & 131,51 \\
\hline 702 & SP79-1011 & m0916062000 & 55 & 143,02 \\
\hline 703 & SP79-1011 & m0916062000 & 60 & 139,63 \\
\hline 2508 & SP79-1011 & $\mathrm{m} 1114062000$ & 75 & 132,37 \\
\hline 2509 & SP79-1011 & m1122072000 & 75 & 131,32 \\
\hline 496 & SP70-1143 & $\mathrm{m} 0905062000$ & 50 & 129,09 \\
\hline 497 & SP70-1143 & m0905062000 & 50 & 124,24 \\
\hline 1511 & SP70-1143 & m0916052000 & 60 & 122,90 \\
\hline 1512 & SP70-1143 & $\mathrm{m} 0916052000$ & 65 & 123,25 \\
\hline 1513 & SP70-1143 & m0916052000 & 70 & 111,40 \\
\hline 1514 & SP70-1143 & m0916052000 & 70 & 119,81 \\
\hline 1515 & SP70-1143 & m0916052000 & 75 & 121,64 \\
\hline 1516 & SP70-1143 & $\mathrm{m} 0915052000$ & 75 & 112,25 \\
\hline 1517 & SP70-1143 & $\mathrm{m} 0915052000$ & 75 & 121,83 \\
\hline 1518 & SP70-1143 & $\mathrm{m} 0915052000$ & 70 & 124,80 \\
\hline 1519 & SP70-1143 & $\mathrm{m} 0915052000$ & 70 & 126,01 \\
\hline 1520 & SP70-1143 & m0916052000 & 70 & 129,62 \\
\hline 1521 & SP70-1143 & m0913052000 & 70 & 120,56 \\
\hline 1522 & SP70-1143 & m0913052000 & 65 & 122,77 \\
\hline 2867 & SP70-1143 & m0910052000 & 75 & 115,81 \\
\hline 2873 & SP70-1143 & m0911052000 & 65 & 112,63 \\
\hline 2874 & SP70-1143 & $\mathrm{m} 0911052000$ & 65 & 111,15 \\
\hline 2875 & SP70-1143 & m0911052000 & 65 & 118,46 \\
\hline 2876 & SP70-1143 & m0911052000 & 70 & 111,64 \\
\hline 402 & RB85-5113 & m0310072000 & 105 & 147,99 \\
\hline 403 & RB85-5113 & m0308072000 & 105 & 153,55 \\
\hline 2003 & RB85-5113 & $\mathrm{m} 0317052000$ & 95 & 120,26 \\
\hline 2501 & RB85-5113 & m1105092000 & 100 & 136,79 \\
\hline 1717 & RB84-5257 & $\mathrm{m} 0216082000$ & 100 & 152,46 \\
\hline 1718 & RB84-5257 & $\mathrm{m} 0217082000$ & 100 & 150,27 \\
\hline
\end{tabular}


Tabela 2. SAFRA 2000/2001.

$\begin{array}{ccccc}\text { Média } & \text { ano e meio } & \begin{array}{c}\text { Estágio/mês plantio } \\ \text { dia análise/mês análise } \\ \text { ano análise }\end{array} & \text { TCH } & \text { ATR } \\ \text { Talhão } & \text { Variedade } & \text { m0219082000 } & 100 & 158,87 \\ 1719 & \text { RB84-5257 } & \text { m0316052000 } & 100 & 126,57 \\ 2004 & \text { SP80-1816 } & \text { m0317052000 } & 90 & 121,80 \\ 2005 & \text { SP80-1816 } & \text { m0315052000 } & 90 & 126,65 \\ 2006 & \text { SP80-1816 } & \text { m0315052000 } & 95 & 125,84 \\ 2007 & \text { SP80-1816 } & & & \\ & & \text { Estágio/mês plantio } & & \\ \text { Tardia } & \text { ano e meio } & \text { dia análise/mês análise } & \text { TCH } & \text { ATR } \\ & & \text { ano análise } & 65 & 134,75 \\ \text { Talhão } & \text { Variedade } & \text { m1127052000 } & 60 & 136,26 \\ 887 & \text { RB72-454 } & \text { m1128052000 } & 50 & 140,96 \\ 889 & \text { RB72-454 } & \text { m1206102000 } & 50 & 147,08\end{array}$

$\begin{array}{ccccc}\text { Precoce } & \text { soca } & \begin{array}{c}\text { Estágio/mês plantio } \\ \text { dia análise/mês análise }\end{array} & & \\ \text { Talhão } & \text { Variedade } & \text { ano análise } & \text { TCH } & \text { ATR } \\ 9 & \text { RB83-5486 } & \text { s0925062000 } & 85 & 147,47 \\ 11 & \text { RB83-5486 } & \text { s0927052000 } & 100 & 138,40 \\ 80 & \text { RB83-5486 } & \text { s0918052000 } & 90 & 148,28 \\ 82 & \text { RB83-5486 } & \text { s0729062000 } & 85 & 150,06 \\ 83 & \text { RB83-5486 } & \text { s0614062000 } & 85 & 142,56 \\ 84 & \text { RB83-5486 } & \text { s0525052000 } & 95 & 133,70 \\ 85 & \text { RB83-5486 } & \text { s0509052000 } & 100 & 131,71 \\ 130 & \text { RB83-5486 } & \text { s0908052000 } & 85 & 134,78 \\ 131 & \text { RB83-5486 } & \text { s0908052000 } & 90 & 136,46 \\ 132 & \text { RB83-5486 } & \text { s0909052000 } & 90 & 136,14 \\ 133 & \text { RB83-5486 } & \text { s0909052000 } & 90 & 137,48 \\ 601 & \text { RB83-5486 } & \text { s0512052000 } & 75 & 134,32 \\ 744 & \text { RB83-5486 } & \text { s0604062000 } & 80 & 144,25 \\ 745 & \text { RB83-5486 } & \text { s0602062000 } & 80 & 136,52 \\ 746 & \text { RB83-5486 } & \text { s0602062000 } & 80 & 139,64 \\ 747 & \text { RB83-5486 } & \text { s0602062000 } & 80 & 133,05 \\ 748 & \text { RB83-5486 } & \text { s0602062000 } & 65 & 130,31 \\ 749 & \text { RB83-5486 } & \text { s0604062000 } & 65 & 144,18 \\ 750 & \text { RB83-5486 } & \text { s0601062000 } & 65 & 134,27 \\ 751 & \text { RB83-5486 } & \text { s0601062000 } & 65 & 142,28 \\ 753 & \text { RB83-5486 } & \text { s0601062000 } & 100 & 137,81 \\ 754 & \text { RB83-5486 } & \text { s0601062000 } & 100 & 139,24 \\ 886 & \text { RB83-5486 } & \text { s0631052000 } & 80 & 138,33 \\ 888 & \text { RB83-5486 } & \text { s0531052000 } & 70 & 135,25 \\ 2667 & \text { RB83-5486 } & \text { s0524052000 } & 85 & 135,84 \\ 2668 & \text { RB83-5486 } & \text { s0523052000 } & 90 & 134,28 \\ 2669 & \text { RB83-5486 } & \text { s0523052000 } & 95 & 131,69 \\ 2670 & \text { RB83-5486 } & \text { s0520052000 } & 95 & 136,69 \\ 2671 & \text { RB83-5486 } & \text { s0519052000 } & 90 & 133,02 \\ 2672 & \text { RB83-5486 } & \text { s0519052000 } & 90 & 130,77 \\ 2836 & \text { RB83-5486 } & \text { s0929072000 } & 65 & 134,54 \\ 2580 & \text { RB83-5486 } & \text { s0520052000 } & 95 & 131,46 \\ 2581 & \text { RB83-5486 } & \text { s0520052000 } & 90 & 138,72\end{array}$


Tabela 2. SAFRA 2000/2001.

\begin{tabular}{|c|c|c|c|c|}
\hline Precoce & soca & $\begin{array}{l}\text { Estágio/mês plantio } \\
\text { dia análise/mês análise }\end{array}$ & & \\
\hline Talhão & Variedade & ano análise & $\mathrm{TCH}$ & ATR \\
\hline 2582 & RB83-5486 & s0522052000 & 100 & 133,02 \\
\hline 2583 & RB83-5486 & s0519052000 & 100 & 131,42 \\
\hline 2584 & RB83-5486 & s0519052000 & 100 & 132,29 \\
\hline 2585 & RB83-5486 & s0520052000 & 90 & 142,28 \\
\hline 2586 & RB83-5486 & s0522052000 & 95 & 137,16 \\
\hline 50 & SP80-1842 & s0618052000 & 80 & 132,39 \\
\hline 86 & SP80-1842 & s0709072000 & 80 & 143,05 \\
\hline 87 & SP80-1842 & s0725072000 & 80 & 138,71 \\
\hline 88 & SP80-1842 & s0725072000 & 80 & 134,52 \\
\hline 89 & SP80-1842 & s0725072000 & 75 & 131,63 \\
\hline 2830 & SP80-1842 & s1027052000 & 75 & 136,78 \\
\hline 2831 & SP80-1842 & s0904062000 & 80 & 140,56 \\
\hline 3050 & SP80-1842 & s0509052000 & 80 & 122,77 \\
\hline 3051 & SP80-1842 & s0528052000 & 75 & 123,41 \\
\hline 3200 & SP80-1842 & s0926072000 & 80 & 138,38 \\
\hline 485 & RB82-5336 & s0605062000 & 70 & 132,05 \\
\hline 2702 & RB82-5336 & s0809062000 & 65 & 136,80 \\
\hline 1721 & RB76-5418 & s0829062000 & 75 & 151,49 \\
\hline 2118 & RB76-5418 & s0518052000 & 40 & 123,91 \\
\hline 2119 & RB76-5418 & s0518052000 & 50 & 121,43 \\
\hline 2120 & RB76-5418 & s0518052000 & 50 & 124,23 \\
\hline 2121 & RB76-5418 & s0518052000 & 50 & 119,16 \\
\hline 821 & RB82-5336 & s0828052000 & 65 & 127,11 \\
\hline 822 & RB82-5336 & s0528052000 & 60 & 119,00 \\
\hline 823 & RB82-5336 & s0528052000 & 80 & 128,39 \\
\hline 2150 & RB82-5336 & s0519052000 & 50 & 121,36 \\
\hline 2151 & RB82-5336 & s0517052000 & 55 & 130,68 \\
\hline 2152 & RB82-5336 & s0517052000 & 55 & 124,98 \\
\hline 2153 & RB82-5336 & s0517052000 & 50 & 124,63 \\
\hline 2154 & RB82-5336 & s0517052000 & 50 & 128,23 \\
\hline 2155 & RB82-5336 & s0517052000 & 50 & 121,91 \\
\hline 2158 & RB82-5336 & s0517052000 & 50 & 121,27 \\
\hline 2636 & SP77-5181 & s0523052000 & 35 & 120,76 \\
\hline 2637 & SP77-5181 & s0523052000 & 40 & 120,01 \\
\hline 2638 & SP77-5181 & s0523052000 & 45 & 130,13 \\
\hline 2639 & SP77-5181 & s0523052000 & 50 & 130,51 \\
\hline
\end{tabular}

$\begin{array}{ccccc}\text { Média } & \text { soca } & \begin{array}{c}\text { Estágio/mês plantio } \\ \text { dia análise/mês análise }\end{array} & & \\ \text { Talhão } & \text { Variedade } & \text { ano análise } & \text { TCH } & \text { ATR } \\ 20 & \text { SP70-1284 } & \text { s0918092000 } & 50 & 132,97 \\ 135 & \text { SP70-1284 } & \text { s0826082000 } & 75 & 142,18 \\ 2900 & \text { RB85-5536 } & \text { s0929092000 } & 75 & 144,06 \\ 2901 & \text { RB85-5536 } & \text { s0929092000 } & 80 & 144,52 \\ 2980 & \text { RB85-5536 } & \text { s0830082000 } & 70 & 146,88 \\ 2981 & \text { RB85-5536 } & \text { s0827082000 } & 70 & 146,07 \\ 2982 & \text { RB85-5536 } & \text { s0826082000 } & 80 & 156,35 \\ 2983 & \text { RB85-5536 } & \text { s0825082000 } & 60 & 145,76 \\ 2984 & \text { RB85-5536 } & \text { s0825082000 } & 50 & 149,52 \\ 2985 & \text { RB85-5536 } & \text { s0825082000 } & 65 & 154,18\end{array}$


Tabela 2. SAFRA 2000/2001.

$\begin{array}{ccccc}\text { Média } & \text { soca } & \begin{array}{c}\text { Estágio/mês plantio } \\ \text { dia análise/més análise }\end{array} & & \\ \text { Talhão } & \text { Variedade } & \begin{array}{c}\text { ano análise } \\ \text { s0904092000 }\end{array} & \text { TCH } & \text { ATR } \\ 426 & \text { SP81-3250 } & \text { s0907092000 } & 70 & 146,86 \\ 762 & \text { SP81-3250 } & \text { s0904092000 } & 80 & 145,52 \\ 1621 & \text { SP81-3250 } & \text { s0702072000 } & 80 & 144,40 \\ 2051 & \text { SP81-3250 } & \text { s0702072000 } & 80 & 146,39 \\ 2053 & \text { SP81-3250 } & \text { s0710072000 } & 70 & 142,72 \\ 456 & \text { SP79-1011 } & \text { s0710072000 } & 70 & 144,70 \\ 457 & \text { SP79-1011 } & \text { s0709072000 } & 65 & 148,84 \\ 458 & \text { SP79-1011 } & \text { s0709072000 } & 65 & 150,98 \\ 459 & \text { SP79-1011 } & \text { s0709072000 } & 65 & 151,86 \\ 460 & \text { SP79-1011 } & \text { s0708072000 } & 70 & 147,72 \\ 461 & \text { SP79-1011 } & \text { s0701072000 } & 60 & 146,63 \\ 2052 & \text { SP79-1011 } & \text { s0909092000 } & 55 & 137,69 \\ 4912 & \text { SP79-1011 } & \text { s0911092000 } & 45 & 139,30 \\ 4913 & \text { SP79-1011 } & \text { s0910092000 } & 45 & 126,95 \\ 4900 & \text { SP70-1143 } & \text { s0910092000 } & 45 & 122,83 \\ 4901 & \text { SP70-1143 } & \text { s0910092000 } & 50 & 134,05 \\ 4902 & \text { SP70-1143 } & \text { s0912092000 } & 50 & 149,28 \\ 4909 & \text { SP70-1143 } & \text { s0713072000 } & 75 & 141,34 \\ 706 & \text { RB85-5113 } & \text { s0713072000 } & 75 & 144,25 \\ 707 & \text { RB85-5113 } & \text { s0907092000 } & 70 & 146,03 \\ 763 & \text { RB85-5113 } & \text { s0904092000 } & 70 & 138,67 \\ 1623 & \text { RB85-5113 } & \text { s0904092000 } & 65 & 138,07 \\ 1625 & \text { RB85-5113 } & \text { s0825082000 } & 70 & 151,04 \\ 2706 & \text { RB84-5257 } & & & \end{array}$

$\begin{array}{ccccc}\text { Tardia } & \text { soca } & \begin{array}{c}\text { Estágio/mês plantio } \\ \text { dia análise/mês análise }\end{array} & & \\ \text { Talhão } & \text { Variedade } & \text { ano análise } & \text { TCH } & \text { ATR } \\ 580 & \text { RB72-454 } & \text { s0909092000 } & 55 & 141,47 \\ 581 & \text { RB72-454 } & \text { s0909092000 } & 65 & 142,82 \\ 582 & \text { RB72-454 } & \text { s0909092000 } & 60 & 140,02 \\ 583 & \text { RB72-454 } & \text { s0909092000 } & 70 & 140,68 \\ 740 & \text { RB72-454 } & \text { s0927092000 } & 70 & 129,14 \\ 741 & \text { RB72-454 } & \text { s0926092000 } & 65 & 136,16 \\ 742 & \text { RB72-454 } & \text { s0927092000 } & 65 & 142,42 \\ 743 & \text { RB72-454 } & \text { s0927092000 } & 65 & 140,95 \\ 874 & \text { RB72-454 } & \text { s0909092000 } & 60 & 139,41 \\ 875 & \text { RB72-454 } & \text { s0908092000 } & 60 & 134,34 \\ 876 & \text { RB72-454 } & \text { s0908092000 } & 65 & 139,60 \\ 1615 & \text { RB72-454 } & \text { s1027092000 } & 70 & 137,51 \\ 1616 & \text { RB72-454 } & \text { s1027092000 } & 70 & 139,17 \\ 1617 & \text { RB72-454 } & \text { s1027092000 } & 70 & 141,95 \\ 1618 & \text { RB72-454 } & \text { s1024092000 } & 70 & 139,36 \\ 1619 & \text { RB72-454 } & \text { s1024092000 } & 65 & 138,36 \\ 1620 & \text { RB72-454 } & \text { s1024092000 } & 60 & 145,41 \\ 1640 & \text { RB72-454 } & \text { s0905092000 } & 75 & 137,71 \\ 1641 & \text { RB72-454 } & \text { s0905092000 } & 75 & 136,18 \\ 1642 & \text { RB72-454 } & \text { s0905092000 } & 80 & 137,09 \\ 1643 & \text { RB72-454 } & \text { s0905092000 } & 80 & 143,04 \\ 1644 & \text { RB72-454 } & \text { s0905092000 } & 80 & 135,92\end{array}$


Tabela 2. SAFRA 2000/2001.

$\begin{array}{ccccc}\text { Tardia } & \text { soca } & \begin{array}{c}\text { Estágio/mês plantio } \\ \text { dia análise/mês análise } \\ \text { ano análise }\end{array} & \text { TCH } & \text { ATR } \\ \text { Talhão } & \text { Variedade } & \text { s0916092000 } & 55 & 140,25 \\ 4945 & \text { RB72-454 } & \text { s0916092000 } & 60 & 145,23 \\ 4946 & \text { RB72-454 } & \text { s0904092000 } & 60 & 129,95 \\ 1622 & \text { RB80-6043 } & \text { s0921092000 } & 60 & 124,55 \\ 4931 & \text { RB80-6043 } & \text { s0916092000 } & 60 & 126,69 \\ 4932 & \text { RB80-6043 } & \end{array}$


Tabela 3. SAFRA 2001/2002.

\begin{tabular}{|c|c|c|c|c|}
\hline Precoce & Variedade & $\begin{array}{l}\text { Estágio/mês plantio } \\
\text { dia análise/mês análise } \\
\text { ano análise }\end{array}$ & $\mathrm{TCH}$ & ATR \\
\hline 101701 & RB83-5486 & a1020082001 & 75 & 150,58 \\
\hline 101702 & RB83-5486 & a1020082001 & 75 & 142,87 \\
\hline 102501 & RB83-5486 & $\mathrm{a} 0806102001$ & 95 & 144,49 \\
\hline 102502 & RB83-5486 & $\mathrm{a} 0816102001$ & 100 & 141,42 \\
\hline 112201 & RB83-5486 & a1020082001 & 80 & 141,59 \\
\hline 140101 & RB83-5486 & a1119082001 & 65 & 143,94 \\
\hline 140102 & RB83-5486 & a1119082001 & 65 & 135,79 \\
\hline 140103 & RB83-5486 & a1119082001 & 65 & 143,01 \\
\hline 140104 & RB83-5486 & a1119082001 & 65 & 139,00 \\
\hline 140107 & RB83-5486 & a1 120082001 & 65 & 139,49 \\
\hline 140108 & RB83-5486 & a1119082001 & 65 & 136,73 \\
\hline 140109 & RB83-5486 & a1119082001 & 65 & 142,11 \\
\hline 164401 & RB83-5486 & a1128102001 & 60 & 136,09 \\
\hline 164402 & RB83-5486 & a1130102001 & 60 & 132,64 \\
\hline 164701 & RB83-5486 & a1130102001 & 60 & 135,09 \\
\hline 218201 & RB83-5486 & a1020092001 & 55 & 158,87 \\
\hline 218202 & RB83-5486 & a1020092001 & 60 & 157,69 \\
\hline 218205 & RB83-5486 & a1019092001 & 65 & 151,92 \\
\hline 218206 & RB83-5486 & a1019092001 & 70 & 155,60 \\
\hline 218207 & RB83-5486 & a1020092001 & 70 & 160,52 \\
\hline 218212 & RB83-5486 & a1020092001 & 70 & 163,74 \\
\hline 218215 & RB83-5486 & a1002092001 & 65 & 153,27 \\
\hline 218216 & RB83-5486 & a1002092001 & 45 & 158,07 \\
\hline 218217 & RB83-5486 & a1002092001 & 60 & 159,53 \\
\hline 218218 & RB83-5486 & a1007092001 & 70 & 152,36 \\
\hline 218219 & RB83-5486 & a1007092001 & 65 & 151,94 \\
\hline 218220 & RB83-5486 & a1008092001 & 65 & 148,93 \\
\hline 218221 & RB83-5486 & a1007092001 & 70 & 151,76 \\
\hline 218222 & RB83-5486 & a1008092001 & 65 & 156,02 \\
\hline 218223 & RB83-5486 & a1008092001 & 65 & 153,96 \\
\hline 218224 & RB83-5486 & a1001092001 & 65 & 155,93 \\
\hline 218225 & RB83-5486 & a1008092001 & 60 & 155,85 \\
\hline 218226 & RB83-5486 & a1008092001 & 60 & 155,76 \\
\hline 218227 & RB83-5486 & a1008092001 & 60 & 160,29 \\
\hline 218228 & RB83-5486 & a1008092001 & 60 & 151,26 \\
\hline 218229 & RB83-5486 & a1008092001 & 65 & 148,67 \\
\hline 218231 & RB83-5486 & a1008092001 & 60 & 154,64 \\
\hline 218232 & RB83-5486 & a1008092001 & 35 & 152,07 \\
\hline 218233 & RB83-5486 & a1008092001 & 60 & 155,30 \\
\hline 159101 & SP80-1842 & a0903092001 & 80 & 150,16 \\
\hline 159102 & SP80-1842 & a0903092001 & 80 & 156,72 \\
\hline 159103 & SP80-1842 & a0911102001 & 80 & 146,02 \\
\hline 159104 & SP80-1842 & a0911102001 & 80 & 147,49 \\
\hline 159105 & SP80-1842 & a0910102001 & 80 & 147,15 \\
\hline 159201 & SP80-1842 & a0928082001 & 75 & 141,90 \\
\hline 159202 & SP80-1842 & a0928082001 & 80 & 148,10 \\
\hline 170101 & SP80-1842 & a0928102001 & 75 & 144,67 \\
\hline 170102 & SP80-1842 & a0929102001 & 75 & 136,05 \\
\hline
\end{tabular}


Tabela 3. SAFRA 2001/2002.

$\begin{array}{ccccc}\text { Precoce } & \text { ano } & \begin{array}{c}\text { Estágio/mês plantio } \\ \text { dia análise/mês análise }\end{array} & & \\ \text { Talhão } & \text { Variedade } & \text { ano análise } & \text { TCH } & \text { ATR } \\ 170103 & \text { SP80-1842 } & \text { a0929102001 } & 75 & 149,94 \\ 170104 & \text { SP80-1842 } & \text { a0929102001 } & 75 & 144,02 \\ 170105 & \text { SP80-1842 } & \text { a0929102001 } & 75 & 143,12 \\ 170106 & \text { SP80-1842 } & \text { a0930102001 } & 75 & 145,71 \\ 170107 & \text { SP80-1842 } & \text { a0930102001 } & 75 & 147,91 \\ 170108 & \text { SP80-1842 } & \text { a0929102001 } & 75 & 149,37 \\ 170109 & \text { SP80-1842 } & \text { a0929102001 } & 80 & 148,26 \\ 170110 & \text { SP80-1842 } & \text { a0929102001 } & 80 & 143,75 \\ 170111 & \text { SP80-1842 } & \text { a0929102001 } & 75 & 144,62 \\ 170112 & \text { SP80-1842 } & \text { a0929102001 } & 75 & 137,58\end{array}$

$\begin{array}{ccccc}\text { Média } & \text { ano } & \begin{array}{c}\text { Estágio/mês plantio } \\ \text { dia análise/mês análise }\end{array} & & \\ \text { Talhão } & \text { Variedade } & \text { ano análise } & \text { TCH } & \text { ATR } \\ 126301 & \text { RB84-5257 } & \text { a1230102001 } & 60 & 141,60 \\ 126302 & \text { RB84-5257 } & \text { a1230102001 } & 60 & 133,27 \\ 126303 & \text { RB84-5257 } & \text { a1231102001 } & 60 & 139,92 \\ 101606 & \text { SP70-1284 } & \text { a1117082001 } & 60 & 137,81 \\ 102402 & \text { SP81-3250 } & \text { a0806102001 } & 100 & 149,07 \\ 157101 & \text { SP80-1816 } & \text { a0928082001 } & 75 & 151,42 \\ 157114 & \text { SP80-1816 } & \text { a0908082001 } & 80 & 146,34 \\ 157115 & \text { SP80-1816 } & \text { a0908082001 } & 75 & 143,15 \\ 157116 & \text { SP80-1816 } & \text { a0908082001 } & 75 & 148,52 \\ 176104 & \text { SP80-1816 } & \text { a1127102001 } & 65 & 141,43 \\ 176106 & \text { SP80-1816 } & \text { a1128102001 } & 65 & 137,07 \\ 182101 & \text { SP80-1816 } & \text { a1114102001 } & 70 & 154,01 \\ 182102 & \text { SP80-1816 } & \text { a1114102001 } & 70 & 139,45 \\ 182103 & \text { SP80-1816 } & \text { a1114102001 } & 70 & 149,99 \\ 182104 & \text { SP80-1816 } & \text { a1114102001 } & 70 & 145,65 \\ 182105 & \text { SP80-1816 } & \text { a1114102001 } & 70 & 146,49 \\ 182106 & \text { SP80-1816 } & \text { a1114102001 } & 70 & 152,87\end{array}$

Precoce ano e meio Estágio/mês plantio dia análise/mês análise

$\begin{array}{ccccc}\text { Talhão } & \text { Variedade } & \text { ano análise } & \text { TCH } & \text { ATR } \\ 111103 & \text { RB83-5486 } & \text { m1227102001 } & 95 & 151,61 \\ 129101 & \text { RB83-5486 } & \text { m0511052001 } & 100 & 113,01 \\ 129103 & \text { RB83-5486 } & \text { m0511052001 } & 100 & 116,35 \\ 129104 & \text { RB83-5486 } & \text { m0511052001 } & 100 & 117,18 \\ 129105 & \text { RB83-5486 } & \text { m0511052001 } & 100 & 119,44 \\ 129106 & \text { RB83-5486 } & \text { m0512052001 } & 100 & 125,25 \\ 129107 & \text { RB83-5486 } & \text { m0511052001 } & 100 & 114,31 \\ 129108 & \text { RB83-5486 } & \text { m0511052001 } & 100 & 117,97 \\ 129110 & \text { RB83-5486 } & \text { m0511052001 } & 90 & 106,06 \\ 226101 & \text { RB83-5486 } & \text { m0319102001 } & 55 & 145,27 \\ 125101 & \text { SP80-1842 } & \text { m0102082001 } & 90 & 149,90 \\ 133201 & \text { SP80-1842 } & \text { m1105102001 } & 60 & 149,00\end{array}$


Tabela 3. SAFRA 2001/2002.

\begin{tabular}{|c|c|c|c|c|}
\hline Média & ano e meio & $\begin{array}{l}\text { Estágio/mês plantio } \\
\text { dia análise/mês análise }\end{array}$ & & \\
\hline Talhão & Variedade & ano análise & $\mathrm{TCH}$ & ATR \\
\hline 117201 & SP79-1011 & $\mathrm{m} 1022052001$ & 70 & 115,15 \\
\hline 117301 & SP79-1011 & $\mathrm{m} 1023052001$ & 60 & 111,47 \\
\hline 117302 & SP79-1011 & $\mathrm{m} 1023052001$ & 60 & 113,06 \\
\hline 126601 & SP79-1011 & $\mathrm{m} 0711052001$ & 65 & 110,20 \\
\hline 126602 & SP79-1011 & m0711052001 & 40 & 105,38 \\
\hline 126603 & SP79-1011 & m0729052001 & 40 & 104,29 \\
\hline 126604 & SP79-1011 & $\mathrm{m} 0726052001$ & 60 & 109,75 \\
\hline 126605 & SP79-1011 & $\mathrm{m} 0714062001$ & 70 & 122,28 \\
\hline 126701 & SP79-1011 & m0729052001 & 55 & 110,17 \\
\hline 126702 & SP79-1011 & m0729052001 & 40 & 114,83 \\
\hline 126703 & SP79-1011 & m0711052001 & 40 & 118,30 \\
\hline 126704 & SP79-1011 & m0711052001 & 40 & 118,58 \\
\hline 126705 & SP79-1011 & m0711052001 & 60 & 104,97 \\
\hline 153203 & SP79-1011 & m0508052001 & 70 & 121,09 \\
\hline 154101 & SP79-1011 & m0927072001 & 70 & 136,64 \\
\hline 154102 & SP79-1011 & m0927072001 & 70 & 139,61 \\
\hline 154103 & SP79-1011 & m0927072001 & 65 & 141,99 \\
\hline 154104 & SP79-1011 & m0927072001 & 60 & 140,93 \\
\hline 154105 & SP79-1011 & m0926072001 & 60 & 145,18 \\
\hline 154106 & SP79-1011 & m0926072001 & 60 & 143,87 \\
\hline 127101 & RB78-5148 & m0902082001 & 65 & 136,80 \\
\hline 127102 & RB78-5148 & m0620052001 & 75 & 113,71 \\
\hline 131101 & RB78-5148 & m1018092001 & 60 & 138,50 \\
\hline 131102 & RB78-5148 & m1022082001 & 60 & 149,46 \\
\hline 133101 & SP81-3250 & $\mathrm{m} 1105102001$ & 65 & 150,95 \\
\hline 158104 & SP81-3250 & m0204092001 & 80 & 154,81 \\
\hline 167101 & SP81-3250 & m1008062001 & 60 & 126,58 \\
\hline 167102 & SP81-3250 & m1008062001 & 60 & 130,01 \\
\hline 167106 & SP81-3250 & m1006092001 & 70 & 157,77 \\
\hline 220103 & SP81-3250 & m0319062001 & 100 & 131,71 \\
\hline 231101 & SP81-3250 & m0206062001 & 100 & 132,03 \\
\hline 231102 & SP81-3250 & $\mathrm{m} 0206062001$ & 110 & 132,39 \\
\hline 231105 & SP81-3250 & m0207062001 & 120 & 131,63 \\
\hline 231106 & SP81-3250 & m0207062001 & 120 & 130,71 \\
\hline 231107 & SP81-3250 & m0207062001 & 115 & 130,20 \\
\hline 231301 & SP81-3250 & m0308062001 & 110 & 126,60 \\
\hline 232101 & SP81-3250 & m0307082001 & 100 & 159,19 \\
\hline 232104 & SP81-3250 & m0323102001 & 110 & 137,93 \\
\hline 232105 & SP81-3250 & m0304092001 & 110 & 161,65 \\
\hline 232107 & SP81-3250 & $\mathrm{m} 0310062001$ & 115 & 137,94 \\
\hline 232108 & SP81-3250 & m0310062001 & 115 & 131,80 \\
\hline 232109 & SP81-3250 & m0309062001 & 110 & 139,19 \\
\hline 232110 & SP81-3250 & m0309062001 & 110 & 133,60 \\
\hline 232112 & SP81-3250 & m0309062001 & 110 & 139,04 \\
\hline 232115 & SP81-3250 & m0223102001 & 100 & 143,31 \\
\hline 249201 & SP81-3250 & m0326092001 & 90 & 153,27 \\
\hline 249202 & SP81-3250 & m0309082001 & 95 & 165,98 \\
\hline 249203 & SP81-3250 & m0302082001 & 95 & 161,67 \\
\hline 249204 & SP81-3250 & m0331072001 & 95 & 152,90 \\
\hline
\end{tabular}


Tabela 3. SAFRA 2001/2002.

\begin{tabular}{|c|c|c|c|c|}
\hline Média & ano e meio & $\begin{array}{l}\text { Estágio/mês plantio } \\
\text { dia análise/mês análise }\end{array}$ & & \\
\hline Talhão & Variedade & ano análise & $\mathrm{TCH}$ & ATR \\
\hline 249205 & SP81-3250 & m0331072001 & 95 & 155,38 \\
\hline 249301 & SP81-3250 & m0431072001 & 90 & 157,37 \\
\hline 249302 & SP81-3250 & m0431072001 & 90 & 160,91 \\
\hline 249303 & SP81-3250 & m0431072001 & 85 & 147,86 \\
\hline 249304 & SP81-3250 & m0431072001 & 90 & 159,47 \\
\hline 249305 & SP81-3250 & m0402082001 & 60 & 157,17 \\
\hline 249306 & SP81-3250 & m0402082001 & 80 & 163,47 \\
\hline 249307 & SP81-3250 & m0402082001 & 90 & 153,68 \\
\hline 249308 & SP81-3250 & m0431072001 & 90 & 149,15 \\
\hline 249309 & SP81-3250 & $\mathrm{m} 0402082001$ & 85 & 151,32 \\
\hline 249401 & SP81-3250 & m0402082001 & 95 & 148,47 \\
\hline 249402 & SP81-3250 & m0404082001 & 90 & 159,78 \\
\hline 249403 & SP81-3250 & m0407082001 & 85 & 166,14 \\
\hline 249404 & SP81-3250 & m0407082001 & 80 & 161,48 \\
\hline 249405 & SP81-3250 & m0404082001 & 90 & 160,15 \\
\hline 249406 & SP81-3250 & m0404082001 & 90 & 157,50 \\
\hline 249407 & SP81-3250 & m0403082001 & 95 & 159,53 \\
\hline 153202 & IAC81-2004 & $\mathrm{m} 0508052001$ & 60 & 110,48 \\
\hline 157201 & RB85-5113 & m1029072001 & 60 & 145,68 \\
\hline 157202 & RB85-5113 & m1029072001 & 55 & 146,15 \\
\hline 157203 & RB85-5113 & m1028072001 & 55 & 147,49 \\
\hline 157204 & RB85-5113 & m1028072001 & 55 & 147,80 \\
\hline 157205 & RB85-5113 & m1028072001 & 55 & 149,00 \\
\hline 157206 & RB85-5113 & m1028072001 & 55 & 148,53 \\
\hline 157207 & RB85-5113 & m1029072001 & 60 & 146,84 \\
\hline 157208 & RB85-5113 & m1029072001 & 60 & 147,69 \\
\hline 167103 & RB85-5113 & m1006092001 & 60 & 160,99 \\
\hline 167104 & RB85-5113 & m1006092001 & 55 & 156,90 \\
\hline 219101 & RB85-5113 & m0417102001 & 100 & 145,67 \\
\hline 219102 & RB85-5113 & m0417102001 & 100 & 146,45 \\
\hline 219103 & RB85-5113 & m0417102001 & 95 & 147,11 \\
\hline 160101 & RB85-5536 & m1004102001 & 60 & 148,85 \\
\hline 160102 & RB85-5536 & m1005102001 & 60 & 146,87 \\
\hline 172301 & RB85-5536 & m1125062001 & 60 & 139,83 \\
\hline 172302 & RB85-5536 & m1125062001 & 60 & 130,33 \\
\hline 172303 & RB85-5536 & m1125062001 & 60 & 135,86 \\
\hline 172304 & RB85-5536 & m1126062001 & 60 & 134,08 \\
\hline 172305 & RB85-5536 & m1126062001 & 60 & 126,11 \\
\hline 220104 & RB85-5536 & m0321062001 & 100 & 135,17 \\
\hline 220201 & RB85-5536 & m0320062001 & 115 & 137,16 \\
\hline 220202 & RB85-5536 & m0320062001 & 110 & 139,38 \\
\hline 220203 & RB85-5536 & m0320062001 & 115 & 142,61 \\
\hline 220204 & RB85-5536 & m0320062001 & 100 & 138,98 \\
\hline 220205 & RB85-5536 & m0319062001 & 105 & 135,96 \\
\hline 220206 & RB85-5536 & m0319062001 & 105 & 137,88 \\
\hline 220207 & RB85-5536 & m0321062001 & 105 & 130,76 \\
\hline 206101 & SP80-1816 & m0422062001 & 100 & 144,53 \\
\hline 206103 & SP80-1816 & m0422062001 & 100 & 133,89 \\
\hline 206104 & SP80-1816 & m0422062001 & 100 & 140,42 \\
\hline
\end{tabular}


Tabela 3. SAFRA 2001/2002.

$\begin{array}{ccccc}\text { Média } & \text { ano e meio } & \begin{array}{c}\text { Estágio/mês plantio } \\ \text { dia análise/mês análise }\end{array} & & \\ \text { Talhão } & \text { Variedade } & \begin{array}{c}\text { ano análise } \\ \text { m0416062001 }\end{array} & \text { TCH } & \text { ATR } \\ 219201 & \text { SP80-1816 } & \text { m0416062001 } & 100 & 136,50 \\ 219202 & \text { SP80-1816 } & \text { m0412062001 } & 100 & 125,74 \\ 219203 & \text { SP80-1816 } & \text { m0416062001 } & 90 & 126,23 \\ 219204 & \text { SP80-1816 } & \text { m0411062001 } & 95 & 131,53 \\ 219205 & \text { SP80-1816 } & \text { m0411062001 } & 110 & 131,39 \\ 219206 & \text { SP80-1816 } & \text { m0411062001 } & 110 & 134,77 \\ 219207 & \text { SP80-1816 } & \text { m0412062001 } & 120 & 134,18 \\ 219301 & \text { SP80-1816 } & \text { m0412062001 } & 120 & 132,86 \\ 219302 & \text { SP80-1816 } & \text { m0412062001 } & 110 & 136,84 \\ 219303 & \text { SP80-1816 } & \text { m0413062001 } & 110 & 136,92 \\ 219304 & \text { SP80-1816 } & \text { m0415062001 } & 110 & 126,09 \\ 219305 & \text { SP80-1816 } & \text { m0415062001 } & 110 & 125,35 \\ 219306 & \text { SP80-1816 } & \text { m0415062001 } & 110 & 133,75 \\ 219307 & \text { SP80-1816 } & \text { m0415062001 } & 110 & 123,75 \\ 219308 & \text { SP80-1816 } & \text { m0412062001 } & 110 & 125,80 \\ 219401 & \text { SP80-1816 } & \text { m0415062001 } & 110 & 126,59 \\ 219402 & \text { SP80-1816 } & \text { m0412062001 } & 110 & 135,59 \\ 219403 & \text { SP80-1816 } & \text { m0412062001 } & 110 & 131,81 \\ 219404 & \text { SP80-1816 } & \text { m0416062001 } & 110 & 128,18 \\ 219406 & \text { SP80-1816 } & \text { m0418062001 } & 105 & 134,15 \\ 219407 & \text { SP80-1816 } & \text { m0416062001 } & 105 & 134,07 \\ 219408 & \text { SP80-1816 } & \text { m0416062001 } & 110 & 130,88 \\ 219409 & \text { SP80-1816 } & \text { m0415062001 } & 110 & 130,99 \\ 219410 & \text { SP80-1816 } & \text { m0413062001 } & 110 & 131,41 \\ 219411 & \text { SP80-1816 } & \text { m0413062001 } & 105 & 132,08 \\ 219412 & \text { SP80-1816 } & \text { m0413062001 } & 100 & 133,34 \\ 219413 & \text { SP80-1816 } & \text { m0414062001 } & 110 & 131,94 \\ 219414 & \text { SP80-1816 } & \text { m0414062001 } & 105 & 137,14 \\ 219415 & \text { SP80-1816 } & \text { m0331072001 } & 100 & 162,56 \\ 235101 & \text { RB73-9359 } & \text { m0331072001 } & 100 & 157,93 \\ 235102 & \text { RB73-9359 } & & & \end{array}$

$\begin{array}{ccccc}\text { Tardia } & \text { ano e meio } & \begin{array}{c}\text { Estágio/mês plantio } \\ \text { dia análise/mês análise } \\ \text { ano análise }\end{array} & \text { TCH } & \text { ATR } \\ \text { Talhão } & \text { Variedade } & \text { m1128092001 } & 55 & 150,56 \\ 122101 & \text { RB72-454 } & \text { m1128092001 } & 65 & 144,98 \\ 122201 & \text { RB72-454 } & \text { m1127092001 } & 65 & 138,94 \\ 122202 & \text { RB72-454 } & \text { m1127092001 } & 60 & 141,72 \\ 122301 & \text { RB72-454 } & \text { m1127092001 } & 60 & 144,62 \\ 122302 & \text { RB72-454 } & \text { m0705062001 } & 65 & 117,88 \\ 126501 & \text { RB72-454 } & \text { m0705062001 } & 50 & 116,25 \\ 126502 & \text { RB72-454 } & \text { m0705062001 } & 65 & 114,08 \\ 126503 & \text { RB72-454 } & \text { m0905062001 } & 65 & 111,10 \\ 126504 & \text { RB72-454 } & \text { m0705062001 } & 65 & 113,71 \\ 126505 & \text { RB72-454 } & \text { m0705062001 } & 60 & 116,34 \\ 126506 & \text { RB72-454 } & \text { m0710062001 } & 60 & 117,38 \\ 126507 & \text { RB72-454 } & \text { m0710062001 } & 60 & 117,64 \\ 126508 & \text { RB72-454 } & \text { m0708062001 } & 60 & 117,32 \\ 126509 & \text { RB72-454 } & & \end{array}$


Tabela 3. SAFRA 2001/2002.

Tardia ano e meio Estágio/mês plantio dia análise/mês análise

\begin{tabular}{|c|c|c|c|c|}
\hline Talhão & Variedade & ano análise & $\mathrm{TCH}$ & ATR \\
\hline 126510 & RB72-454 & m0908062001 & 65 & 115,77 \\
\hline 126511 & RB72-454 & m0908062001 & 60 & 116,49 \\
\hline 126512 & RB72-454 & $\mathrm{m} 0708062001$ & 60 & 114,05 \\
\hline 126513 & RB72-454 & $\mathrm{m} 0711062001$ & 60 & 120,25 \\
\hline 126515 & RB72-454 & $\mathrm{m} 0710062001$ & 55 & 119,80 \\
\hline 126516 & RB72-454 & m0709062001 & 60 & 113,58 \\
\hline 126517 & RB72-454 & $\mathrm{m} 0711062001$ & 50 & 128,07 \\
\hline 126518 & RB72-454 & $\mathrm{m} 0714062001$ & 60 & 134,14 \\
\hline 127301 & RB72-454 & m0916062001 & 55 & 135,10 \\
\hline 139101 & RB72-454 & m1124102001 & 65 & 140,51 \\
\hline 162101 & RB72-454 & m1027082001 & 55 & 145,45 \\
\hline 162102 & RB72-454 & m1028052001 & 55 & 148,93 \\
\hline 162103 & RB72-454 & $\mathrm{m} 1027082001$ & 60 & 152,66 \\
\hline 163201 & RB72-454 & m1004102001 & 70 & 152,00 \\
\hline 163202 & RB72-454 & $\mathrm{m} 1003102001$ & 65 & 147,49 \\
\hline 163203 & RB72-454 & m1003102001 & 65 & 150,07 \\
\hline 163204 & RB72-454 & m1030052001 & 65 & 145,73 \\
\hline 167302 & RB72-454 & m1004092001 & 55 & 155,67 \\
\hline 167303 & RB72-454 & m1004092001 & 60 & 155,43 \\
\hline 167304 & RB72-454 & m1004092001 & 60 & 152,77 \\
\hline 167305 & RB72-454 & $\mathrm{m} 1004092001$ & 60 & 155,14 \\
\hline 167306 & RB72-454 & m1004092001 & 60 & 158,77 \\
\hline 167307 & RB72-454 & m1004092001 & 60 & 158,90 \\
\hline 167308 & RB72-454 & m1004092001 & 60 & 156,03 \\
\hline 167309 & RB72-454 & $\mathrm{m} 1005092001$ & 60 & 159,19 \\
\hline 167310 & RB72-454 & $\mathrm{m} 1005092001$ & 60 & 159,39 \\
\hline 167311 & RB72-454 & $\mathrm{m} 1005092001$ & 60 & 156,77 \\
\hline 167312 & RB72-454 & $\mathrm{m} 1005092001$ & 60 & 161,39 \\
\hline 167313 & RB72-454 & $\mathrm{m} 1005092001$ & 60 & 156,65 \\
\hline 167314 & RB72-454 & m1005092001 & 60 & 153,47 \\
\hline 167315 & RB72-454 & m1005092001 & 55 & 164,34 \\
\hline 167316 & RB72-454 & m1005092001 & 55 & 160,36 \\
\hline 167317 & RB72-454 & m1005092001 & 60 & 166,82 \\
\hline 172101 & RB72-454 & m1122062001 & 65 & 132,96 \\
\hline 243101 & RB72-454 & m1118072001 & 60 & 143,98 \\
\hline 243102 & RB72-454 & m1118072001 & 45 & 141,52 \\
\hline 243103 & RB72-454 & m1118072001 & 55 & 138,27 \\
\hline 243104 & RB72-454 & m1118072001 & 55 & 139,23 \\
\hline 243105 & RB72-454 & m1118072001 & 50 & 137,24 \\
\hline 243106 & RB72-454 & m1119072001 & 45 & 147,84 \\
\hline 243107 & RB72-454 & m1120072001 & 45 & 145,60 \\
\hline 243108 & RB72-454 & m1119072001 & 45 & 142,97 \\
\hline 243109 & RB72-454 & m1123072001 & 50 & 132,89 \\
\hline 243110 & RB72-454 & m1123072001 & 50 & 145,23 \\
\hline 243111 & RB72-454 & m1121072001 & 50 & 137,94 \\
\hline 243112 & RB72-454 & m1121072001 & 50 & 145,66 \\
\hline 243113 & RB72-454 & m1119072001 & 50 & 139,72 \\
\hline 243114 & RB72-454 & m1119072001 & 50 & 139,65 \\
\hline 243115 & RB72-454 & m1119072001 & 45 & 138,57 \\
\hline
\end{tabular}


Tabela 3. SAFRA 2001/2002.

Tardia ano e meio Estágio/mês plantio

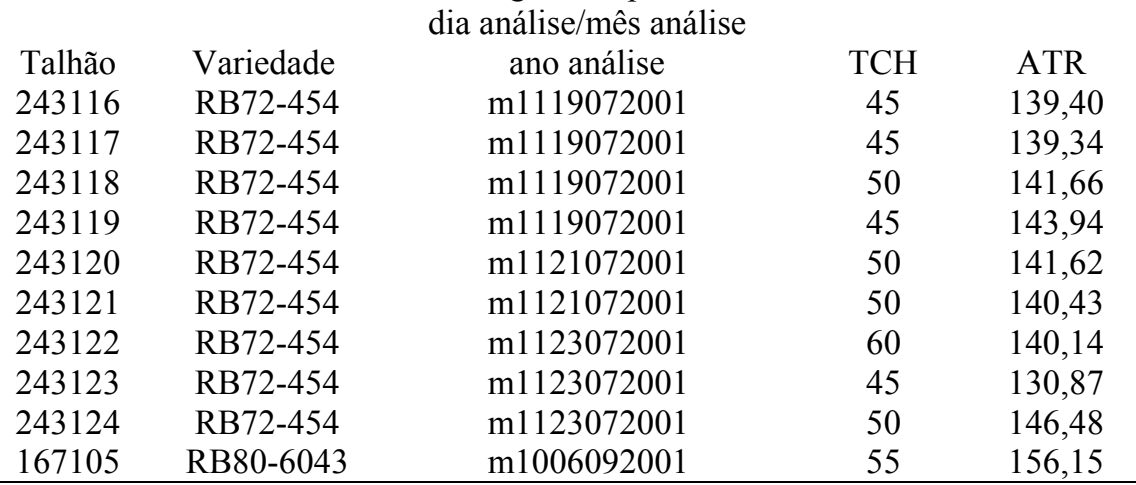


Tabela 11. Série histórica da precipitação na região de Ribeirão Preto (em mm).

\begin{tabular}{|c|c|c|c|c|c|c|c|c|c|c|c|c|}
\hline ANO & JAN & FEV & MAR & ABR & MAI & JUN & JUL & $\mathrm{AGO}$ & SET & OUT & NOV & DEZ \\
\hline 1937 & 396,3 & 130,1 & 134,2 & 188,1 & 52,6 & 32,1 & 0,0 & 14,4 & 5,0 & 179,0 & 265,7 & 352,0 \\
\hline 1938 & 244,8 & 119,0 & 140,7 & 47,2 & 119,1 & 0,0 & 0,0 & 7,3 & 32,9 & 171,5 & 111,6 & 306,7 \\
\hline 1939 & 270,0 & 221,2 & 124,2 & 67,5 & 123,8 & 66,2 & 23,0 & 0,0 & 43,9 & 47,0 & 227,0 & 263,3 \\
\hline 1940 & 357,2 & 303,8 & 80,1 & 15,4 & 34,1 & 0,0 & 0,8 & 3,4 & 21,2 & 117,8 & 234,1 & 186,1 \\
\hline 1941 & 206,9 & 59,8 & 67,8 & 62,8 & 15,0 & 1,3 & 31,4 & 2,4 & 217,4 & 75,1 & 246,6 & 163,6 \\
\hline 1942 & 185,8 & 303,7 & 288,2 & 72,7 & 14,9 & 6,7 & 4,0 & 8,6 & 20,0 & 114,9 & 131,9 & 388,6 \\
\hline 1943 & 464,1 & 221,4 & 149,0 & 44,4 & 0,2 & 23,2 & 0,0 & 0,0 & 50,1 & 170,0 & 89,5 & 279,5 \\
\hline 1944 & 211,9 & 160,5 & 118,1 & 78,6 & 0,0 & 0,0 & 1,2 & 0,0 & 6,2 & 26,4 & 99,5 & 33,0 \\
\hline 1945 & 303,4 & 256,5 & 279,5 & 45,1 & 4,1 & 35,4 & 11,8 & 0,0 & 22,6 & 157,6 & 240,9 & 299,6 \\
\hline 1946 & 202,5 & 197,7 & 174,6 & 52,6 & 3,0 & 6,0 & 60,0 & 0,0 & 30,7 & 105,2 & 170,5 & 233,7 \\
\hline 1947 & 341,7 & 162,4 & 384,5 & 7,0 & 15,0 & 25,6 & 18,9 & 62,2 & 92,4 & 142,6 & 121,9 & 177,1 \\
\hline 1948 & 170,7 & 309,9 & 228,3 & 0,0 & 17,1 & 0,0 & 17,7 & 8,7 & 12,0 & 66,6 & 144,8 & 189,5 \\
\hline 1949 & 235,5 & 254,6 & 117,7 & 73,1 & 41,0 & 24,9 & 0,0 & 0,0 & 0,0 & 66,8 & 113,2 & 489,1 \\
\hline 1950 & 344,6 & 242,4 & 182,0 & 91,9 & 0,0 & 1,4 & 14,2 & & 19,2 & 196,8 & 184,8 & 225,4 \\
\hline 1951 & 579,9 & 230,4 & 172,0 & 67,0 & 8,6 & 7,5 & 0,5 & 12,9 & 0,0 & 99,6 & 242,4 & 157,4 \\
\hline 1952 & 276,8 & 298,7 & 366,6 & 27,5 & 0,0 & 78,8 & 0,0 & 0 , & 15,9 & 123,7 & 188,3 & 175,9 \\
\hline 1953 & 164,2 & 174,6 & 131,8 & 35,7 & 45,7 & 46,5 & 45,5 & 1,8 & 40,0 & 139,1 & 129,1 & 391,2 \\
\hline 1954 & 276,4 & 249,4 & 175,8 & 18,6 & 209,3 & 41,0 & 3,2 & 0,0 & 4,4 & 48,1 & 153,9 & 180,6 \\
\hline 1955 & 198,9 & 151,4 & 262,0 & 109,6 & 15,8 & 14,1 & 0,0 & 32,5 & 0,0 & 127 & 100,1 & 333,1 \\
\hline 1956 & 87,1 & 161,8 & 33,5 & 80,6 & 76,4 & 58,0 & 39,8 & 62,8 & 70,9 & 257,5 & 22,4 & 236,2 \\
\hline 1957 & 234,6 & 303,0 & 198,3 & 96,7 & 122,5 & 15,9 & 100,2 & & 115,5 & 114,9 & 129,2 & 154,2 \\
\hline 1958 & 217,9 & 176,8 & 195,1 & 118,6 & 138,5 & 40,0 & 20,1 & 11,4 & 65,7 & 184,5 & 66,1 & 143,4 \\
\hline 1959 & 494,3 & 69,3 & 199,2 & 42,7 & 52,5 & 9,2 & 0,0 & 50 & 22,4 & 99,2 & 194,9 & 183,9 \\
\hline 1960 & 293,0 & 326,7 & 163,6 & 50,9 & 55,0 & 26,1 & 0,0 & 15,1 & 2,3 & 102,4 & 348,3 & 478,4 \\
\hline 1961 & 256,7 & 327,5 & 132,6 & 84,1 & 67,2 & 5,2 & 0,2 & 4,6 & 3,0 & 116,2 & 189,5 & 140,9 \\
\hline 1962 & 200,3 & 149,4 & 316,1 & 15,0 & 35,0 & 67,5 & 5,7 & 21,5 & 87,9 & 255,3 & 62,9 & 384,2 \\
\hline 1963 & 419,8 & 155,0 & 27,4 & 6,3 & 45,0 & 0,0 & 0,0 & 7,6 & 1,4 & 52,2 & 165,2 & 72,6 \\
\hline 1964 & 323,1 & 291,7 & 86,5 & 96,7 & 91,6 & 13,6 & & & 60,1 & 164,4 & 115,6 & 381,6 \\
\hline 1965 & 365,0 & 313,7 & 135,3 & 60,0 & 42,4 & 39,7 & 77,8 & 5,4 & 76,2 & 167,0 & 120,0 & 343,3 \\
\hline 1966 & 289,2 & 182,2 & 193,0 & 109,0 & 48,7 & 0,0 & 0,0 & 14,9 & 42,7 & 68,6 & 248,0 & 345,6 \\
\hline 1967 & 371,5 & 280,0 & 112,0 & 75,8 & 3,5 & 74,3 & 2,8 & 0,0 & 67,6 & 131,2 & 175,1 & 412,8 \\
\hline 1968 & 167,1 & 60,0 & 183,9 & 47,2 & 0,9 & 2,9 & 9,2 & 49,0 & 24,9 & 121,3 & 110,8 & 284,6 \\
\hline 1969 & 126,9 & 122,6 & 110,8 & 82,7 & 1,8 & 15,3 & 1,8 & 4,6 & 31,0 & 193,3 & 216,2 & 130,8 \\
\hline 1970 & 349,4 & 392,4 & 78,6 & 16,4 & 24,9 & 52,8 & 20,0 & 53,1 & 47,9 & 233,7 & 147,1 & 122,0 \\
\hline 1971 & 161,6 & 167,2 & 249 & 39,0 & 53,8 & 116,8 & 35,1 & 0,3 & 48,3 & 144,1 & 136,7 & 320,4 \\
\hline 1972 & 289,2 & 384,4 & 128,7 & 59,3 & 82,1 & 0,0 & 126,8 & 80,5 & 47,9 & 206,6 & 185,0 & 179,4 \\
\hline 1973 & 139,1 & 208,7 & 217,5 & 173,3 & 42,2 & 14,0 & 16,5 & 2,7 & 45,0 & 244,4 & 209,0 & 337,4 \\
\hline 1974 & 357,2 & 121,0 & 340,7 & 50,2 & 5,5 & 69,3 & 0,0 & 1,3 & 11,9 & 133,2 & 131,7 & 462,4 \\
\hline 1975 & 181,6 & 190,2 & 14,9 & 128,8 & 2,8 & 0,0 & 27,2 & & 49,5 & 109,7 & 376,1 & 191,9 \\
\hline 1976 & 200,8 & 314,7 & 212,2 & 42,0 & 110,9 & 16,9 & 104,1 & 102,6 & 134,5 & 127,7 & 187,2 & 290,5 \\
\hline 1977 & 342,1 & 92,8 & 130,6 & 293,5 & 5,6 & 24,3 & 3,2 & 19,0 & 83,7 & 76,4 & 171,7 & 274,5 \\
\hline 1978 & 239,2 & 133,1 & 150,8 & 7,3 & 78,6 & 43,7 & 63,7 & 0,0 & 48,0 & 158,4 & 235,5 & 248,0 \\
\hline
\end{tabular}


Tabela 11. Série histórica da precipitação na região de Ribeirão Preto (em mm).

\begin{tabular}{ccccccccccccc} 
ANO & JAN & FEV & MAR & ABR & MAI & JUN & JUL & AGO & SET & OUT & NOV & DEZ \\
1979 & 192,8 & 227,6 & 69,1 & 97,2 & 121,8 & 0,0 & 24,9 & 19,2 & 138,2 & 128,1 & 111,0 & 375,9 \\
1980 & 285,3 & 343,7 & 57,6 & 157,3 & 11,5 & 84,0 & 0,0 & 13,1 & 80,1 & 47,0 & 197,9 & 406,9 \\
1981 & 321,8 & 33,9 & 191,6 & 73,5 & 9,1 & 80,7 & 0,1 & 3,4 & 24,4 & 196,7 & 83,5 & 315,3 \\
1982 & 457,2 & 174,4 & 275,9 & 61,6 & 48,9 & 79,4 & 30,2 & 28,3 & 26,5 & 225,1 & 79,8 & 406,3 \\
1983 & 252,1 & 353,4 & 196,3 & 162,5 & 177,6 & 50,4 & 65,1 & 0,0 & 237,4 & 231,4 & 152,1 & 332,9 \\
1984 & 128,3 & 92,7 & 111,1 & 91,2 & 49,4 & 0,0 & 4,3 & 71,3 & 110,6 & 55,8 & 175,7 & 324,1 \\
1985 & 395,2 & 130,7 & 221,2 & 48,0 & 15,1 & 0,7 & 0,5 & 0,9 & 6,3 & 83,8 & 219,0 & 218,8 \\
1986 & 222,8 & 164,6 & 292,1 & 38,3 & 99,1 & 0,0 & 48,7 & 157,8 & 6,1 & 83,7 & 251,0 & 729,4 \\
1987 & 292,8 & 372,8 & 94,2 & 43,7 & 138,8 & 14,1 & 29,8 & 4,2 & 105,9 & 75,6 & 210,1 & 229,6 \\
1988 & 142,5 & 273,3 & 123,1 & 183,1 & 92,0 & 31,6 & 0,0 & 0,0 & 5,2 & 170,3 & 107,5 & 174,7 \\
1989 & 337,6 & 338,0 & 101,8 & 33,4 & 33,5 & 34,8 & 62,3 & 29,2 & 57,5 & 111,1 & 320,4 & 341,5 \\
1990 & 230,0 & 144,4 & 219,6 & 49,2 & 96,0 & 0,0 & 12,9 & 66,6 & 16,9 & 58,6 & 141,6 & 163,8 \\
1991 & 278,2 & 220,3 & 271,6 & 262,5 & 50,7 & 2,0 & 9,0 & 0,0 & 53,0 & 59,4 & 48,0 & 336,9 \\
1992 & 235,6 & 182,6 & 179,3 & 91,1 & 87,4 & 0,0 & 10,0 & 14,3 & 171,1 & 201,4 & 162,0 & 153,6 \\
1993 & 172,1 & 427,6 & 212,1 & 101,4 & 73,0 & 65,6 & 0,6 & 43,2 & 87,2 & 88,6 & 169,2 & 301,9 \\
1994 & 320,2 & 60,8 & 161,0 & 14,2 & 82,9 & 25,9 & 14,1 & 0,0 & 1,4 & 91,1 & 273,5 & 225,4 \\
1995 & 202,0 & 409,4 & 105,8 & 104,5 & 79,0 & 19,3 & 18,6 & 0,9 & 36,3 & 126,2 & 83,1 & 258,8 \\
1996 & 244,1 & 175,2 & 172,2 & 53,1 & 59,4 & 23,0 & 0,0 & 24,7 & 116,6 & 188,1 & 229,1 & 231,3 \\
1997 & 325,0 & 99,8 & 85,5 & 45,4 & 67,4 & 167,5 & 12,6 & 0,0 & 21,3 & 36,8 & 350,0 & 215,5 \\
1998 & 108,1 & 279,9 & 177,8 & 44,4 & 62,0 & 1,8 & 0,5 & 43,6 & 22,9 & 175,5 & 207,7 & 385,8 \\
1999 & 399,3 & 266,4 & 123,0 & 93,6 & 18,8 & 23,9 & 0,5 & 0 & 90 & 36,5 & 73,8 & 251,1 \\
2000 & 353,6 & 326,2 & 184,0 & 0,2 & 0,9 & 0,2 & 39,2 & & & & & \\
\hline & & & & & & & & & & & &
\end{tabular}




\section{Resultado 1. ATR para cana de ano (precoce, média ou tardia) com colheita no período} de agosto a outubro.

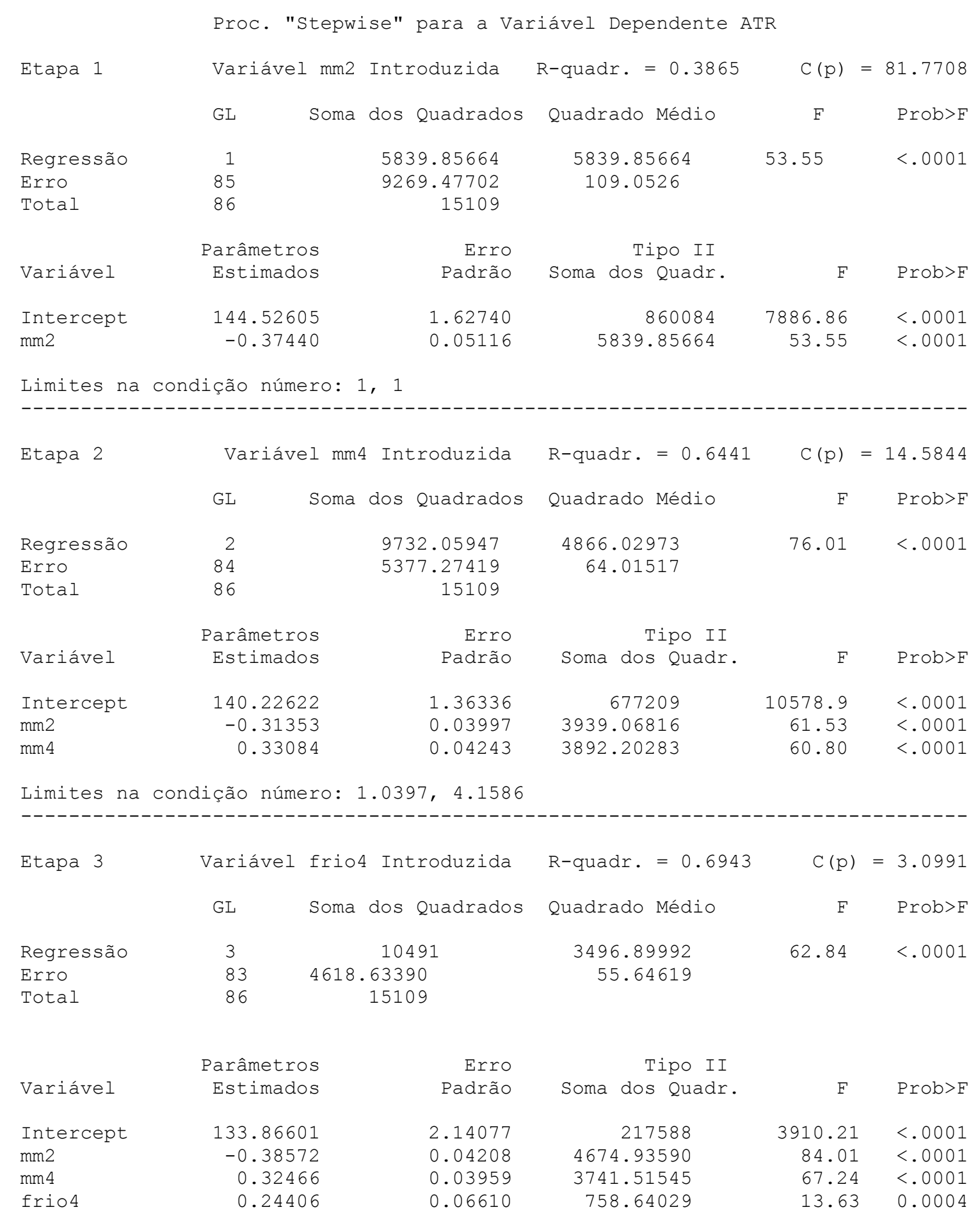

Limites na condição número: 1.3259, 10.94 
Todas as variáveis selecionadas pelo modelo significativas ao nível de 0.1500. Nenhuma outra variável alcançou este nível para inclusão.

\begin{tabular}{|c|c|c|c|c|c|c|c|c|}
\hline Etapa & $\begin{array}{l}\text { Variável } \\
\text { Introduzida }\end{array}$ & $\begin{array}{l}\text { Variável } \\
\text { Remov. }\end{array}$ & $\begin{array}{l}\text { Número } \\
\text { In. }\end{array}$ & $\begin{array}{l}\text { Parcial } \\
\mathrm{R} * * 2\end{array}$ & $\begin{array}{l}\text { Modelo } \\
\mathrm{R} * \star 2\end{array}$ & $C(p)$ & F & $\operatorname{Pr}>F$ \\
\hline 1 & $\mathrm{~mm} 2$ & & 1 & 0.3865 & 0.3865 & 81.7708 & 53.55 & $<.0001$ \\
\hline 2 & mm4 & & 2 & 0.2576 & 0.6441 & 14.5844 & 60.80 & $<.0001$ \\
\hline 3 & frio4 & & 3 & 0.0502 & 0.6943 & 3.0991 & 13.63 & 0.0004 \\
\hline
\end{tabular}

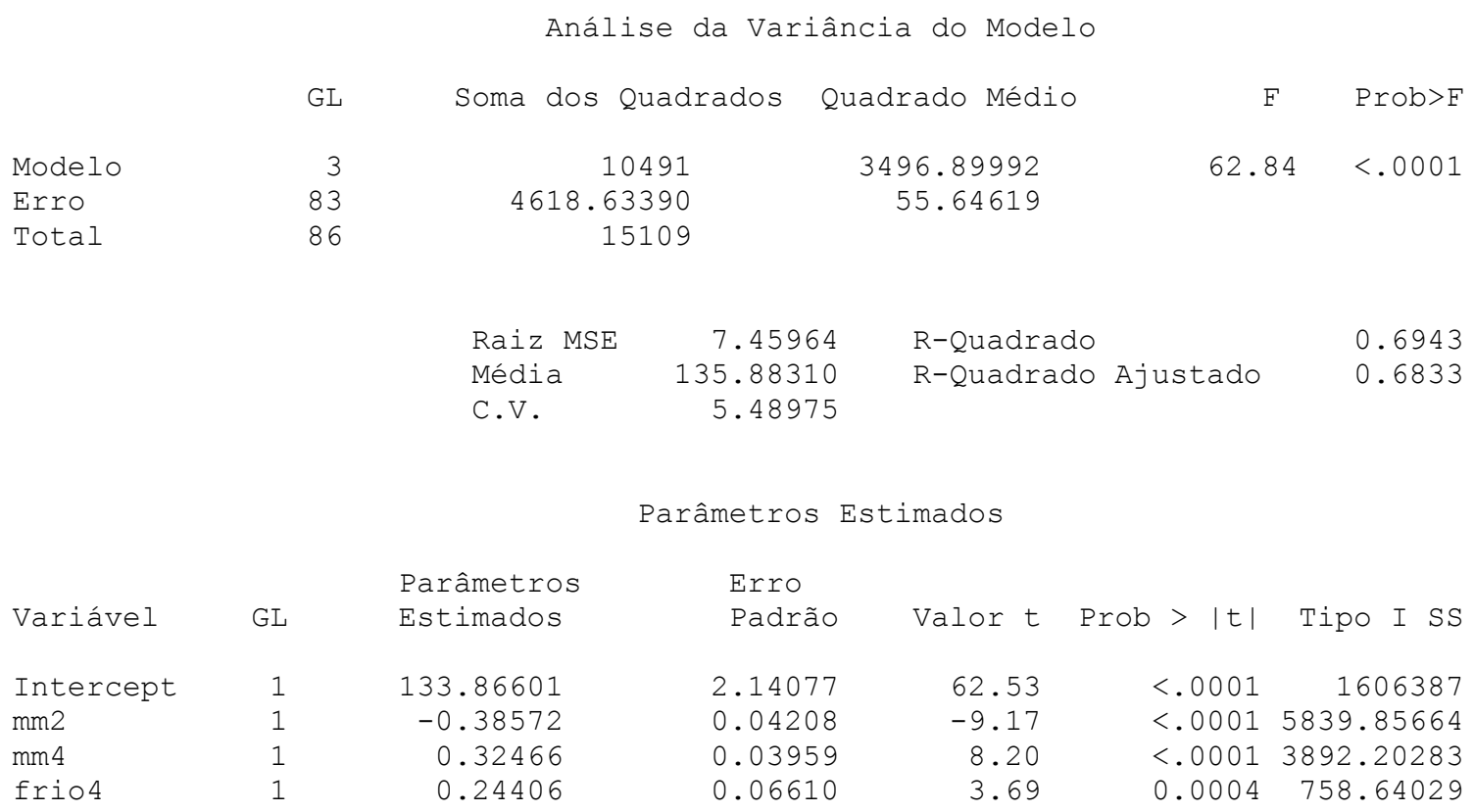

Resultado 2. ATR para cana de ano e meio (precoce, média ou tardia) com colheita no período de maio a outubro.

Etapa 1

Proc. "Stepwise" para a Variável Dependente ATR

Variável gd2 Introduzida R-quadr. $=0.4519 \quad \mathrm{C}(\mathrm{p})=257.9391$

$\begin{array}{lrrrrr} & \text { GL } & \text { Soma dos Quadrados } & \text { Quadrado Médio } & \text { F } & \text { Prob }>\text { F } \\ \text { Regressão } & 1 & 16666 & 16666 & 176.42 & <.0001 \\ \text { Erro } & 214 & 20216 & 94.46733 & & \\ \text { Total } & 215 & 36882 & & & \end{array}$

$\begin{array}{lccccc} & \text { Parâmetros } & \text { Erro } & \text { Tipo II } & & \text { F } \\ \text { Variável } & \text { Estimados } & \text { Padrão } & \text { Soma dos Quadr. } & \text { Prob }>\text { F } \\ \text { Intercept } & 156.16890 & 1.34991 & 1264327 & 13383.7 & <.0001\end{array}$


Limites na condição número: 1, 1

Etapa 2

Variável mml Introduzida R-quadr. $=0.4949 \mathrm{C}(\mathrm{p})=223.0799$

GL Soma dos Quadrados Quadrado Médio

F $\quad$ Prob $>$ F

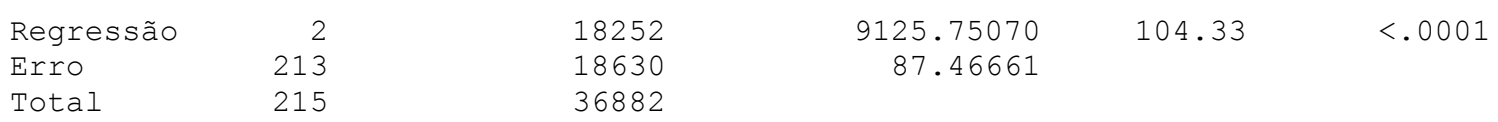

\begin{tabular}{|c|c|c|c|c|c|}
\hline & Parâmetros & Erro & Tipo II & & \\
\hline Variável & Estimados & Padrão & Soma dos Quadr. & F & Prob $>F$ \\
\hline Intercept & 155.12242 & 1.32198 & 1204320 & 13768.9 & $<.0001$ \\
\hline mm1 & 0.07793 & 0.01830 & 1585.62063 & 18.13 & $<.0001$ \\
\hline gd2 & -0.15364 & 0.01069 & 18081 & 206.71 & $<.0001$ \\
\hline
\end{tabular}

Limites na condição número: 1.042, 4.1682

Etapa 3

Variável frio2 Introduzida R-quadr. $=0.6171 \quad \mathrm{C}(\mathrm{p})=120.2410$

GL Soma dos Quadrados Quadrado Médio F $\quad$ Prob>F

\begin{tabular}{|c|c|c|c|c|c|}
\hline Regressão & 3 & 22761 & 7587.16661 & 113.91 & $<.0001$ \\
\hline Erro & 212 & 14120 & 66.60561 & & \\
\hline Total & 215 & 36882 & & & \\
\hline & Parâmetros & Erro & Tipo II & & \\
\hline Variável & Estimados & Padrão & Soma dos Quadr. & F & Prob $>F$ \\
\hline Intercept & 189.48843 & 4.33274 & 127394 & 1912.67 & $<.0001$ \\
\hline $\mathrm{mm} 1$ & 0.15643 & 0.01860 & 4709.11804 & 70.70 & $<.0001$ \\
\hline$g d 2$ & -0.36231 & 0.02702 & 11977 & 179.82 & $<.0001$ \\
\hline Erio2 & -0.59873 & 0.07276 & 4509.99841 & 67.71 & $<.0001$ \\
\hline
\end{tabular}

Limites na condição número: 8.747, 55.673

Etapa 4

Variável mm5 Introduzida R-quadr. $=0.6698 \quad \mathrm{C}(\mathrm{p})=77.1068$

\begin{tabular}{|c|c|c|c|c|c|}
\hline & Soma & dos Quadrados & Quadrado Médio & $\mathrm{F}$ & Prob $>\mathrm{F}$ \\
\hline Regressão & 4 & 24703 & 6175.77470 & 107.00 & $<.0001$ \\
\hline Erro & 211 & 12179 & 57.71938 & & \\
\hline Total & 215 & 36882 & & & \\
\hline & Parâmetros & Erro & Tipo II & & \\
\hline Variável & Estimados & Padrão & Soma dos Quadr. & $\mathrm{F}$ & Prob $>F$ \\
\hline Intercept & 171.90926 & 5.04527 & 67012 & 1160.99 & $<.0001$ \\
\hline m1 & 0.20656 & 0.01936 & 6573.61485 & 113.89 & $<.0001$ \\
\hline m5 & 0.12860 & 0.02217 & 1941.59897 & 33.64 & $<.0001$ \\
\hline$d 2$ & -0.34481 & 0.02533 & 10695 & 185.29 & $<.0001$ \\
\hline
\end{tabular}


frio2

$-0.45595$

0.07207

2310.28407

$40.03<.0001$

Limites na condição número: 9.5059, 88.62

Etapa 5

Variável gdl Introduzida R-quadr. $=0.7363 \mathrm{C}(\mathrm{p})=22.0852$

GL

Soma dos Quadrados Quadrado Médio

F

Prob $>$ F

Regressão 210

Erro

215

27156
9725.81194
36882

5431.21539

117.27

$<.0001$

Total

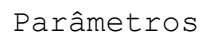

Erro

46.31339

Variável

Estimados

Padrão

Tipo II

Intercept

156.39760

4.99675

F

Prob $>$ F

$\mathrm{mm} 1$

0.22633

0.01755

45372

7703.11226

$0.02717 \quad 4356.76918$

0.18290

0.02513

2452.97817

$-0.43622$

0.02594

13102

$\operatorname{gd} 2$

$-0.47808$

0.06463

2534.35595

$979.68<.0001$

$166.33<.0001$

$94.07<.0001$

$52.96<.0001$

$282.90<.0001$

$54.72<.0001$

Limites na condição número: 11.591, 150.35

Etapa 6

Variável frio4 Introduzida $\mathrm{R}$-quadr. $=0.7472 \mathrm{C}(\mathrm{p})=14.7574$

$\begin{array}{lrrrrr} & \text { GL } & \text { Soma dos Quadrados } & \text { Quadrado Médio } & \text { F } & \text { Prob }>\text { F } \\ \text { Regressão } & 6 & 27557 & 4592.89055 & 102.94 & <.0001 \\ \text { Erro } & 209 & 9324.54558 & 44.61505 & & \\ \text { Total } & 215 & 36882 & & \end{array}$

$\begin{array}{lr}\text { Variável } & \begin{array}{r}\text { Parâmetros } \\ \text { Estimados }\end{array} \\ \text { Intercept } & 147.18602 \\ \text { mm1 } & 0.21371 \\ \text { mm5 } & 0.29585 \\ \text { gd1 } & 0.12769 \\ \text { gd2 } & -0.37042 \\ \text { frio2 } & -0.38459 \\ \text { frio4 } & 0.16777\end{array}$

Erro Padrão

5.78674

0.01773

0.02876

0.03078

0.03361

0.07068

0.05594
Tipo II

28863

6480.33184

4719.62727

767.83720

5419.77408

1320.94450

401.26636

$\begin{array}{rl}F & \text { Prob }>F \\ & \\ 646.94 & <.0001 \\ 145.25 & <.0001 \\ 105.79 & <.0001 \\ 17.21 & <.0001 \\ 121.48 & <.0001 \\ 29.61 & <.0001 \\ 8.99 & 0.0030\end{array}$

Limites na condição número: 20.205, 290.82 


\begin{tabular}{|c|c|c|c|c|c|}
\hline & Parâmetros & Erro & Tipo II & $F$ & Prob $>F$ \\
\hline variaves & Estimados & & soma dos vuadr. & $\mathrm{F}$ & PYOD>F \\
\hline Intercept & 138.87880 & 6.33548 & 20669 & 480.52 & $<.0001$ \\
\hline mm1 & 0.21102 & 0.01743 & 6301.23668 & 146.50 & $<.0001$ \\
\hline $\mathrm{mm} 4$ & 0.12318 & 0.04156 & 377.90452 & 8.79 & 0.0034 \\
\hline mm5 & 0.25010 & 0.03219 & 2597.01457 & 60.38 & $<.0001$ \\
\hline gdl & 0.08163 & 0.03398 & 248.19189 & 5.77 & 0.0172 \\
\hline$g d 2$ & -0.34190 & 0.03437 & 4255.84028 & 98.94 & $<.0001$ \\
\hline frio2 & -0.36126 & 0.06984 & 1150.79574 & 26.75 & $<.0001$ \\
\hline frio4 & 0.40344 & 0.09664 & 749.67179 & 17.43 & $<.0001$ \\
\hline
\end{tabular}

Limites na condição número: 21.922, 528.15

Todas as variáveis selecionadas pelo modelo significativas ao nível de 0.1500. Nenhuma outra variável alcançou este nível para inclusão.

Resumo do Proc. "Stepwise" para Variável Dependente ATR

\begin{tabular}{|c|c|c|c|c|c|c|c|c|}
\hline & Variável & Variável & Número & Parcial & Modelo & & & \\
\hline Etapa & Introduzida & Remov. & In & $\mathrm{R} * \star 2$ & $R * \star 2$ & $C(p)$ & F & $\operatorname{Pr}>F$ \\
\hline 1 & $g d 2$ & & 1 & 0.4519 & 0.4519 & 257.939 & 176.42 & $<.0001$ \\
\hline 2 & mm1 & & 2 & 0.0430 & 0.4949 & 223.080 & 18.13 & $<.0001$ \\
\hline 3 & frio2 & & 3 & 0.1223 & 0.6171 & 120.241 & 67.71 & $<.0001$ \\
\hline 4 & $\mathrm{~mm} 5$ & & 4 & 0.0526 & 0.6698 & 77.1068 & 33.64 & $<.0001$ \\
\hline 5 & gd1 & & 5 & 0.0665 & 0.7363 & 22.0852 & 52.96 & $<.0001$ \\
\hline & frio4 & & 6 & 0.0109 & 0.7472 & 14.7574 & 8.99 & 0.0030 \\
\hline & & & & 00102 & & 7972 & 8.79 & $0 \cap 034$ \\
\hline
\end{tabular}

Análise da Variância do Modelo

$\begin{array}{lrrrrr} & \text { GL } & \text { Soma dos Quadrados } & \text { Quadrado Médio } & \text { F } & \text { Prob }>\text { F } \\ \text { Modelo } & 7 & 27935 & 3990.74969 & 92.78 & <.0001 \\ \text { Erro } & 208 & 8946.64106 & 43.01270 & & \\ \text { Total } & 215 & 36882 & & \end{array}$

$\begin{array}{lrll}\text { Raiz MSE } & 6.55841 & \text { R-Quadrado } & 0.7574 \\ \text { Média } & 140.53796 & \text { R-Quadrado Ajustado } & 0.7493 \\ \text { C.V. } & 4.66664 & & \end{array}$

Parâmetros Estimados

\begin{tabular}{|c|c|c|c|c|c|c|}
\hline Variável & GL & $\begin{array}{l}\text { Parâmetros } \\
\text { Estimados }\end{array}$ & $\begin{array}{l}\text { Erro } \\
\text { Padrão }\end{array}$ & Valor $t$ & Prob $>|t|$ & Tipo I SS \\
\hline Intercept & 1 & 138.87880 & 6.33548 & 21.92 & $<.0001$ & 4266199 \\
\hline $\mathrm{mm1}$ & 1 & 0.21102 & 0.01743 & 12.10 & $<.0001$ & 170.99663 \\
\hline $\mathrm{mm} 4$ & 1 & 0.12318 & 0.04156 & 2.96 & 0.0034 & 2998.96081 \\
\hline mm5 & 1 & 0.25010 & 0.03219 & 7.77 & $<.0001$ & 349.33772 \\
\hline $\operatorname{gdl} 1$ & 1 & 0.08163 & 0.03398 & 2.40 & 0.0172 & 6577.65560 \\
\hline $\operatorname{gd} 2$ & 1 & -0.34190 & 0.03437 & -9.95 & $<.0001$ & 12967 \\
\hline frio2 & 1 & -0.36126 & 0.06984 & -5.17 & $<.0001$ & 2121.17086 \\
\hline frio4 & 1 & 0.40344 & 0.09664 & 4.17 & $<.0001$ & 749.67179 \\
\hline
\end{tabular}




\section{Resultado 3. TCH para cana de ano (precoce, média ou tardia) com colheita no período}

\section{de agosto a outubro.}

Proc. "Stepwise" para a Variável Dependente TCH

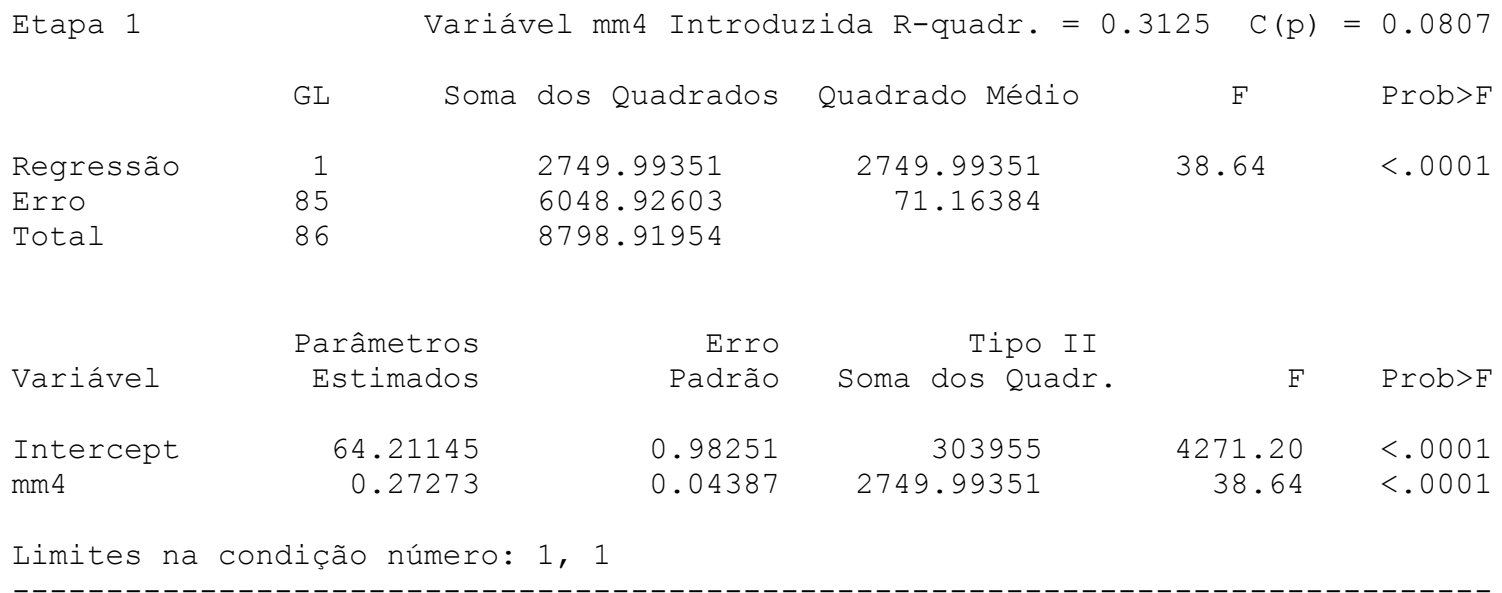

Todas as variáveis selecionadas pelo modelo significativas ao nível de 0.1500. Nenhuma outra variável alcançou este nível para inclusão.

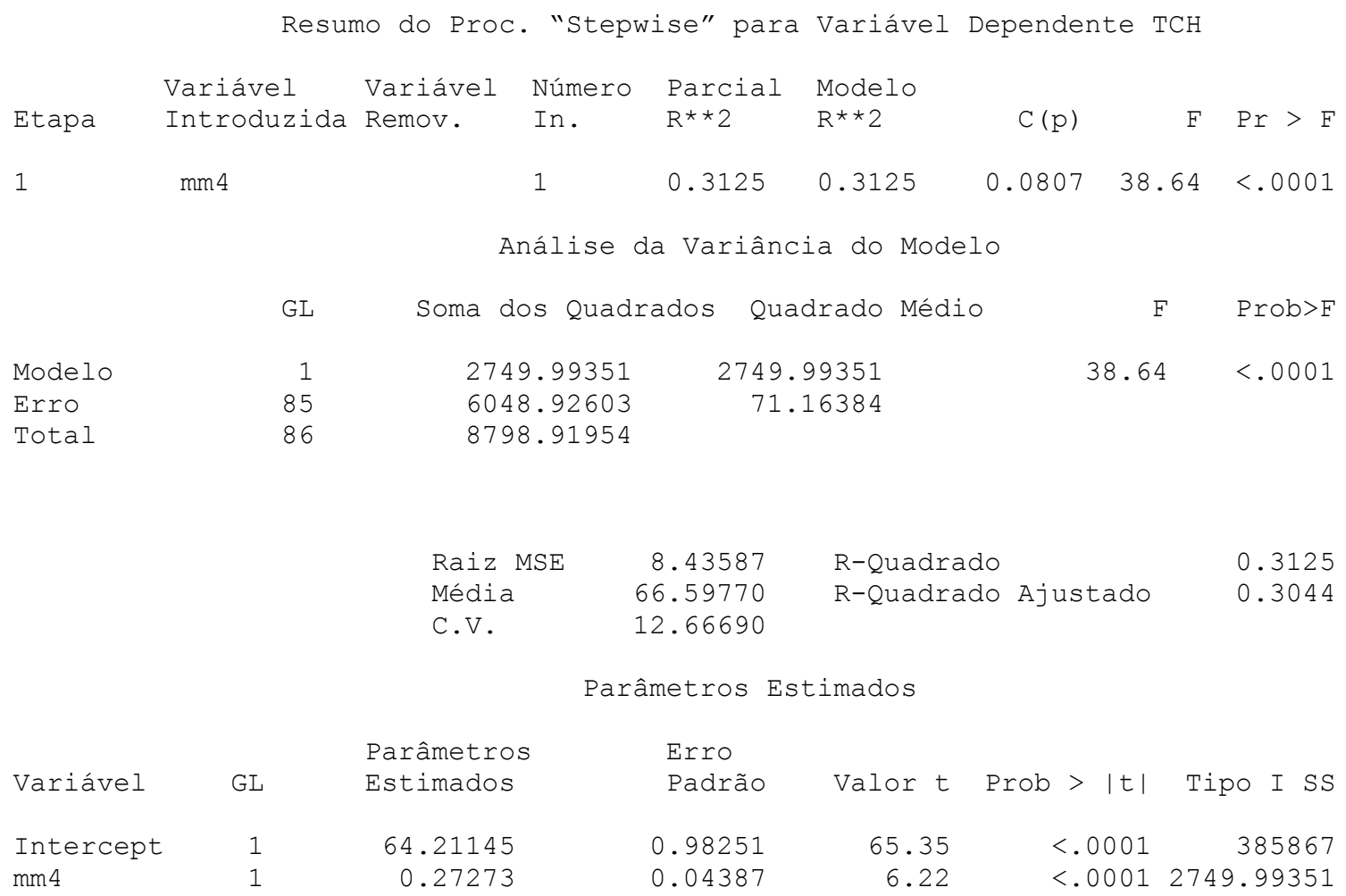




\section{Resultado 4. TCH para cana de ano e meio (precoce, média ou tardia) com colheita no} período de maio a outubro.

Proc. "Stepwise" para a Variável Dependente TCH

Etapa 1 Variável mm5 Introduzida R-quadr. $=0.0784 \quad \mathrm{C}(\mathrm{p})=114.3184$

GL Soma dos Quadrados

Quadrado Médio

F $\quad$ Prob $>$ F

Regressão 1
214

13423

157754

Total

215

171177

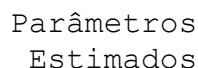

Variável

Estimados

$$
73.10751
$$

0.23849

Intercept

mm5

Limites na condição número: 1, 1

Etapa 2

Variável mml Introduzida R-quadr. = 0.2229

$\mathrm{C}(\mathrm{p})$

737.17023

18.21

$<.0001$

37.17025

$\begin{array}{rrrr}\text { Erro } & \text { Tipo II } & & \\ \text { Padrão } & \text { Soma dos Quadr. } & \text { F } & \text { Prob }>\text { F } \\ & & & \\ 5.15599 & 148207 & 201.05 & <.0001 \\ 0.05589 & 13423 & 18.21 & <.0001\end{array}$

Etapa 2

\begin{tabular}{|c|c|c|c|c|c|}
\hline & Soma & dos Quadrados & Quadrado Médio & F & Prob $>F$ \\
\hline Regressão & 2 & 38151 & 19076 & 30.54 & $<.0001$ \\
\hline Erro & 213 & 133026 & 624.53582 & & \\
\hline Total & 215 & 171177 & & & \\
\hline & Parâmetros & Erro & Tipo II & & \\
\hline Variável & Estimados & Padrão & Soma dos Quadr. & F & Prob $>F$ \\
\hline Intercept & 48.77627 & 6.12161 & 39650 & 63.49 & $<.0001$ \\
\hline $\mathrm{mm} 1$ & 0.34412 & 0.05469 & 24728 & 39.59 & $<.0001$ \\
\hline mm5 & 0.41665 & 0.05872 & 31443 & 50.35 & $<.0001$ \\
\hline
\end{tabular}

Etapa 3

Variável gd4 Introduzida $\mathrm{R}$-quadr. $=0.3441 \mathrm{C}(\mathrm{p})=24.2285$

$\begin{array}{lrrrrr} & \text { GL } & \text { Soma dos Quadrados } & \text { Quadrado Médio } & \text { F } & \text { Prob }>\text { F } \\ \text { Regressão } & 3 & 58909 & 19636 & 37.08 & <.0001 \\ \text { Erro } & 212 & 112268 & 529.56532 & & \\ \text { Total } & 215 & 171177 & & \end{array}$

Variável

Parâmetros

Erro Tipo II

Intercept

Estimados

Padrão

Soma dos Quadr.

F $\quad$ Prob $>$ F

$\mathrm{mm} 1$

\begin{abstract}
41.11548
\end{abstract}
5.76825

0.05774

26906

43110

$50.81<.0001$

$81.41<.0001$ 


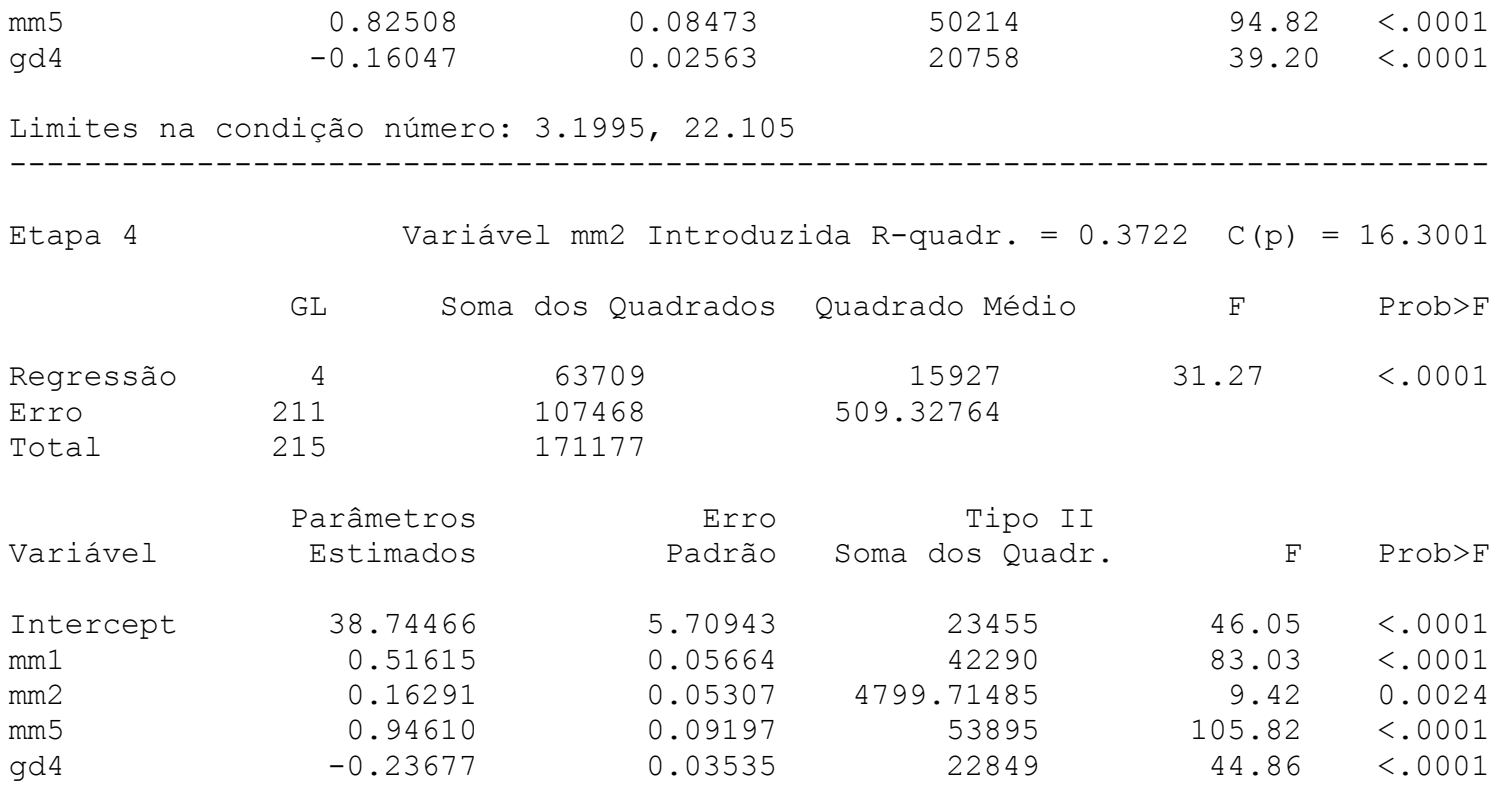

Limites na condição número: 4.8582, 51.399

Etapa 5

Variável mm4 Introduzida R-quadr. $=0.3932 \mathrm{C}(\mathrm{p})=10.8419$

$\begin{array}{lrrrrr} & \text { GL } & \text { Soma dos Quadrados } & \text { Quadrado Médio } & \text { F } & \text { Prob }>\text { F } \\ \text { Regressão } & 5 & 67315 & 13463 & 27.22 & <.0001 \\ \text { Erro } & 210 & 103863 & 494.58342 & & \\ \text { Total } & 215 & 171177 & & \end{array}$

\begin{tabular}{|c|c|c|c|c|c|}
\hline & Parâmetros & Erro & Tipo II & & \\
\hline Variável & Estimados & Padrão & Soma dos Quadr. & $\mathrm{F}$ & Prob $>F$ \\
\hline Intercept & 35.72306 & 5.73641 & 19180 & 38.78 & $<.0001$ \\
\hline mm1 & 0.57487 & 0.05991 & 45546 & 92.09 & $<.0001$ \\
\hline $\mathrm{mm} 2$ & 0.22957 & 0.05783 & 7793.97166 & 15.76 & $<.0001$ \\
\hline $\mathrm{mm} 4$ & 0.29839 & 0.11051 & 3605.61456 & 7.29 & 0.0075 \\
\hline mm5 & 0.89310 & 0.09273 & 45873 & 92.75 & $<.0001$ \\
\hline $\operatorname{gd} 4$ & -0.34098 & 0.05199 & 21274 & 43.01 & $<.0001$ \\
\hline
\end{tabular}

Limites na condição número: 10.821, 136.39

Todas as variáveis selecionadas pelo modelo significativas ao nível de 0.1500. Nenhuma outra variável alcançou este nível para inclusão.

Resumo do Proc. "Stepwise" para Variável Dependente TCH

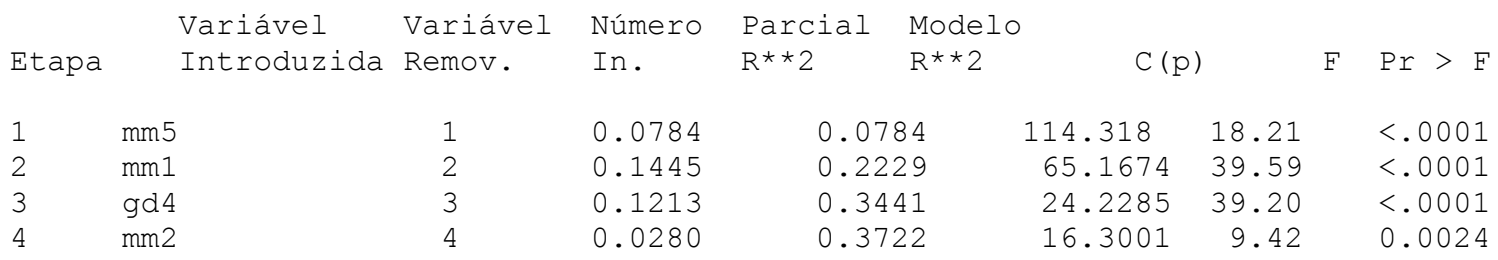


Análise da Variância do Modelo

\begin{tabular}{|c|c|c|c|c|c|}
\hline Modelo & 5 & 67315 & 13463 & 27.22 & $<.0001$ \\
\hline Erro & 210 & 103863 & 494.58342 & & \\
\hline Total & 215 & 171177 & & & \\
\hline
\end{tabular}

103863

$\begin{array}{llll}\text { Raiz MS } & 22.23923 & \text { R-Quadrado } & 0.3932 \\ \text { Média } & 93.64815 & \text { R-Quadrado Ajustado } 0.3788 \\ \text { C.V. } & 23.74765 & & \\ & \text { Parâmetros Estimados }\end{array}$

Variável GL $\begin{array}{ll}\text { Parâmetros } \\ \text { Estimados }\end{array}$

Intercept

$\mathrm{mm} 1$

$\mathrm{mm} 2$

$\mathrm{mm} 4$

mm5

$\operatorname{gd} 4$
35.72306
0.57487
0.22957
0.29839
0.89310
$-0.34098$

Erro

Padrão

5.73641

0.05991

0.05783

0.11051

0.09273

0.05199

Valor $t$
6.23
9.60
3.97
2.70
9.63
-6.56

6.23

Prob $>|t|$

Tipo I SS

$\begin{array}{rr}<.0001 & 1894315 \\ <.0001 & 6707.80592 \\ <.0001 & 19.62668 \\ 0.0075 & 9403.90619 \\ <.0001 & 29909 \\ <.0001 & 21274\end{array}$

